\title{
LA PANOPLIA GUERRERA DE LA NECRÓPOLIS DE VILLANUEVA DE TEBA (BURGOS)*
}

\author{
POR \\ IGNACIO RUIZ VÉLEZ
}

\begin{abstract}
RESUMEN - RÉSUMÉ
La necrópolis de Villanueva de Teba, aunque escasa en número de tumbas pues son 35, destaca por el elevado número de ellas con armas. Sin embargo la panoplia guerrera es sencilla: puñal, escudo, punta de lanza/regatón y cuchillo. Carece de espadas. Estas características son típicas de los momentos finales de la Edad del Hierro. Pero la tipología de algunos elementos da carácter a esta necrópolis, sobre todo la de los puñales. Además, hay otro elemento peculiar, la presencia en muchas tumbas de arreos de caballo.

La nécropole de Villanueva de Teba, même si le nombre de ses enterrements n'est pas élevé (il y en a 35), est remarquable par le grand nombre d'entre eux qui contiennent des armes. Cependant, la panoplie est simple : poignard, bouclier, fer de lance, bouterolle et couteau. On n'y trouve pas d'épées. Ces caractéristiques sont propres aux derniers moments de l'Âge du fer, mais la typologie de certains éléments, surtout celle des poignards, donne du caractère à cette nécropole. Il y a aussi un autre élément particulier: la présence de harnais (mors de cheval notamment) dans de nombreux enterrements.
\end{abstract}

\section{PALABRAS CLAVE - KEY WORDS}

Necrópolis, panoplia, puñal tipo Villanueva de Teba, umbo tipo Monte Bernorio, finales Segunda Edad del Hierro. Cemetery, weaponry, Villanueva-type dagger, Monte Bernorio type shield boss, Second Iron age.

\section{EL CASTRO Y LA NECRÓPOLIS DE VILLANUEVA DE TEBA.}

Desde el punto de vista geomorfológico el emplazamiento de la necrópolis, en el pago denominado La Cascajera, corresponde a una superficie amesetada de planta triangular con uno de sus vértices orientado hacia el norte donde se encuentra la máxima altura y un basculamiento muy suave hacia el sur en el que se ha encontrado la necrópolis. Esta superficie triangular aterrazada tiene unas dimensiones de $250 \mathrm{~m}$ en la base y una altura de $500 \mathrm{~m}$. aproximadamente. Es decir, corresponde a un espacio ligeramente superior a las 6 ha.

Como podemos ver, una serie de elementos morfológicos permiten individualizar la necrópolis del contexto físico distinguiéndole del entorno. La superficie excavada, dividida en cinco sectores, se encuentra en la base de ese triángulo alcanzando unas dimensiones de aproximadamente $3000 \mathrm{~m}^{2}$, destacando el Sector E con 24 tumbas y $1.500 \mathrm{~m}^{2}$. El resto no proporcionó ninguna tumba, salvo la $\mathrm{n}^{\circ} 20$ que se descubrió más al norte y lejos del área excavada. Se abrieron las correspondientes zanjas en sentido este-oeste porque algunos

\footnotetext{
* Los dibujos son originales de la Dirección General de Patrimonio de la Junta de Castilla y León.
} 
hallazgos superficiales permitían una posible alineación en ese sentido pero este hecho quedó reducido a las ocho primeras ya que las demás parecen no responder a un criterio ordenado en su disposición. El proceso de excavación se desarrolló sin grandes problemas metodológicos porque sólo se puede hablar de una estratigrafía horizontal sencilla ya que todas las tumbas se presentan en un mismo plano con la particularidad de que bastantes de ellas han sido descabezadas por la reja del arado cuyos restos permitieron desvelar la existencia del yacimiento. Todas las tumbas se asientan en un nivel de tierra arcillosa y canto rodado que se corresponde con la naturaleza edáfica superficial de La Bureba. Algunas llegaban a rozar un nivel inferior de arcilla amarillenta adonde no ha llegado la reja del arado.

La necrópolis de La Cascajera se excavó a comienzos de los 80 del siglo pasado sacando a la luz 35 tumbas con un rico y variado ajuar. Los trabajos de excavación fueron dirigidos por los Drs. José Antonio Abásolo Álvarez y Juan Carlos Elorza Guinea. El contexto de la necrópolis es muy peculiar ofreciendo un carácter único respecto a sus coetáneas tanto del ámbito celtibérico, en sentido amplio, o del resto del alto valle del Ebro (La Hoya, Carasta). Si bien hay un fondo que es común a todas las necrópolis de los ámbitos citados porque las formas del rito son similares, si no idénticas, la tipología de los objetos integrantes del ajuar son peculiares y con pocos paralelismos con sus congéneres. Esta individualidad tipológica es la que impide precisar aspectos concretos en su cronología.

Las tumbas consisten en un simple hoyo de boca circular de un diámetro de $50-60 \mathrm{~cm} \mathrm{y}$ una profundidad de $60-70 \mathrm{~cm}$. Carecen de urna pero se acompaña de un vaso funerario hecho a mano, de tendencia globular y tamaño pequeño con la pasta poco cuidada. Al lado se ubican las cenizas y los huesos que en algún enterramiento ocupan, curiosamente, lugares distintos. Las cantidades de cenizas y huesos son pequeñas, quizás porque son el resultado de una selección de los mismos. Sobre estos elementos se colocan, siempre tumbados, los otros objetos integrantes del ajuar, constituido por diversos tipos de placas (Bureba, rectangulares ibéricas, grandes placas), fíbulas (anulares hispánicas de puente ancho abombado y uniforme, de cazoleta, de apéndice de botón, de la Tène), puñales (de tipología específica), umbos de escudo, arreos de caballo, cuchillos, puntas de lanza, etc. No ha aparecido ninguna espada, lo cual no tiene que resultar sorprendente porque en las necrópolis de estas tierras no se ha encontrado ninguna, o al menos, que se sepa. Por otro lado, puede ser un indicador de cronología avanzada. La tumba se sellaba con una banda periférica de cantos rodados rodeando la boca, que en algunos casos, llega a cubrir toda la boca e incluso parte del perfil de la tumba.

Dos hechos destacan de esta necrópolis desde el punto de vista formal. Por un lado, casi todas las tumbas presentan algún elemento del ajuar, cuando es frecuente que muchas de ellas no den ningún material en otros ámbitos geográficos y culturales. Por otro, este ajuar es muy peculiar, sin parangón con las necrópolis sincrónicas del valle del Ebro y de toda la Meseta. Muchos de sus objetos responden a tipologías nuevas que no encajan en el marco conocido. Esto resulta más sorprendente cuando no encontramos elementos de cultura celtibérica, salvo la fíbula de caballito procedente de prospección. No han aparecido formas torneadas cuando sabemos que la celtiberización de La Bureba fue muy intensa.

Si destacan los puñales porque están presentes en las tres cuartas partes de las tumbas, no es menos sorprendente el hecho de que los arreos de caballo (bocado, muserola, agarradores) aparecen en el $40 \%$ de las tumbas. Hay bocados de camas circulares, de camas rectas, lobulados con desveno en algún caso, agarradores de diversa naturaleza y muserolas con una placa de bronce interior decorada. La presencia de arreos de caballo en estos enterramientos dota a esta necrópolis (o sector de la necrópolis) de un carácter específico en la que el binomio persona-caballo alcanza un nivel de asociación poco conocido en el mundo prerromano de la Península.

Con estos datos es muy difícil dar una cronología precisa pero hay ciertos elementos que, al menos, nos pueden ubicar esta necrópolis en una cronología avanzada de la Segunda Edad 
del Hierro. Por un lado, parece claro que en el yacimiento asistimos a un proceso de sustitución de las placas tipo Bureba por las rectangulares ibéricas. Aquella sólo está presente en la tumba 22 (además de otra de prospección), asociada al único puñal tipo Monte Bernorio procedente de excavación. Esta tumba sería la más antigua en un contexto cronológico del siglo III, avanzado incluso. Por otro, la concepción de los puñales, el dominio absoluto de las placas ibéricas, la fíbula de La Tène, las fíbulas anulares hispánicas y los resortes de algunas fíbulas de cazoleta y de apéndice de botón, las fíbulas o broches de omega y las similitudes con contextos tardíos de otras necrópolis, nos permiten determinar que nos encontramos ante fechas avanzadas dentro de los siglos II e incluso I a.C.

Por analogía con otras necrópolis, no sólo del área celtibérica de la Meseta Oriental, sino de los vacceos o de los vetones, sabemos que la de Villanueva de Teba no está muy alejada del poblado; nunca más de $2 \mathrm{~km}$ aunque habitualmente es a menos de 1,5 km. En todos los casos se demuestra una relación visual entre aquella y el poblado indicando la importancia de la «ciudad de los muertos» en aquella época. Al noroeste de la necrópolis se encuentra un altozano denominado La Atalaya, situado a $1.200 \mathrm{~m}$ de distancia en el cual se han encontrado abundantes restos que se corresponden con contextos arqueológicos de Cogotas I, de la Primera Edad del Hierro y de época medieval. Algunas cerámicas celtibéricas parecen confirmar la sincronía con la necrópolis. En el cerro próximo, en el término conocido como La Llana, se encontraron abundantes restos de época romana perteneciendo a un asentamiento de tipo villa o quizás la mansión Vindeleia (Houston: 1974, 423-424, Abásolo: 1985, 318, Campillo: 1999, 20-25).

Aunque ha sido el tema de nuestra Tesis Doctoral (Ruiz Vélez: 2002) ya avanzamos algunos aspectos de ella referidos tanto a una visión general del yacimiento (Ruiz Vélez et alii: 1998; Ruiz Vélez: 2001, 85-104) como al estudio preliminar de algunas de las piezas más representativas; así se han abordado trabajos específicos sobre los puñales (Ruiz Vélez et alii: 1997, 273-303) y las placas rectangulares ibéricas (Ruiz Vélez et alii: 1999, 297-306).

\section{LOS PUÑALES}

Los puñales están presentes en 25 tumbas (de las 35) lo cual representa el 71' $4 \%$, cifra realmente alta en comparación de cualquier otra necrópolis del segundo Hierro; pero debe tenerse en cuenta que estas cifras son poco expresivas porque no se ha excavado toda ella y por lo tanto es un dato muy sesgado. También hemos de tener en cuenta el saqueo de este cementerio pues piezas procedentes de este yacimiento se han visto en lugares alejados de aquí y en colecciones particulares.

Tres aspectos generales señalaríamos de estos puñales que les hacen muy distintos de los demás. Por una parte su vinculación al cinturón, pues forman una pieza única ya que los sistemas de anclaje son fijos; de otra parte, estos son peculiares pues posibilitan llevar el puñal inclinado unos $45^{\circ}$ para permitir un desenfunde más rápido; finalmente, ciertos elementos morfológicos específicos que le otorgan una singularidad aunque manteniendo elementos de conexión con el resto de las culturas de este ámbito céltico y otros que son exclusivos de esta necrópolis. Ya hicimos un breve estudio sobre las grandes novedades de esta tipología de Villanueva de Teba (Ruiz Vélez y Elorza: 1997, 273-303).

Además de estos tres rasgos básicos, debemos señalar que se da un aspecto común y es el aparecer un único ejemplar en cada tumba, salvo las $\mathrm{n}^{\mathrm{o}} 12,17,22$ y 27 en las que hay dos piezas o evidencias de haber sido dos. Por otro lado, y en consonancia con lo expuesto anteriormente, siempre que hay un puñal están las placas, o alguna de ellas, del cinturón que recuerdan las de tipo Hundersingen por sus paralelismos con estas piezas hallstátticas (KiliamDirlmeier 1972: 35-37, láms. 16 y 17). No aparecen placas de cinturón en las tumbas $\mathrm{n}^{\circ} 8$, 
$15,16,25,2733$ y 34 , circunstancia que se debe a que muchas tumbas han sido semibarridas por la reja del arado eliminando parte de los materiales de muchos ajuares. Por otra parte, el puñal y la vaina están presentes en la mayoría, salvo en las tumbas $\mathrm{n}^{\circ} 2,16$ y 27 en las que sólo está el puñal, y en la tumbas $\mathrm{n}^{\mathrm{0}} 8$ y 13 en las que se encontró únicamente alguna placa de la vaina.

Son puñales cortos aunque hay algunos que presentan medidas no habituales. La hoja más larga (sin espiga) es la $\mathrm{n}^{\circ} 2$, de prospección que alcanza $\operatorname{los} 28,5 \mathrm{~cm} ; 27 \mathrm{~cm}$ tiene la $\mathrm{n}^{\circ} 5$ de prospección; $24 \mathrm{~cm}$ tienen la $\mathrm{n}^{\mathrm{o}} 4$ de prospección y de la tumba 22 ; y $23 \mathrm{~cm}$ la pieza $\mathrm{n}^{\mathrm{o}} 16$ de prospección. Los demás presentan una longitud inferior a $20 \mathrm{~cm}$, siendo la hoja más pequeña la de la tumba 2, con $16 \mathrm{~cm}$. La espiga alcanza una longitud entre los 11 y los 14,5 $\mathrm{cm}$. Son por lo tanto, empuñaduras de reducidas dimensiones, razón por la que pensamos que son piezas de función específica, indicadoras, por tanto, de status o pertenencia a un grupo de prestigio. Las vainas superan en 3-4 $\mathrm{cm}$ la longitud de la hoja.

La tipología de los puñales de Villanueva de Teba está emparentada con la de algunos modelos de los momentos finales del segundo Hierro (tipo frontón o de Alpanseque y biglobular o de tipo Uxama) pero los nuestros presentan muchas peculiaridades derivadas de la complejidad del montaje, sobre todo de la empunadura, que les apartan de sus parientes tipo Monte Bernorio y los citados anteriormente. Esta complejidad nos hace pensar que no fueron objetos de uso cotidiano sino para grandes celebraciones, ya civiles, ya religioso-funerarias, aunque B. Griño (1989: 91) piensa lo contrario. Los nuestros ofrecen una singularidad, determinando que cada ejemplar sea un tipo distinto, como que no significan una producción estandarizada sino específica, ajena a su diseño formal, aunque en casi todos hay unas líneas estructurales básicas que se complementan con detalles derivados del elevado número de elementos que integran su composición.

Hemos distinguido cuatro tipos de puñales: el tipo Monte Bernorio que marcaría los comienzos de la necrópolis; el tipo II, una especie híbrida entre el anterior y el específico de Villanueva; el tipo III también peculiar pero con una concepción que remeda al biglobular; y el tipo IV, el más abundante y común de Villanueva.

\section{GRUPO I. PUÑAL TIPO MONTE BERNORIO.}

Tumba 22: (Lam. I; fig. 2)

1. Hoja de hierro de $12 \mathrm{~cm}$ de longitud conservado y $2,5 \mathrm{~cm}$. de máxima anchura conservada y el pequeño arranque que queda de la espiga. Es de sección biconvexa.

2. Pomo formado por dos piezas simétricas, ligeramente curvadas, de $9,8 \mathrm{~cm}$ de longitud y 2,8 de anchura rematadas en apéndice con un botón en los arriaces. Ambas placas se unen con dos pernos que servía de enlace al puño.

3. Fragmento de la vaina, de hierro, correspondiente al tercio inferior, formada por los fragmentos de dos placas afrontadas convexas, montadas la una sobre la otra y rematadas en la contera circular igualmente formada por la prolongación de ambas placas. Su diámetro es de $2,4 \mathrm{~cm}$.

4. Guarda de la empuñadura constituida por dos piezas de hierro simétricas trapezoidales opuestas y curvadas que se unen con dos pernos de hierro. En la mitad inferior presenta la típica escotadura donde se embutía la lengüeta de la embocadura del puñal.

6. Cuatro botones de las orejetas, para remachar el sistema de anclaje, de forma bitroncocónica, como es habitual en estos puñales. Pertenecen a la parte de la vaina que falta.

7. Tahali de hierro, curvado y rematado en garfio, de $24 \mathrm{~cm}$ de longitud y $1,6 \mathrm{~cm}$ de anchura que se completa en el tercio superior con el ensanchamiento típico, de $2,4 \mathrm{~cm}$ de 
anchura. Presenta dos acanalados longitudinales en la parte estrecha que están decorados con sendas láminas de bronce embutido.

\section{En posición secundaria:}

1. Vaina de puñal de hierro, de $19,1 \mathrm{~cm}$ de longitud y $3 \mathrm{~cm}$ en la embocadura. Está formada por dos láminas convexas, simétricas, que ya fue publicada por B. de Griño (1989: cat. 96, fig. 100). Tiene dos los remaches de orejetas y la contera circular decorados (fig. 1, 1 Lam. II).

2. Guarda de la empuñadura de forma naviforme y de una sola pieza, de $3 \mathrm{~cm}$ de longitud por la parte inferior donde se encuentra la embocadura y que podría corresponder con casi toda seguridad a la hoja $\mathrm{n}^{\mathrm{o}} 10$ de prospección, de $11 \mathrm{~cm}$ de longitud conservada, de sección losángica y espiga de sección circular de $9 \mathrm{~cm}$ de longitud. La guarda está decorada con un sogueado de tres líneas en sentido longitudinal. Esta guarda y esa hoja pueden pertenecer a la vaina de prospección, pues la anchura de la embocadura y la longitud de la guarda es la misma y además muestran concordancia decorativa.

3. Dos fragmentos distintos de las láminas convexas de sendas vainas, de hierro. El primero conserva una decoración sogueada de las mismas características que los casos anteriores. El segundo mantiene un remache de la orejeta bitroncocónico en bronce.

4. Contera circular y arranque de la vaina que parecen de una sola pieza.

5. Tahali de hierro de $33 \mathrm{~cm}$ de longitud con garfio en un extremo y engrosamiento en el tercio superior del otro extremo. Por el reverso es plano y por el anverso tiene un acanalado longitudinal decorado con una hilada de eses. La parte ancha presenta dos acanalados longitudinales lisos. Incluso tiene una perforación quizás para añadir otra pieza. Aunque está roto, no lleva más agujeros para hacer ensamblajes. (fig. 1,8).

6. Hoja de las mismas características que la anterior de la que sólo se conservan $10,40 \mathrm{~cm}$ de la hoja y el arranque de la espiga. Carece de la lengüeta en el arranque de la espiga.

Todas estas piezas son específicas del puñal tipo Monte Bernorio (fig. 2). Corresponden al Tipo IV de Griño (1989: 42-44), al Tipo III de Quesada (1997: 287-290) y al modelo de la Fase de Expansión de C. Sanz Mínguez (1990a: 180-187; 1997: 434-439). Las hojas son rectas, es decir, no son tendentes al perfil pistiliforme ni con estrangulamiento en el tercio inferior, y la vaina específica de esa fase de Sanz que coincide con fechas avanzadas como vamos a ver. Es decir, la cronología de las piezas estudiadas hasta ahora es similar a la de los puñales que se pueden comparar con los de otras zonas.

Esta Fase de Expansión corresponde con los momentos más importantes del puñal de tipo Monte Bernorio porque es cuando alcanza mayor difusión (Sanz Mínguez 1990a: fígs. 1 y 2; 1997: figs. 227 y 228) que cronológicamente coincide con los siglos III, II y el I a.C. Uno de los criterios que permiten clasificar estos puñales en esta última fase es que reducen sus dimensiones, en todos los ejemplos conocidos, por debajo de los $20 \mathrm{~cm}$ para la vaina, como es nuestro caso.

La guarda está constituida por dos piezas; una que, a su vez, está formada por dos elementos y la otra que es maciza; pero son morfológicamente idénticas y muy similares en el tamaño. La escotadura para la embocadura de la hoja es más pequeña en la de la tumba 22 y algo más grande en la de prospección. Este sistema, frente a las cuatro piezas de los modelos anteriores, da más consistencia a la empuñadura, según opinión de Sanz Mínguez (1997: 181). La única diferencia que constatamos respecto a las apreciaciones de este autor es que las aletas de la embocadura de la vaina que tienden a desarrollarse, en nuestro caso se caracterizan por lo contrario; es decir, por estar suavemente esbozadas. Las dos guardas de la empuñadura tienen 3 y $4 \mathrm{~cm}$. de largo cada una, es decir, unas medidas pequeñas frente a todas 
las demás de esta fase de expansión, bien entendido que esa prolongación de la embocadura se refiere a los modelos I y III de Griño, pero no al tipo IV que mantiene sus dimensiones más reducidas; lo cual es coherente porque nuestros modelos son del tipo IV.

Solamente tenemos un pomo, el de la tumba 22 y presenta unas características especiales, distintas a los demás. Los pomos más desarrollados corresponden a los tipos I y III de Griño; frente al tipo IV que tienden a ser más cortos. También los hay rematados en discos, típicos del grupo III de Griño, que pueden recordar, según Sanz (1990a: 181) la estética de las espadas de antenas atrofiadas y estructuralmente a los puñales biglobulares. Nuestro pomo no encaja en las versiones conocidas. Frente al dominio de las formas quebradas, el nuestro tiende a las formas redondeadas. Sí que presenta la forma naviforme; es relativamente grande pues alcanza casi los $9 \mathrm{~cm}$ de longitud. El desarrollo de la parte superior no es recta sino ligeramente convexa y por la parte inferior se desarrollan dos escotaduras que rematan en los arriaces con sendos botones de cabeza semiesférica y un tema inciso en forma de cruz que nosotros llamamos cabeza Philips, por la similitud con la cabeza de ese tipo de tornillo. El tornillo se asienta sobre una arandela de bronce. Es un caso específico.

Las hojas que conocemos en Villanueva de Teba no son muchas y aparecen poco claras, pero algunas características podemos sacar. La hoja de la tumba 22 se encuentra muy deteriorada por la oxidación. Es de sección biconvexa y parece que sí pudo tener, con bastante seguridad, la lengüeta de prolongación de la embocadura. Habría que señalar que la presencia de este elemento es característica indispensable de las hojas de tipo Monte BernorioMiraveche. La única hoja que presenta esa lengüeta es la pieza $\mathrm{n}^{\circ} 10$ de prospección que es de sección losángica (de cuatro mesas), con $11 \mathrm{~cm}$ de longitud conservada y 9 de espiga de sección circular. Podría adivinarse una cierta nervadura central, pero es difícil precisarlo. Ya apuntamos más arriba que esta hoja podría corresponder a la guarda de prospección pues la medidas coinciden. No nos atrevemos a incluir en este apartado de hojas de tipo Monte Bernorio-Miraveche el $\mathrm{n}^{\mathrm{o}} 9$ de prospección porque no conserva la lengüeta de la embocadura; es recta, con desarrollo pistiliforme y nervadura central sin acanaladuras. La espiga es el único caso de sección rómbica. Cosa muy peculiar en la necrópolis. La forma se aproxima más al tipo IV de Villanueva de Teba.

La vaina es de perfil casi recto, salvo la embocadura y el descenso suave de la anchura en la mitad inferior. Está formada por dos partes simétricas idénticas convexas, afrontadas, formando una misma pieza con la contera. En las orejetas de la cara anterior presenta dos remaches de cabeza casi hemisférica (tipo $2 \mathrm{~b}$ de Griño), también de hierro, sin arandela. Lo genuino de esta vaina radica en el sistema de anclaje al cinto, ya descrito por Griño (1989: 216) que es peculiar de este puñal. Los remaches de la cara anterior sujetan por la cara posterior otra chapa de hierro rectangular que ocupa la mitad de la vaina la cual también se sujeta por el otro extremo, a través de una perforación rectangular, a una hembrilla soldada a la vaina. Por esa hembrilla se cruza un pasador. Ese pasador tiene los dos extremos doblados en sentido contrario. Por lo tanto, esa placa se fija desde dos puntos. Por el reverso de la contera, en posición central, hay una hembrilla a la que iría enganchada una cadenita, al modo de algunos puñales de tipo Monte Bernorio de La Hoya (Filloy, 1990: fig. 4). Esa disposición del sistema de ensamblaje nos pone de manifiesto que el puñal iba dispuesto de manera paralela al tahalí pero no en el hombro sino en la cintura, como pensamos nosotros que es más razonable. En este sentido, la incurvación del tahalí nos indica que el mismo discurría por uno de los costados de la cintura. Por lo tanto el puñal iba dispuesto horizontalmente en la dicha cintura. El resto sería material de cuero para completar el cinturón. Este sistema será sustituido, en la necrópolis de Villanueva de Teba, por otro mecanismo que implica, aun estando el puñal en posición central sobre el abdomen, más rapidez a la hora de desenfundar. Es el sistema típico del modelo IV de esta necrópolis.

Los botones de las orejetas están presentes en los dos cuerpos de la vaina de la que acabamos de hablar, del tipo 2 b, según Griño. Los otros conservados son los de la tumba 22 de 
los que hay cuatro del tipo 3, bitrococónicos pero que están solos sin la vaina. Se entiende que era una vaina con cuatro botones, sistema que también es típico de la Fase de Expansión del puñal.

Los dos tahalíes, uno de prospección y otro de la tumba 22, morfológicamente son idénticos, y aunque sólo son dos hay que verlos como un elemento de unidad y de indicación de que son de cronología posterior, y en este caso último, respecto a todos los demás. Corresponden al tipo VII de Griño (1989: 59, esq. 22) y se caracteriza por la incurvación bastante grande, longitud mayor que todos los demás, desarrollo paralelo en los dos tercios de su longitud y remate en un ensanchamiento que unas veces es oblongado y otras un desarrollo más alargado como es el caso de los de Villanueva de Teba. Estos modelos suelen estar decorados, en nuestro caso los dos. Uno, el de prospección con los acanalados y una hilada longitudinal de eses; el otro con dos laminillas de bronce insertas en el hierro y dispuestas a lo largo. Estos motivos longitudinales nos recuerdan los acanalados y las secciones de algunas fíbulas de apéndice turriforme que aparecen asociadas a estos puñales en Las Cogotas (Sanz Mínguez, 1990a: 183). En nuestro caso es más evidente y reiterativo en todos los puentes de las fíbulas de apéndice de cazoleta. Este sistema encaja en el gusto estético de que a través del relieve se crean juegos de luces y sombras implicando una concepción artística muy peculiar y reiterativa en esta necrópolis de Villanueva de Teba.

Hasta hace bien poco, la dispersión de los puñales de la fase de expansión se circunscribía a la zona meridional de la Meseta que correspondían a los tipos I y III de Griño salvo tres de La Osera, encuadrables en la fase de desarrollo. Más recientemente los hallazgos se refieren a otras áreas determinando que esta fase sea la de mayor difusión del modelo. Es el caso de los hallazgos en el alto Duero como la tumba 30 de Ucero (García-Soto, 1989: 367-388), o los dos ejemplares de Almazán (Griño, 1989: cat. 121 y 122). En el Duero medio tenemos los ejemplares de las tumbas 17, 30,32, 33 y 35 de la necrópolis de Las Ruedas en Padilla de Duero (Sanz Mínguez, 1997: 434-439, fgs 91 y 192) y el ejemplar del poblado de El Soto de Medinilla consistente en una hoja triangular sin vaina pero conservando toda la empuñadura (Escudero 1988, 40). Más al norte tenemos evidencias en Palenzuela cuya necrópolis ha deparado un ejemplar con discos en el pomo (Martín Valls, 1984: 40, fig. $14 \mathrm{n}^{\mathrm{o}}$ 2-3). En cambio, en Monte Bernorio no se han encontrado puñales de esta fase. En la zona burgalesa, que nos afecta más directamente, tampoco son muchos los hallazgos aunque se reducen a dos yacimientos. En la necrópolis de Miraveche los tres ejemplares conocidos aparecieron en las tumbas 22, 42 y 60 (Griño, 1989: cat. 60, 80 y 74 respectivamente); los dos primeros del tipo III y los otros dos del IV. El otro yacimiento es el que nos ocupa ahora y está representado por la vaina entera de la que hemos hablado. Cerca de Villanueva de Teba tenemos la necrópolis de La Hoya en Laguardia (Álava) (Filloy, 1990: fig. 4) la cual ha proporcionado varios tahalíes y tres ejemplares de puñal del tipo I, así como algunas piezas con contera de un solo disco asignables al grupo IV (Llanos, 1990: 138 y 142). Fuera de estas áreas, como indicador del grado de expansión alcanzada, habría que citar los ejemplares de Matienzo (Smith y Muñoz 1984: lam. IV) o el de Caravias (Cabré, 1931: fig. 2, nº 3-4), en la zona cántabro-astur o el de Cáceres (Griño, 1989: cat. 97).

Respecto a la cronología, ya señaló Sanz Mínguez (1997: 438), que no es nada fácil. Dicho autor apunta que debe datarse desde finales del siglo IV, centrando su implantación en el III perdurando hasta el siglo II aunque habrá que adaptar las fechas según las regiones, como es nuestro caso al que habrá que señalar una cronología relativamente tardía, dentro de ese siglo II. B. de Griño también se centra en esas cronologías (Griño 1986-87: 306; 1989: 103104) y García-Soto (1989: 379). En el caso de la necrópolis de Miraveche en cuya tumba 31 hay un puñal, éste sería el más antiguo de la necrópolis según Martín Valls y Esparza (1992: 264), fechado en el siglo IV. El ejemplar de nuestra necrópolis presenta un carácter residual; 
es decir, de las últimas producciones del género en nuestra necrópolis porque es suplantado por el modelo nuevo, dominante en toda la necrópolis ya que todos los demás presentan los rasgos comunes del tipo nuevo con ligeras variantes formales. Ya anteriormente nos atrevimos a dar una cronología dentro del siglo III (Abásolo et alii 1982: 26). De un área próxima a esta procede un ejemplar (Álvarez, Cebolla y Blanco, 1990: fig. 8, 1), una vaina, de forma idéntica a la nuestra con contera de un solo disco y formada de dos placas, ricamente decoradas con triángulos al grenetti. Por la presencia de placas ibéricas idénticas a las de Villanueva de Teba y dos de esas grandes placas, exclusivas de dicha necrópolis, nos atreveríamos a decir que proceden de la necrópolis burgalesa porque nos consta de la frecuente presencia de expoliadores en este yacimiento. Otra pieza interesante es el tahalí de la colección Fontaneda (Sanz, Escudero y Fontaneda, 1997: fig. 2) el cual presenta elementos de transición hacia los nuevos puñales que se generalizan en la necrópolis de Villanueva y con los biglobulares.

Las cronologías dadas para la necrópolis de La Hoya entre mediados del siglo $\mathrm{V}$ y mediados del siglo VI nos parecen excesivamente altas (Filloy, 1990: 24) y particularmente si se confirma que convivieron con puñales biglobulares. Entonces, si La Hoya representa el momento en que entran en competencia los puñales de tipo Monte Bernorio-Miraveche, Villanueva de Teba significa el momento en que el bernoriano es sustituido por los modelos de Villanueva de Teba. En este sentido hay unos argumentos cronológicos interesantes; y son los que nos dan los modelos abulenses de Chamartín de la Sierra que aparecen asociados a fíbulas de torrecilla lateral con cabecera perforada. Esa asociación se da en las tumbas 4, 509 y 514 de la zona VI (Cabré, Cabré y Molinero, 1950: 183) que nos manifiestan una cronología de mediados del siglo III. Además, las dos últimas tumbas aparecen fosilizadas por el tercer recinto del castro cuya construcción se asocia a las campañas de Postumio (179 a.C) o de Viriato (155 a.C.) según Martín Valls (1985: 129). La fase de desarrollo del puñal estaría poco representada en esa necrópolis y menos en otra necrópolis más al sur, la de El Raso de Candeleda cuya cronología más moderna se situaría a mediados del siglo III a.C. (Fernández Gómez, 1986: 984) cuando aún no había llegado los influjos bernorianos a estas latitudes. Estos hechos nos ponen de manifiesto el marco de relaciones comerciales del área septentrional y cómo y de qué manera llegaron a las tierras del sur de la cuenca del Duero. Estos argumentos son válidos para situar cronológicamente el ambiente cultural de nuestra necrópolis. En consecuencia, para el origen de Villanueva de Teba habría que pensar en cronlogías similares a esas, desde este punto de vista. A esas fechas del siglo II nos apunta también el ejemplar citado anteriormente de El Soto de Medinilla que apareció asociado a una fíbula de caballito procedente de los cenizales que se sitúan a lo largo del siglo II sin descartar el final del siglo anterior (Escudero, 1995: 198).

Cierto paralelismo con la contera de la tumba 22 tendría la de la tumba 30 de Las Ruedas (Sanz Mínguez, 1997: 81, fig. 73) que C. Sanz fecha a inicios del siglo III articulando la cronología del puñal, la de las pinzas depilatorias y ciertas decoraciones impresas. Habría que pensar en esas fechas para buscar el comienzo de la necrópolis de Villanueva de Teba, o al menos no anterior a ella. La tumba 32 dio un puñal espectacular por su decoración a base de temas en visión cenital los cuales Romero y Sanz (1992: 453-471) sitúan en fechas tardías del siglo I a.C. pero que en este caso, dichos puñales no se pueden rebajar más del siglo II a.C.

Es precisamente en esos momentos cuando la necrópolis de Villanueva de Teba desarrolla su potencial cultural manifestado en esos objetos con una tipología específica.

La historia de la investigación de este tipo de puñal es muy antigua y por eso ha sido el arma más estudiada. Se inició su identificación cuando Cabré (1916: 1-16; 1920: 5-34) definió las características del tipo. Poco más tarde realizó una seriación tipológica (Cabré, 1931: 221-241) que luego se completó con un estudio cronológico por este autor (Cabré y Cabré 1933: 37-45) y por García Bellido (1933: 144-146) el cual quiere buscar orígenes centroeu- 
ropeos para el puñal frente a los itálicos de otros investigadores. Schüle (1969: 108-112) culminaría esta primera etapa de investigaciones. Durante la década de los 80 y 90 comienzan a aparecer una serie de trabajos que van puntualizando muchos aspectos hasta culminar en concienzudos estudios sobre su problemática, aunque quedan todavía muchas cosas por definir. Los trabajos de catalogación y seriación tipológica continuaron con los Cabré (Cabré y Morán, 1982: 74) y Griño (1989: 35) que han sido punto de referencia básico para ulteriores investigaciones una vez que han sido desmenuzados los aspectos formales. Esta autora incorpora puñales inéditos de La Osera, las Cogotas, Miraveche, Almaluez y la vaina de Villanueva de Teba a la que nos hemos referido. Pero los trabajos más interesantes y completos por sus implicaciones cronológicas, seriales y secuenciales han sido llevados a cabo por Sanz Mínguez (1986: 25-46; 1990a: 172-187; Sanz, Escudero y Fontaneda, 1987: 79-93; Sanz, 1997: 427-439), con algunas aportaciones como las de Martín Valls y Esparza (1992: 259279), García-Soto (1989: 367-388) o Filloy (1990: 241-246). Nuevos hallazgos se han ido produciendo en estos últimos años que han aumentado la visión del conjunto expuestos en trabajos como el de Martín Valls para Palenzuela (1984: 32-41), Escudero (1988: 32-41) para El Soto de Medinilla, Smith y Muñoz (1989: 129-139) para el área astur-cántabra, Zamora Canellada (1987: 20-55) para Segovia, Álvarez, Cebolla y Blanco (1990: 287-304) para piezas que pueden proceder de áreas próximas a Villanueva de Teba, García-Soto (1989: 367-388) y Martínez (1992: 559-570) para Soria.

\section{PUÑAL DEL GRUPO II.}

Este grupo lo hemos considerado como una transición, pero no precisamente desde el tipo Monte Bernorio-Miraveche hacia el modelo específico de la necrópolis ya que es el más representado aunque presenta muchas variantes en cuanto a la concepción de la empuñadura. Se trataría del grupo IV.

Estas serían las piezas que corresponden a este grupo.

\section{Segundo puñal de la tumba 22:}

1. Hoja de hierro de $24 \mathrm{~cm}$ de longitud mas los 5,3 cm que conserva la espiga. Ésta es de sección rectangular, típico del grupo IV, y la hoja dispone de la nervadura central que viene definida por dos acanalados longitudinales a cada lado que dejan ese resalte a modo de nervadura. Esos dos acanalados no llegan a la parte inferior de la hoja. Presenta estrangulamiento, típico de los perfiles pistiliformes.

2. Lámina de bronce de la cara anterior de la vaina de $20,4 \mathrm{~cm}$ de longitud y $2,6 \mathrm{~cm}$ de anchura de desarrollo paralelo salvo el tercio inferior cuyos lados convergen hasta el disco de la contera. Ese disco tiene $3,3 \mathrm{~cm}$ de diámetro y presenta cuatro roblones, de cabeza de bronce y perno de hierro, para ensamblar a la caja de la contera. La lámina presenta en el centro un calado rectangular sobre el que iba uno de los sectores transversales de la vaina. En el extremo proximal tiene un aplanamiento y carece de decoración porque era donde se ensamblaba el sector transversal superior de la vaina. Dispone de una banda decorativa periférica a cada lado formada por tres esquemas: tres líneas incisas a cada lado bordean un acanalado que va de arriba hasta abajo. El disco no tiene decoración.

3. Sector transversal superior de la cara anterior de la vaina. Iba montada en la parte superior de la pieza anterior. Mide 5,9 por 3,1 cm doblándose en los bordes para ensamblar con la pieza posterior y las guías de hierro de la vaina. En cada lado corto lleva dos roblones (cabeza de bronce y perno de hierro), en las esquinas para ensamblar 
todo el dispositivo. La decoración es idéntica a la de la placa anterior. Dos bandas periféricas, en la parte superior y en la parte inferior con el mismo esquema: tres líneas incisas, acanalado y tres líneas incisas.

4. Sector transversal medio de la cara anterior de la vaina. Pieza idéntica a la anterior en todo salvo que mide $5,4 \mathrm{~cm}$ de ancho por 3,1 de alto.

5. Tahalí rectangular rematado en gancho, de hierro y muy curvado. Mide $24 \mathrm{~cm}$ de longitud por 3,5 de anchura. En la parte inferior, donde enganchaba a otras piezas idénticas presenta una lámina de bronce transversal con dos pernos decorada con tres bandas de líneas incisas paralelas. Bajo ella van, a cada lado, sendas laminillas de bronce lisas, por los bordes del tahalí. En el centro y cerca del gancho hay una perforación, probablemente para ensamblar una lámina decorativa de bronce.

\section{De prospección:}

1. Hoja de hierro, de $27,5 \mathrm{~cm}$ de longitud y $10 \mathrm{~cm}$ de espiga que es de sección rectangular, elemento ya específico del grupo IV. La hoja es idéntica a la de la tumba 22. Es decir, de cuatro mesas en cuyo centro discurre un nervio semicircular definido más bien por el rebaje de las dos acanaladuras que discurren una a cada lado.

2. Lámina de bronce de la cara anterior de la vaina. Mide $27,3 \mathrm{~cm}$ de largo y 3,2 de ancho pero en el tercio inferior los lados son convergentes hacia el disco de la contera. Presenta la misma decoración periférica que su homóloga de la tumba 22, salvo que no llega al arranque de la contera sino que se corta poco antes con tres líneas incisas transversales. El disco de la contera presenta decoración, además de los cuatro roblones con cabeza circular de bronce y perno de hierro para ensamblar a la caja de la contera. Esa decoración está formada por dos bandas circulares, una de ochos al greneti y otras de eses formando un sogueado; las dos separadas y bordeadas por doble círculo inciso. (fig. 1, 13).

Este segundo grupo lo hemos individualizado porque no tiene nada que ver con el puñal tipo Monte Bernorio y presenta elementos que van a ser específicos del grupo IV, característico de esta necrópolis, pero que en este ejemplar no aparecen netamente definidos. Esa individualización viene especificada, en primer lugar, por la hoja que es de mayores dimensiones que las del puñal de Monte Bernorio y las de grupo IV. En ambos tipos son inferiores a los $20 \mathrm{~cm}$ de hoja. Por otro lado, el perfil de la hoja es de cuatro mesas con el nervio romo que aparece mejor definido por los acanalados longitudinales a cada lado. Carece de estrías que son habituales en el grupo IV. Por esa razón pensamos que es una variante formal que prefigura el modelo de Villanueva de Teba.

En el anterior trabajo sobre la tipología de este puñal (Ruiz Vélez y Elorza, 1997: 282) incluimos algunas piezas en este grupo pero que ahora debemos desechar porque corresponden a un tercer puñal presente en la tumba 22 y que es ya específico del grupo IV, con su sistema de cruz o guarda, pomo y tahalí-cinto específico y la pieza en ese del sistema de ensamblaje al cinto.

La vaina es otro de los elementos que nos permite individualizar este segundo grupo. No es una pieza compacta como la vaina del modelo anterior, Monte Bernorio, sino que ya presenta unas peculiaridades que son las específicas del grupo IV. Veámoslas. En primer lugar, la vaina debía tener (no se ha conservado ningún resto) unas guías de hierro, periféricas, de sección en $\mathrm{V}$, donde enganchaban las demás piezas a través de roblones de cabeza de bronce y perno de hierro. Esas guías rematarían en la contera. En esas guías enlazan los dos sectores transversales, citados anteriormente, a través de dos botones a cada lado. Por debajo de esas piezas iba la lámina de bronce que remata en disco, el cual tapaba la contera y con los botones que presentan ensamblaría la lámina posterior dando cohesión a la contera y a la vaina. 
Esas láminas transversales y la longitudinal forman una pieza en el grupo IV. Esa es la diferencia entre los dos grupos (II y IV) en cuanto a la vaina pero sería una variante significativa que por haber aparecido únicamente en la tumba 22 (además de las dos piezas de prospección) pensamos que serían el paso previo al modelo IV ya que en esta tumba 22 es donde hemos encontrado el único ejemplar de tipo Monte Bernorio.

El sistema de enganche de la vaina al cinto no tiene nada que ver con el sistema de hembrillas y perno que son específicos de ese modelo. Pensamos que ya podría ser el típico del grupo IV. Es decir, en la cara posterior de la vaina va una pieza en ese, cruzada en unos $45^{\circ}$ rematada en ganchos cerrados en los que ensamblaban las piezas en forma curva del cinto. Esas piezas hacían que el enganche al cinto, por un lado, se hiciese a la altura de la embocadura de la vaina y, por otro, hacia el centro de la vaina. En la tumba 22 ha aparecido el fragmento de una pieza en «ese» pero correspondería al puñal $n^{\circ} 3$ que es el específico del grupo IV, pero como ya aparecen los elementos típicos de ese grupo, es probable que también presentase el mismo sistema de enganche. El tahalí que hemos asignado a este puñal no es todavía el específico del grupo IV, como veremos más adelante, porque es liso, de menores dimensiones y carente de decoración, pero la presencia de dos perforaciones, en el centro y cerca del garfio, nos están indicando que con toda probabilidad iría montada una lámina de bronce decorada como ocurre en muchas piezas del cinto del grupo IV.

No sabemos nada de la empuñadura de este puñal. Probablemente ha sido barrida por las labores del arado pero pensamos que debía tener alguna relación formal con el tipo IV en sus muchas variantes, siendo la más corriente el remate de la espiga con una virola embutida en la espiga que servía también de elemento de cohesión del puño que posiblemente fuese de materia orgánica.

\section{PUÑAL DEL GRUPO III.}

Este grupo está representado exclusivamente por el único puñal de la tumba 33 (fig. 3) que aparece vinculado a algunas piezas que nos pueden estar indicando una cronología antigua dentro de la necrópolis pues está asociado a una placa ibérica que nosotros integramos en el grupo I, el cual se caracteriza por una serie de elementos que recuerdan otras placas similares de Miraveche. Esos momentos antiguos de la necrópolis coinciden con la cronología del puñal de tipo Monte Bernorio de la tumba 22; es decir, a los momentos iniciales, posteriores al mundo de Miraveche pero los rasgos morfológicos de la empuñadura del puñal parece indicarnos lo contrario.

La hoja es exclusiva, de forma triangular con un desarrollo recto y con una anchura en la embocadura similar a los demás puñales, $5,4 \mathrm{~cm}$. Es de sección biconvexa. La espiga es de sección rectangular como la del modelo IV. Carece de estrías o nervio central. Es decir, la hoja recordaría la forma de algunos puñales bien tipo Alcacer do Sal o bien puñales sureños tipo Almedenilla (Quesada, 1997: fig. 164 y 165) pero sin alcanzar la anchura de estos y sin la presencia de las estrías. De cualquier manera, esa hoja no se asemeja a los de tipo Monte Bernorio, aunque quizás sí a algunas hojas triangulares de la fase de expansión (Sanz Mínguez, 1990: 181, fig. $3 \mathrm{n}^{\circ}$ 32) en las que pudo estar inspirada, pero en nuestro caso con la sección biconvexa, no losángica con nervio. En ese sentido nuestro puñal es muy peculiar. Este tipo de hoja lo encontramos en algunos puñales de frontón de Osma y Alpanseque y en algunos biglobulares (Quintanas de Gormaz, Osma, Numancia) y con el mismo tipo de guarda, recta y maciza de bronce y con el diseño de la empuñadura de tipo laminar. En el centro va la espiga y en ambas caras dos láminas iguales, de bronce en la anterior y de hierro en la posterior formado la empuñadura. 
La empuñadura es tripartita formada por tres piezas yustapuestas. La guarda o la cruz es maciza, como acabamos de decir, en la que se embute la hoja y la espiga a presión y se compacta a través de un recocido intermedio. Presenta dos incisiones en forma de aspa cubriendo toda la superficie. Es de forma trapezoidal. El puño y el pomo son elementos constituidos por el mismo tipo de piezas pero con aspectos formales específicos. Ambos están definidos por tres placas o láminas superpuestas. La central, en la que estaba embutida la espiga, sería de materia orgánica porque no se ha conservado nada. Por la parte delantera va una lámina de bronce cuyo sector del puño es de paredes rectas, paralelas y remata en el sector del pomo con una forma casi semicircular con la incurvación hacia el puño. Está profusamente decorada. Por la parte posterior va otra lámina idéntica de hierro y sin decoración. El sistema de ensamblaje de las tres láminas y la espiga es a base de botones de cabeza esférica de bronce y perno de hierro forjado en la lámina de hierro. Por la cara anterior esos botones se complementan con la decoración. Así, cuando se presenta en la lámina anterior un tema circular, el centro está ocupado por uno de esos botones; de ahí la distribución simétrica de esa decoración. En total son siete botones de ensamblaje como puede verse en el dibujo. Esta concepción de la empuñadura está inspirada en los puñales biglobulares. Y en cuanto a la decoración, hasta podríamos decir que el pomo parece indicarnos la presencia de unos ojos apotropaicos (Cabré, 1952: 101-106; Morán Cabré, 1973: 597-604; Cabré y Morán, 1973: 605-610) que aparecen en otras piezas como las placas y las espadas con esa misma simbología. Los dos elementos compositivos básicos de la decoración son la simetría y la disposición en bandas. Dicha decoración se centra en la lámina anterior de bronce, formando campos decorativos separados por tema funicular dispuesto transversalmente en la lámina. Así se han creado cuatro campos decorativos distribuidos en dos grupos de anchura distinta. En la parte inferior, el primer campo, más estrecho, se decora con dos temas de dos círculos concéntricos incisos cuyo centro lo ocupan sendos roblones de anclaje, citados anteriormente. El segundo campo, que actúa de tema central del puño y es más ancho que el anterior y el siguiente, dispone un tema central sobre el roblón de enganche formado por un esquema circular funicular y dos círculos concéntricos. Después como remate de la zona del puño va el tercer campo idéntico al primero y a continuación el campo que corresponde al pomo flanqueado por ese tema funicular y en el centro dos temas circulares alrededor de los dos roblones como en el tema central del puño.

La vaina es una pieza compleja y se asemeja a la del grupo IV. Presenta los elementos estructurales que vimos en el grupo II y que van a ser los específicos del puñal de Villanueva de Teba. Periféricamente, la vaina se constituye a partir de un alma o guía formada por una pieza de hierro de sección en $\mathrm{V}$ de perfil delgado en la que ensamblan los demás elementos. Esa guía se prolonga por la contera definiendo el círculo de la misma y sujeta la guía y las dos láminas de cierre con un botón central. Por la cara anterior se cubre la caja con una serie de cuatro láminas de bronce decoradas dispuestas de la siguiente manera: en la embocadura el primer sector transversal, decorado y en el centro de la vaina el segundo transversal, decorado de la misma manera que el primero. Entre ambos sectores, por debajo, va otra lámina dispuesta longitudinalmente con una decoración muy rica. También embutida en el segundo sector transversal va otra lámina en igual disposición hasta la contera formando una sola pieza. También está decorada como en el caso anterior. Estas láminas de bronce parecen constituir una sola pieza en el grupo IV. La lámina de la contera también está decorada. Por la parte posterior únicamente van, en hierro, los dos sectores transversales de la lámina dejando al descubierto los demás sectores. Los botones que ensamblan toda la estructura, situados uno a cada lado de las partes transversales, son los que enganchan el sistema de anclaje al cinto que en este tipo de puñal aparece definido por dos puentes, uno a cada lado, enganchados por esos botones a los que aludíamos anteriormente. Esta es otra peculiaridad de este puñal.

La decoración de la vaina también es rica centrándose en las piezas de bronce. Los sectores transversales son idénticos distribuyéndose los temas en sentido transversal al eje del 
puñal. En el centro van dos dobles líneas incisas; le siguen a cada lado sendas bandas de tres puntos troquelados y finalmente un acanalado; todos hacen de cenefas longitudinales. Las placas verticales disponen de una decoración simétrica. La primera, la placa superior presenta en el centro un sogueado de botoncitos (al greneti) de tres nudos. Se flanquea ese sogueado con dos hiladas verticales de greneti, una a cada lado y se remata con dos baquetones, también verticales, huecos por el reverso. La otra placa vertical igualmente presenta esos dos baquetones huecos, pero el sogueado ocupa el tercio superior de la lámina quedando el resto en un campo liso, sin decoración. La contera también está decorada. Alrededor del botón central van dos círculos incisos, otro círculo de ochos al greneti y dos círculos más al greneti siendo los más exteriores. La contera de la vaina viene definida por tres elementos formales. El cuerpo lo constituye la prolongación de la guía desarrollada periféricamente. Por la cara anterior cierra con la lámina de bronce y por el reverso con la lámina de hierro. Es por lo tanto un esquema que aparece en algunos puñales del grupo IV (tumbas 19, 26, 27, 31) aunque el más corriente es la contera en forma de caja constituida por la prolongación de la lámina posterior. La vaina mide $23,5 \mathrm{~cm}$ de largo y $5,3 \mathrm{~cm}$ de ancho en la embocadura; es decir, dentro de los parámetros del grupo IV por lo que puede estar relacionado con él en este sentido.

Este sistema de anclaje es típico de muchos puñales biglobulares como el de la tumba 383 de Las Cogotas, pero el ejemplar más próximo, casi idéntico es el de la necrópolis de Uxama (Cabré, 1931: lm. XX; Cabré, 1990: fig. 9), aunque la concepción del enganche al cinto es diferente. Paralelos encontramos también en la necrópolis de La Hoya (Laguardia, Álava) (Filloy, 1990: 244-245, fig. 2 no 3 y fig. 3) donde hay algunos puñales con este mismo sistema y que allí llaman «de cañas». En esta necrópolis han descubierto dos modelos de unión a esas cañas que nosotros llamamos puentes. Por una parte el que se realiza a través de un tahalí rematado en un disco que es donde se encuentra la argolla de ensamblaje al puente, $y$ otro en el que el enganche se hace con una pieza rectangular de cabeza cuasisemicircular. Esta pieza uniría, según los alaveses, al cinto de cuero. Este segundo sistema es el que parece responder a nuestro puñal pero no porque hayan aparecido evidencias en la tumba en este sentido sino porque el modelo del grupo IV sería el mismo que el del grupo III; es decir, un cinturón de piezas metálicas que podrían tener un protector interno de cuero formado por placas articuladas mediante un sistema de bisagras. Por lo tanto no se puede hablar de tahalíes. El enganche del cinto sería a través de un garfio que encajaba en una pieza pasiva. En los dos puentes de la vaina conserva los dos elementos de enganche que están formadas por dos placas de una sola pieza que giran formando el gancho de sección circular. Sobre la cara anterior va una lámina de bronce decorada con una hilada periférica de granitos (greneti) o perlitas como los llama Sanz Mínguez. Dichas piezas miden 5,3 cm de largo por 2,6 cm de ancho. Dichas piezas ensamblaban con otra placa de bronce sobre otra de hierro que tiene la misma anchura, 2,6 cm y 5,6 cm. de longitud existente. Esta placa, de desarrollo recto, se decora ricamente con una hilada longitudinal y central de botones con dos temas funiculares a cada lado. Por el borde va una línea incisa a cada lado. Conserva en el arranque de la placa un tema transversal de hilada de cuatro botones (los dos extremos para enganchar a la placa de hierro del reverso) bordeados por un tema funicular de líneas rectas. Sólo se conserva del cinto del puñal esta pieza pero podemos deducir que esa placa sería una de las que formaban el cinto que sujetaba el puñal y que presumiblemente discurría por la cintura como pensamos que es el sistema común en el puñal del grupo IV.

\section{PuÑal del GRUPo IV, TiPo VillanueVA DE TEBA.}

El grupo IV se muestra como el puñal específico de esta necrópolis que aparece representado en ella por 21 ejemplares de los cuales en dos casos no se conserva la hoja. Si a estos unimos el ejemplar del grupo I, los dos del grupo II y el único del grupo III, sumamos 25 
puñales para 35 tumbas lo cual representa un porcentaje muy grande si comparamos con los 14 puñales aparecidos en la necrópolis de Las Ruedas. Pero hemos de tener en cuenta que la nuestra no está totalmente excavada; de cualquier manera es un dato objetivo el elevado número de puñales pero no por el número en sí sino porque está presente en casi las tres cuartas partes de las tumbas.

Este modelo de puñal presenta una gran uniformidad en cuanto a la hoja y la vaina pero con variaciones formales en la concepción del pomo de la empuñadura que responde a una riqueza decorativa y que alcanza significación simbólica, como veremos en el apartado correspondiente. Son puñales muy elaborados, con un diseño rico y minucioso que no tiene parangón con sus congéneres de Monte Bernorio y los biglobulares con los que convivió, o con los de frontón o antenas atrofiadas. Un elevado número de piezas en su constitución hacen de este tipo un modelo particular y poco consistente para una función militar, de defensa o ataque. Esto nos ratifica en la idea de que, aparte de su finalidad funeraria, es un objeto de prestigio que nos reseña, por una parte, el status de un grupo social alto y, por otra, la unidad formal en la representación de ese status que nos apunta hacia la existencia de un grupo homogéneo y cohesionado que ha podido ubicarse en un lugar específico de la necrópolis respondiendo a una diversidad social del poblado en el que vivieron.

Por otro lado, a través de las distintas muestras presentes en esta necrópolis, sabemos todo respecto a su forma y disposición, lo cual nos facilita mucho las cosas a la hora de establecer comparaciones con sus congéneres.

\section{Las hojas del puñal.}

Estos puñales parecen presentar un mismo tipo de hoja, que se caracteriza por su perfil suavemente pistiliforme, con nervadura central recta y una serie de estrías que discurren paralelamente dibujando el perfil pistiliforme de la hoja. Es un hierro de mucha calidad que está acerado en muchos casos; por lo tanto testigos de un proceso de fabricación de calidad.

TABLA I. LONGITUDES DE LAS HOJAS DEL PUÑAL SIN LA ESPIGA.

\begin{tabular}{|l|c|c|c|c|c|c|c|}
\cline { 2 - 8 } \multicolumn{1}{c|}{} & \multicolumn{7}{c|}{ LONGITUDES $(\mathrm{CM})$} \\
\hline EXCAV. & $17-18$ & $18,1-19$ & $19,1-20$ & $20,1-21$ & $21,1-22$ & $22,1-23$ & $23,1-24$ \\
\hline TUMBA & $12,15,17$ & $2,14,26$ & $4,17,19,33,34$ & $1,15,31$ & $1,6,27,31$ & 11,16 & 22 \\
\hline PROSPEC. & 4 & 1 & - & 1 & 2 & 1 & - \\
\hline
\end{tabular}

Sus dimensiones son las típicas para este tipo de armas. La hoja más pequeña apareció en el puñal de la tumba 2 pues tiene $16 \mathrm{~cm}$ (longitud únicamente de la hoja) siendo la más larga la de la tumba 16 con $23 \mathrm{~cm}$. Es decir, tienen unas dimensiones similares a los demás puñales, quizás un poco más pequeñas pero poco significativas desde el punto de vista cuantitativo. Todos disponen de la nervadura central y las estrías que están entre dos, cuatro y seis, simétricamente distribuidas a cada lado de la nervadura. El perfil, en todos, es romboidal con las modificaciones que introducen dicha nervadura y las estrías.

Las hojas de prospección, que son pocas y referidas a este mismo tipo, presentan unas medidas ligeramente mayores. Algunas de estas alcanzan unas dimensiones que parecen indicarnos que escapan a la norma general del resto de los puñales, planteando otra vez el dilema de si son hojas de puñal o de espada corta, pero como en esta necrópolis no ha apareci- 
do nada que se pueda asociar a una espada, es probable que podamos hablar de hojas de puñal exclusivamente y así lo entendemos. Tampoco son medidas excesivamente grandes las de $\operatorname{los} \mathrm{n}^{\mathrm{o}} 2,4$ y 8 de prospección como para concluir que son espadas.

La espiga es siempre de sección rectangular, casi cuadrada y presenta irregularidades debidas a su proceso de forja, como probablemente fue hecha también la hoja, pero en este caso, en aquellos puñales en los que se ha llevado a cabo una restauración importante, se observa la superficie lisa y acerada de un proceso de elaboración cuidado y esmerado. Es decir, estamos ante un proceso de fabricación selecto entre los mejores del género. Se conserva la espiga entera en pocos casos y no guarda relación con la dimensión de la hoja porque la espiga de la tumba 11 tiene 12,5 cm (la hoja 19,5), la de la tumba $1511 \mathrm{~cm}$ (la hoja $17,7)$, los dos puñales de la tumba 17 tienen respectivamente $14,3 \mathrm{~cm}$ (la hoja 19,2) y 12,1 $(17,1)$, la de la $2512,5 \mathrm{~cm}(20,5)$, la de la $2612 \mathrm{~cm}(18,7)$, la de la $2710 \mathrm{~cm}(18,5)$ y la de la $3411 \mathrm{~cm}$. (20). En cualquier caso debemos señalar que las medidas de las espigas son muy similares y además pequeñas para explicar su funcionalidad militar. El remate de la espiga lo veremos con la empuñadura al analizar esta parte del puñal.

\section{La vaina.}

Ya hemos indicado que esta pieza del puñal es muy uniforme en este grupo pues estructuralmente consta de los mismos elementos aunque hay ligeras variaciones formales como vamos a ver (fig. 5).

Las medidas de estas vainas, incluida la contera, está en torno a los $20 \mathrm{~cm}$. siendo la más pequeña conservada la de la tumba 12 que tiene $16,5 \mathrm{~cm}$ de largo y $6,5 \mathrm{~cm}$ de embocadura; la segunda de la tumba 17 tiene $18,8 \mathrm{~cm}$ de largo y 6 de embocadura; las demás sobrepasan los 20 $\mathrm{cm}: 26,5$ x 5 (la primera medida es la longitud de la vaina y la segunda de la embocadura) en la tumba $1,20 \times 5$ en la tumba 4,21,4 x 6,5 en la tumba $6,23,2 \times 6$ en la tumba 9,22,9 x 5,7 en la tumba $11,20,5$ por 5 ' 7 en la tumba $15,21,5 \times 5,5$ en la tumba $17,22,4 \times 5,3$ en la tumba 26 , 20,2 x 5,5 y 21,4 x 5,4 en la tumba 27. Es decir, son medidas muy uniformes.

La funda del puñal se compone, básicamente, de tres grandes piezas que son las siguientes. Una guía de hierro, fina, que recorre todo el perímetro de la vaina, con un perfil en $\mathrm{V}$, en la que ensamblan las demás piezas por pernos de hierro con cabeza esférica de bronce. Esa guía dibuja el perfil suavemente pistiliforme y se prolonga definiendo el círculo de la contera. Sobre la cara anterior y posterior van sendas láminas, generalmente de bronce en la cara anterior y de hierro en la cara posterior, que cierran herméticamente la funda. Ambas cierran la vaina y la contera. El diseño de estas láminas está en función del sistema de sujeción. Así tenemos que las láminas presentan en la parte superior, junto a la embocadura y en el centro de la funda, dos ensanchamientos rectangulares en cuyas esquinas se sitúa el perno que va a ensamblar la lámina anterior, la guía y la lámina posterior. El sistema es seguro y práctico. Fuera de esos ensanchamientos de las láminas queda la guía al descubierto produciendo una sensación cromática entre la lámina de bronce y el hierro de dicha guía en la mitad superior de la vaina y en la mitad inferior. La lámina de la contera tapa casi totalmente la guía. La sujeción de estas tres piezas se hace mediante cuatro pernos en cada sector transversal de las láminas y con otro más en el centro de la contera. La lámina de bronce siempre está decorada, como veremos en ese apartado.

De todo el conjunto de las láminas, distinguimos dos salvedades o peculiaridades que son los puñales de las tumbas 6 y 31 . El primer caso se caracteriza porque la lámina anterior es de hierro, no de bronce como en todos los demás ejemplos (fig. 6).

Pero estructuralmente tiene la misma forma y sujeta del mismo modo. Esa lámina presenta una pequeña arista central en los sectores transversales y longitudinales en el resto de 
la lámina. En la de la tumba 31 la única diferencia es que en vez de sujetar con dos pernos a cada lado de los sectores transversales, lo hace con uno sólo.

La decoración de la lámina de bronce también es un elemento de unidad en estas piezas pues se repite el mismo esquema y las mismas técnicas decorativas. Dicha decoración se dispone por sectores en la lámina pero que repiten tanto en los dos sectores transversales como en los dos longitudinales o verticales.

La contera presenta dos variaciones en cuanto a su concepción formal:

1. Vaina tripartita: viene definida por la prolongación de la guía que forma la caja de la contera y que se cierra por las respectivas caras con las correspondientes láminas. Se ensamblan las tres piezas con un botón central. Estos son los ejemplares: los de las tumbas $19,25,26$, los dos de la 27 y el de la 31.

2. Vaina bipartita: que está formada por dos elementos nada más. La caja que está definida por la prolongación de la lámina posterior, por lo tanto es de hierro. Ha desaparecido la guía y se cierra con el segundo elemento, la lámina de bronce de la cara anterior. El sistema de ensamblaje es el mismo. Esta variedad está presente en las tumbas $1,4,6,9,11$, el primero de la 12 y los dos de la 17.

La decoración de estas conteras se dispone alrededor del botón funcional del centro a base de líneas incisas o círculos concéntricos y una hilada de roblones como en los casos de las tumbas $1,4,11,12,19,27$ y 31 . En algún caso - tumba 9 y $17\left(n^{\circ} 1\right)$ - son únicamente cuatro botones coincidiendo con los puntos cardinales. En este segundo caso, cada botón está enmarcado por hilada de perlitas o botoncitos estampadas. El ejemplar de la tumba 26 (fig. 9) sólo presenta dos botones, aparte del central, uno a la izquierda y otro a la derecha. La contera de la tumba 15 no tiene botones pero dispone de dos temas funiculares paralelos en círculo. La de la tumba 6, como es de hierro, es totalmente lisa.

Hay otros elementos estructurales en la vaina y son los que determinan el sistema de sujeción al cinturón. En la parte superior de la lámina posterior se dispone una pieza de hierro en forma de ese, (fig. 5) en unos $45^{\circ}$ de inclinación, que va remachada a la lámina por dos pernos que han sido martillados para evitar que sobresalgan. Dicha pieza cierra en un gancho abierto por los extremos que es donde ensamblan los elementos triangulares del arranque del cinturón del puñal. Esta disposición determina que el enganche superior al cinto aparezca a la altura del sector transversal superior, y el otro enganche en el segundo sector transversal de la vaina. Es decir se busca una simetría en la distribución de los elementos estructurales y en la decoración, como veremos luego. Esa pieza en forma de «ese» está formada por una lámina de hierro también forjada que en la mayoría de los casos es idéntica salvo algunos ejemplos aislados. La de la tumba 12, en el centro presenta un ligero ensanchamiento en ángulo que introduce una variación nada más. Y la pieza de la tumba 9 que no tiene forma de ese sino que es de lados convexos y de forma simétrica pero dispuesta con la inclinación idéntica de todas las demás piezas. Estas dos variaciones no van unidas a otras de otros elementos que hubiesen permitido diferenciaciones morfológicas.

\section{La empuñadura.}

Es el elemento más vistoso y peculiar de este tipo de puñal. Además, en el de la tumba 11 (fig. 7), se ha conservado entero y a través de él podemos reconstruir todos los elementos integrantes de esa empuñadura que son muchos. Para ello seguimos la estructuración que de la empuñadura han hecho Griño y Kurtz los cuales distinguen tres elementos: pomo, puño y 
guarda o cruz, como dicen otros autores dedicados al tema tales como los Cabré, García Lledó (1986-87: 311-320) y tantos otros.

En el estudio de estos tres elementos veremos que hay modificaciones formales pero que no tienen que ver con posibles variaciones que introducirían subgrupos en el tipo IV. Son variaciones aleatorias que son el producto de una dinamicidad formal y estética reflejo del gusto artístico y del interés por este puñal para la función que fue diseñado.

El sistema de ensamblaje de la empuñadura a la espiga es siempre el mismo y responde a la herencia hallstáttica de las espadas de antenas, frente a otras formas en las que no se dispone de espiga. Todo el complejo de la empuñadura va montado sobre esa espiga sujetado por presión mediante dos anillas en el puño, el anclaje por presión y recocido intermedio de la guarda y el remate de la virola o algún elemento del pomo que va metido por presión a la espiga. Este es el sistema básico de montaje de la empuñadura.

La cruz o guarda de la empuñadura se ha conservado en muy pocos ejemplares, concretamente en los puñales de la tumbas 11, el segundo de la 17, 19 y 22. Por lo tanto tenemos pocos elementos de juicio para poder sacar muchas conclusiones, pero a partir del puñal de la tumba $\mathrm{n}^{\mathrm{o}} 11$ podremos presumir el carácter y forma general aunque los demás ofrezcan ligeras variantes, alguna muy importante. La guarda es un elemento macizo de materia orgánica, probablemente madera (porque no se ha conservado ninguna evidencia de material duro como el hierro o el bronce), que va embutido en la espiga. Es de forma perfectamente rectangular cuya medida media es los 5,6 cm de longitud por 1,7 de anchura. Por la parte anterior se monta una lámina de bronce de las mismas medidas. Se sujeta al hierro con dos pernos de cabeza de bronce situadas en los extremos. Esa lámina está decorada con el mismo esquema que la lámina de bronce de la vaina con la que hace juego. Esto al menos en los puñales de la tumba 11 y 19. La lámina del puñal de la tumba 22 presenta una decoración formada por dos temas funiculares, uno por la parte superior y otro por la inferior que enmarcan un tema de línea quebrada incisa. Esta pieza correspondería al tercer puñal de la tumba 22 ya que tiene uno de tipo Monte Bernorio, otro del grupo II y este del grupo IV. Esa lámina de la guarda tiene que corresponder a la pieza del sector transversal superior que se decora con dos bandas de eses enmarcadas por tres líneas paralelas incisas. Más espectacular es la guarda del primer puñal de la tumba 17 porque es una pieza calada (fig. 8), cosa inaudita porque es un caso único en el yacimiento, que deja al descubierto una lámina de plata que va entre la lámina de bronce y la madera que iría debajo formando el cuerpo de la guarda. La de plata, además, está decorada con un repujado de puntitos. Éste sería un elemento procedente o bien del ámbito ibérico o del mundo de La Tène. La lámina de bronce de este puñal de la tumba 17 no es perfectamente rectangular sino que el lado superior presenta una evolución trapezoidal hasta dejar una anchura de $1,7 \mathrm{~cm}$ que era donde encajaba el puño de la empuñadura. Esto implicaría que esta parte del puño podría ser de sección cuadrada o rectangular, pero es poco posible porque conserva un anillo circular de sujeción del puño y la caperuza del pomo que es semiesférica; por lo tanto el puño será de sección circular.

El puño de la empuñadura estaría formado por una pieza de materia orgánica que iba embutida en la espiga de hierro. Dicha pieza se cubría con unas láminas de bronce finamente decoradas, como en el puñal de la tumba 11 con triángulos estampados llenos de perlitas (greneti) dejando en resalte un zig-zag, que cubría el soporte. Estas láminas se sujetaban en el arranque de la guarda con un anillo de bronce que iría a presión. Uno por la parte inferior y otro idéntico por la parte superior. Estos anillos están también decorados y han aparecido en algunas tumbas, concretamente en la 11,15, 16, 25, 27. Suelen estar decorados con estampaciones de dos círculos concéntricos por la parte central del perímetro (tumbas 11 y 19). En las tumbas 15 y 16 son dos bandas cóncavas y en la 27 esas dos bandas se rellena con incisiones paralelas.

El pomo también es una pieza interesante y, sobre todo, compleja porque hay algunas variedades en su concepción formal y porque el modelo más repetido es el más complejo. Distinguimos varios tipos de pomo: 
1. Pomo formado por cilindros de bronce: le denominamos así por el elevado número de piezas que forman parte de su diseño y composición porque son doce piezas distintas que irían montadas sobre un cuerpo de madera u otra materia orgánica. Es el caso de los pomos de las tumbas 9, 11, 19, 26 (fig. 9), 27 y 34 (fig. 10). No se ha conservado íntegro ninguno, salvo la tumba 11; aparecerá habitualmente constatado por una, dos o alguna más de las piezas. De prospección proceden algunos restos también. Este pomo está constituido por tres cilindros de bronce que forman el cuerpo del pomo. Esos cilindros irían montados sobre materia orgánica que serviría de sujeción pero las piezas se ensamblan perfectamente unas con otras. El cilindro central, que va sobre la espiga, está formado por dos chapitas no perfectamente semicirculares, más abiertas que se sujetan con dos pernos de hierro con cabeza esférica de bronce. Adosados, pero independientes, están los otros dos, uno a cada lado. Por la parte superior, cerrando a los tres cilindros, hay una chapa trilobular de tres círculos, el central oblongado, que tapan perfectamente. En el centro de cada círculo hay una perforación por la que pasa el perno de hierro rematado en cabeza de botón de cabeza esférica y cuerpo troncocónico. El central va embutido en la espiga de la hoja y los laterales cruzan el cilindro por el centro hasta el otro extremo del cilindro donde sujetan una chapita circular que cierra los cilindros laterales. Como vemos, es una estructura compleja que parece dibujar de manera muy somera una cabeza humana muy esquematizada cuya concepción encaja en ese proceso de ambigüedad y abstracción de formas figuradas que aparecen en otras piezas como las fíbulas y que trataremos más adelante.

De la tumba 9 sólo ha aparecido un cilindro lateral, de la 19 un cilindro lateral y el botón central, de la 26 los tres cilindros de bronce, de la 27 la placa superior trilobular y dos botones de bronce y de la 34 la placa trilobular, un botón de bronce y la lámina anterior del cilindro central.

2. Pomo de virola semiesférica: han aparecido dos puñales, tumbas 15 y 25, (fig. 11) con este remate del pomo. Aparte de ese elemento se han recogido también los dos anillos que sujetaban las láminas de bronce que rodeaban el puño; por lo tanto sería de la misma forma y manera que en el caso anterior. La única diferencia es que el pomo es mucho más sencillo; carece de los tres cilindros y consiste sencillamente en una virola semiesférica de bronce que tiene un diámetro en la base idéntico al de los anillos de sujeción del puño. Por lo tanto es posible que careciese de otros elementos en el pomo.

3. Pomo con virola hemisférica y de cuerpo cóncavo: el tercer puñal de la tumba 22 está representado por una virola formada por un botón de bronce de cabeza hemisférica y un cuerpo cóncavo. Es el único ejemplar de estas características. Podría ponerse en duda la existencia de este tercer puñal de la tumba 22 porque esta virola podría corresponder al grupo II, lo cual nos indicaría que estas variaciones simples del pomo del grupo IV serían anteriores al pomo de estructura compleja.

4. Pomo con virola esférica y casquete de bronce: también hay un único ejemplar, el primero de la tumba 17 (fig. 8) y, probablemente el segundo (fig. 12), porque ambos cierran el pomo con el mismo tipo de virola esférica de bronce. Del segundo puñal no se ha encontrada nada más de la empuñadura. En el primero ya señalamos que la guarda es calada y con una lámina de plata repujada. También dijimos que el enmangue parecía tener junto a la guarda una sección cuadrangular pero que la presencia de una anillo de sujeción del mismo hace más probable que el puño sea circular o poligonal si presentaba las láminas finas que le rodeaban como el ejemplar de la tumba 11. La virola esférica de bronce tiene un diámetro de $8 \mathrm{~mm}$ y está decorada con tres líneas incisas en la posición de su ecuador. Pero lo más interesante es el casquete hemisférico hueco que iba entre el puño y la virola. Está formado por una lámina de bronce de $2,6 \mathrm{~cm}$ de diámetro y una altura de 1,2 , por lo que es casi hemisférico. Está decorado con unas incisiones transversales por todo el borde dándole un aspecto 
dentado. Por encima de este tema se disponen dos líneas paralelas periféricas. En el centro del casquete está la perforación para la virola y de allí arrancan tres líneas paralelas en el sentido de los puntos cardinales que van hasta la otra banda de dos líneas. Probablemente este casquete estuviese relleno de materia orgánica, seguramente madera para hacerlo macizo y en esa base estaría el cilindro de bronce de la parte superior. Estructuralmente sería parecido al primer grupo, el de los pomos de tres cilindros.

Estas modificaciones en la concepción del pomo no van acordes con unas variaciones formales en el resto de la empuñadura o en la vaina por lo que no podemos decir que todo esto implique tipología nueva sino simples derivaciones formales de un mismo tipo que sería nuestro Grupo IV

Cuando hemos hablado de la presencia de materia orgánica, particularmente madera, en la construcción del puñal Grupo IV es porque en alguna tumba hemos encontrado restos de ese material que pertenecen al puñal; incluso en uno de ellos, el de la tumba 11, la presencia es evidente. En la tumba 19 el fragmento de vaina tenía adherido un trozo de madera que resulta difícil determinar si formaba parte de la construcción de la vaina; probablemente sí porque en el segundo ejemplo, el primer puñal de la tumba 17 conserva el disco de esa misma materia que iba embutido en la contera de la vaina. Corresponde al puñal con la guarda calada y decorada con lámina de plata.

\section{Sistemas de enganche del cinturón al puñal.}

El sistema de enganche al cinto, como ya hemos visto en los diferentes modelos, presenta tres variaciones en Villanueva de Teba que van unidas a los distintos tipos de puñal. La primera de ellas se refiere al puñal tipo Monte Bernorio, del primer grupo, que iba en posición horizontal en la cintura y agarrado con lámina de hierro y cadenilla en las hembrillas de la contera. Este sistema ya lo analizó Cabré (1920: fig. 4; 1931, fig. 1; Cabré y Morán, 1973: lám. VII), luego Sanz Mínguez (1986: 31 y 88) y lo han completado ahora Griño (1989: 8388), Filloy (1990: 244-245, fig. 2 y 3) y de nuevo Sanz (1990: 180). Por lo tanto no vamos a insistir en ello. Las otras dos modalidades son sistemas que están presentes en los puñales de cronología baja como los de frontón y los biglobulares de los que tomó, sin duda, el modelo, o viceversa. La segunda variante, vinculada a nuestro Grupo III, consiste en dos barras laterales de hierro y paralelas al borde que enganchan en el primer y segundo sectores transversales de las láminas de la vaina. Este sistema es habitual en muchos puñales biglobulares de la Meseta (Uxama, Quintanas de Gormaz, Cogotas, etc,). La tercera modalidad introduce un cambio en el sistema. Mediante una barrita de hierro, ya recta ya en «ese» (lo más habitual), unida a la lámina de hierro que se encuentra en el reverso de la vaina a través de dos pernos de hierro en posición oblicua de unos $45^{\circ}$ respecto al eje del puñal, se engancha al cinto. El puñal, entonces, iba en la cintura montado sobre el cinto en condiciones habituales, inclinado hacia la derecha en todos los casos, lo cual facilitaba su uso siendo más rápido su desenfunde. Por eso los autores clásicos hablaban de la agilidad y habilidad de estas gentes en los combates a corta distancia, actividad en la que eran diestros. Se ha conservado este sistema de enganche en los puñales de las tumbas 4, 9, 11, 12 (dos), 26 y 27. La lámina unida a la vaina es una pieza plana con dos prolongaciones en los límites para acoplar los extremos del cinto, salvo los de las tumbas 9 y 27 en los que es recta. Tal sistema apareció ya en un puñal de La Osera (tumba 418 de la zona VI) llamando la atenci6n de Cabré aunque le impresionaron más las antenas del puñal. Dicho ejemplar tiene la pieza en «ese». Esta circunsatancia de llevar el puñal inclinado no implica la presencia de esta pieza pues se consigue el mismo efecto enganchando directamente junto a la embocadura y en el centro de la vaina por el otro lado. Basta fijarse en algunos ejemplares de Numancia (Schüle 1969: lam. 1661 y 2), Las 
Cogotas (Schüle, 1969: lám. 114 nº 1 y 118 no 1), Osma (Schüle, 1969: lám. 59 1), Quintanas de Gormaz (Schüle, 1969: lám. 362 y 37 2), Carratiermes. En todos los casos son puñales de frontón o biglobulares.

Una placa del remate final del cinto que sirve de enganche fijo al puñal, parecida a la de Villanueva de Teba, procede del castro de Amaya y está en los fondos del Museo de Burgos (Bohigas, 1986-87: fig. 2D) aunque la decoración es más compleja que la publicada pues la banda periférica es de eses troqueladas flanqueada por hilada de botoncitos. Muy similar pero conectando ya con lo romano es la pieza encontrada en el campamento de la Legio IIII Macedónica en Herrera de Pisuerga (Fernández Ibáñez, 1999: 335-345) que plantea el sistema de las armas romanas pero que no es objeto de este estudio.

Esta similitud con las piezas señaladas nos están indicando, en cualquier caso, cronologías tardías que encajan en esos ambientes de las postrimerías del mundo indígena, acorde con Villanueva de Teba.

Podría deducirse que las piezas señaladas más arriba, particularmente las vinculadas al Grupo III y las semejantes de La Hoya y las Cogotas, presentan unas dimensiones más pequeñas en aquellas que se refieren al enganche del puñal al cinto; pero las del grupo IV, como es un sistema fijo, esa pieza de enganche es más grande porque ya no es un tahalí sino un cinturón pero que conserva el sistema de fijación al cuerpo idéntico en los dos casos. Estas piezas concluyen en una estructura próxima al semicírculo formada por la de hierro que termina en el gancho con la placa de bronce de remate de la parte superior que aparece generalmente decorada. Estas piezas las estudiamos en su conjunto con el cinto.

\section{Los cintos de los puñales del Grupo IV.}

Asociados a los puñales van unas placas rectangulares, en la mayoría de los casos de bronce, que eran el soporte y sistema de transporte de aquellos. Estas placas constituían el cinto que remataba en placa con garfio para poder quitárselo y ponérselo. La unión al cinto se hacía con sendas piezas semicirculares de hierro a base de una lámina de bronce en la cara superior rematadas con garfio fijo que enganchaba en las piezas en «ese» del reverso de la vaina, por ambas partes. Desgraciadamente no ha aparecido ningún ejemplar completo no sabiendo con exactitud cuántas placas llevaban y el sistema de apertura y cierre del cinto. El ejemplar de la tumba 33 nos puede apuntar el sistema de estas piezas que se haría con las pequeñas láminas de bronce de cabecera circular rematada en garfio.

De prospección se recogieron 27 placas (fig. 13), algunas fragmentadas, tres de las cuales eran con gancho y 8 plaquitas auxiliares que van en los extremos de las anteriores. De excavación proceden también 27 repartidas así: una en la tumba 1; 2 en la tumba 2; placa auxiliar en la tumba 3; plaquita auxiliar y placa semicircular de enganche en la tumba 4; dos placas, una con gancho en la tumba 6; pieza semicircular en la tumba 9; tres piezas, una con gancho en la tumba 11; tres, una con gancho en la 14; pieza semicircular de enganche en la tumba 15; tres piezas, una con gancho y dos semicirculares de enganche en la 17; tres placas y una de enganche en la 19; una de gancho y otra de enganche en la 22; seis piezas, dos con gancho en la 26; una placa en la 30; y cuatro, dos con gancho en la 31. Las sepulturas que llevan puñal pero no han dado placas Hundersingen son: $\mathrm{n}^{\circ} 8,9,13,15,16,25,27,33$ y 31 . Las que tienen restos del cinto pero no tienen puñal son las tumbas $n^{\circ} 3$ y 30 .

Estas láminas son de bronce, salvo alguna de hierro y otras mixtas en cuyo caso la placa funcional es la de hierro. Presentan una gran uniformidad decorativa pero hemos distinguido tres grupos con dos subgrupos cada uno. Son placas de superficie plana, pero de perfil ligeramente curvado o muy curvado (porque iban en los laterales de la cintura). En los bordes llevan 
sendas crestas (con una altura media de $0,7 \mathrm{~cm}$.) que desaparece a $1,5 \mathrm{~cm}$ de los extremos porque allí se colocan transversalmente las placas auxiliares que con dos botones sujetan la lámina de hierro de la cara posterior que constituye la charnela. La decoración está formada por una serie de bandas longitudinales, de cuatro a ocho, formadas por líneas de zig-zag a base de triángulos rellenos de botoncitos alternativamente dispuestos y opuestos por el vértice. Esta decoración está troquelada y por el reverso se nota la impronta del troquel debido a la presión. Las medidas oscilan entre los 12 y los $15 \mathrm{~cm}$ de longitud y los 3,3 y 5,5 de anchura. Las placas con gancho son siempre mayores y siempre muy curvadas lo que nos indica que el cinto cierra por la espalda, llevando el puñal en frente. Estas placas con gancho tienen unas dimensiones entre los 26 y los $31,5 \mathrm{~cm}$ de longitud. Son, por lo tanto, las piezas más largas.

En un intento de reconstrucción, diremos que el cinto estaba formado por cinco placas: dos ligeramente curvadas que enganchan al puñal, una a cada lado; les siguen dos muy curvadas (laterales de la cintura), una de las cuales lleva el gancho; y por la espalda una o dos ligeramente curvadas en la que enganchaba el garfio. En muchos casos, como hemos dicho, llevan láminas de hierro por el reverso que constituía la articulación del cinto a través de charnelas de bisagra. Pero algunas placas de bronce no parecen llevar huellas de hierro, por eso cabría la posibilidad de que fuesen montadas sobre cuero, como ocurre en la Europa del Hallstatt, si bien allí son muy finas. Las nuestras, en cambio, son gruesas (entre 1 y 1 '5 mm de espesor) y pesadas. El sistema de unión de las placas y con la pieza de unión al puñal es mediante una bisagra de hierro de un cuerpo (hay algún caso aislado de dos) con pasador de hierro que remata en dos botones de bronce. Ésta es siempre de hierro y cuando en el cinturón la placa es de bronce el sistema se monta con la pieza de hierro que va por debajo. Es decir, que cuando aparecen piezas de bronce son siempre decorativas. Para ocultar la bisagra y el remate de la placa de bronce que va sobre la de hierro, en los extremos de todas las placas, se dispone una lámina de bronce de unos 11-17 mm remachada con dos roblones. Está decorada por una hilada longitudinal de robloncitos, dos de los cuales (generalmente los dos últimos o los penúltimos) sirven para ensamblar a la de bronce. A ambos lados van líneas incisas que enmarca una acanaladura. Este sistema decorativo es el mismo que hemos visto en la decoración de muchas de las placas anteriores de bronce de las vainas de los puñales. Es decir, el sentido de unidad estética y de buen gusto es un elemento común a estas piezas.

Las medidas de estas placas son muy similares estando asociadas a los dos tipos de placas: la larga rematada en el garfio con una gran incurvación, y la suavemente incurvada, más pequeña, unida a la anterior como en las tumbas 11, 17 y 26. Las más largas rematan en un garfio que permitía la apertura o cierre del cinto y se adaptaban bien a la incurvación lateral de la cintura. De prospección no se ha encontrado ninguna entera con remate en el garfio pero la $\mathrm{n}^{\circ} 18$ llega a los 19,5 $\mathrm{cm}$. Sin embargo en las tumbas sí que han aparecido enteras y presentan las medidas que se ven en las tablas.

TABLA II. MEDIDAS DE LAS PLACAS LARGAS DEL CINTURÓN.

\begin{tabular}{|c|c|}
\hline TUMBAS & MEDIDAS \\
\hline 6 & $26 \times 4,5$ \\
\hline 11 & $30 \times 3,5$ \\
\hline 17 & $29^{\prime} 8 \times 3,3$ \\
\hline 22 & $34 \times 4,3$ \\
\hline 31 & $31,5 \times 4,2,29,9 \times 4,2$ \\
\hline
\end{tabular}


TABLA III. MEDIDAS DE LAS PLACAS CORTAS DEL CINTURÓN.

\begin{tabular}{|l|c|}
\hline TUMBAS & MEDIDAS \\
\hline 2 & $13 \times 4,7,14 \times 4,7$ \\
\hline 6 & $13,8 \times 4$ \\
\hline 11 & $16,5 \times 3,5$ \\
\hline 12 & $20 \times 5,4$ \\
\hline 17 & $12,4 \times 3,4,15,2 \times 3,3$ \\
\hline 19 & $14 \times 4,7,14,5 \times 4,514,1 \times 44,5$ \\
\hline 26 & $18,5 \times 5,5,15 \times 5,511,5 \times 3,5,15,3 \times 3,515,5 \times 3,5$ \\
\hline PROSPECCIÓN & $16 \times 4,9$ \\
\hline 1 & $13,5 \times 3,2$ \\
\hline 11 & $12,2 \times 5,4$ \\
\hline 12 & $14,5 \times 4,9$ \\
\hline 15 & $20 \times 3,6$ \\
\hline 16 & $15,4 \times 4$ \\
\hline 25 & \\
\hline
\end{tabular}

Su decoración es muy peculiar y aparece dispuesta en bandas separadas por pequeños baquetones o crestas. Esta organización decorativa es la que nos ha inducido a denominar estas placas con un apelativo céltico centroeuropeo, no sólo por las similitudes formales sino porque quizás haya que ver en ellas unas ciertas reminiscencias hallstáttica que ya hace casi cien años se vislumbraron y que permitió a Bosch Gimpera calificar de «mundo posthallstáttico» a estas producciones de bronce.

En cuanto a la posición en el cinto hemos hablado de placas rematadas en garfio y muy curvadas, y placas menos incurvadas y rectangulares que ocuparían una posición intermedia. No hemos encontrado piezas que pudiesen corresponder a la placa pasiva en la que encajaría dicho garfio, y es un hecho raro. Quizás en este contexto encajen algunas piezas que recuerdan las de enganche del cinto al puñal que presentan una perforación en el centro y son de mayor anchura, como es el caso de la tumba 15 o la 19. Pero al ser de mayor anchura que las placas, es poco probable esta asociación. En algunas tumbas se han encontrado piezas en U con ganchos pero son muy finas para este sistema de soporte y las hebillas con apéndices de anzuelo parece que van asociadas a cinturones estrictamente decorativos. Por otro lado, y esto es común a ambos tipos de placas, atendiendo a las variaciones en su conformación hemos distinguido tres grupos:

\section{GRUPO A:}

Son placas únicamente de bronce, que irían sobre un soporte de hierro, con las características típicas pero que la decoración se dispone de dos maneras, lo que nos permite establecer las dos variedades. Una, cuando las bandas de triángulos rellenos de botoncitos (perlitas para otros) están separados por unas crestas con línea incisa longitudinal. Son los casos de las dos láminas de la tumba 2 , la pieza 3 de la tumba 11 , las $\mathrm{n}^{\mathrm{o}} 1$ y 2 de la tumba 12 , la dos y la tres de la 17, las 1 y 2 de la 19, las 4,5 y 6 de la 26 (fig. 14) y la última de la tumba 31 . Estas placas tienen de cinco a siete bandas decorativas. De prospección son las placas $\mathrm{n}^{\mathrm{o}} 1,2,4,5$, $9,11,12,13,14,15,19,20,22,25$ y 26 (la $\mathrm{n}^{\circ} 15$ es la única con ocho bandas). La segunda variedad se caracteriza porque han desaparecido las aristas y en su lugar hay una línea acana- 
lada. Es el caso de la pieza $n^{\circ} 1$ de la tumba 31. La primera variedad de este grupo es la más representada de toda la necrópolis con veintitrés piezas y tres fragmentos $(43 \%)$. Las bandas decorativas suelen ser siempre cinco, seis u ocho, aunque hay alguna con cuatro bandas.

\section{GRUPO B:}

Está formado por siete piezas (dos de la tumba 26, la de la tumba 30 ? y los $\mathrm{n}^{\mathrm{o}} 3,5$ de prospección). La placa está constituida por un cuerpo de hierro con las dos aristas laterales integradas. Entre ellas va embutida la lámina de bronce decorada, placa sin aristas y con las correspondientes bandas de triángulos de botoncitos. Las dos de la tumba 26 (fig. 14) (18,5 x $5,5-4,3-3,5$; y 15 x 5,5-4,3-3,5 cm) presentan una estructura única en la necrópolis, como puede verse en el dibujo. Hay una placa inferior de hierro, una es la que remata en el garfio, que en algunos tramos presenta un resalte exterior que se decora con un hilo de bronce moldurado en cuyos extremos presenta una incurvación para clavarse en el hierro. La segunda placa también es de hierro y va sobre la segunda la cual presenta unas acanaladuras en las cuales se inserta la pieza superior que es de bronce y con la decoración consabida. Es un caso único. Además dicha tumba presenta también otro juego de tres placas de otro cinto que pertenece al grupo anterior.

\section{GRUPO C:}

Las placas que integran este grupo son piezas mixtas. La placa funcional es de hierro con las aristas laterales, con las pequeñas aristas que separan las bandas decorativas, con sogueado en las crestas o baquetones y con las camas de las bandas decorativas en las que se embuten las laminillas de bronce que llevan la banda de triángulos de botoncitos que han sido decoradas por estampado. Esta variante aparece en dos placas de la tumba 11 (fig. 15) $(30 \times 3,5$ $\mathrm{cm} 16,5 \times 3,5 \mathrm{~cm}$.), en una de la $12(20 \times 5,4 \mathrm{~cm})$, en una de la 14 , en una de la $19(14,1 \mathrm{x}$ $4,5 \mathrm{~cm})$ y en las tres primeras de la $31\left(31,5 \times 4,2,29,9 \times 4,2,14 \times 4,2 \mathrm{~cm}\right.$.); además los $\mathrm{n}^{\mathrm{o}}$ $11,16,17,18,24$ y 27 de prospección. En total 14 placas $(56,41 \%$ de total de las placas). Pero esta es la primera variedad del grupo, la más común, porque hay otra representada por dos ejemplares idénticos de la tumba 6. Están formadas las placas por una lámina de hierro. Los bordes, en vez de aristas, llevan a cada lado una fina lámina de bronce con una hilada de roblones: les siguen a ambos lados un hilo o alambre de hierro y luego dos camas longitudinales en las que va embutida una laminita de bronce con el tema de los triángulos rellenos de botoncitos, pero con la novedad de que el zig-zag es repujado, no troquelado. Señalamos que estas dos placas van asociadas al único puñal del Grupo IV cuyas dos láminas de la vaina del puñal son de hierro. Es decir el conjunto puñal-cinto de esta tumba es una variedad específica de esta necrópolis pero dentro de ese grupo IV.

Junto a esta peculiaridad de la tumba 6 , también queremos anotar que el puñal tipo Monte Bernorio (Grupo I) y el otro puñal (Grupo II), ambos de la tumba 22, no llevan este tipo de placas sino que van asociados a las placas de tipo Bureba, aunque en el Grupo II es probable que ya se asociase al sistema de cinto del grupo IV. Tampoco la tumba 33 con puñal del Grupo III lleva este tipo de placas. Se concluye, entonces, que las placas llamadas por nosotros de «Tipo HUNDERSINGEN» por sus paralelos europeos, van asociadas exclusivamente a los puñales del Grupo IV, es decir, el puñal específico de Villanueva de Teba. Hemos de destacar que esta asociación de puñal y cinto son elementos totalmente nuevos en la armamentística meseteña. Es evidente que ambas elementos, cinto y puñal, están asociados y además forman un conjunto uniforme porque su sistema de enganche es fijo; es decir, el cinto servía exclusivamente para llevar ese puñal. Por eso podemos concluir que solo utilizaron 
este modelo de arma en combates cuerpo a cuerpo que viene corroborado por la ausencia total de espadas en esta necrópolis, tan abundantes en la fase D de la Meseta Oriental (García-Soto, 1990: 33), sincrónica de nuestra yacimiento. Sin embargo no hemos de olvidar que con más posibilidades son elementos de prestigio. Y por lo que se puede deducir, a raíz de las excavaciones de las necrópolis sorianas, la de El Raso o la de Padilla de Duero, es que parece seguir una evolución específica con algunos elementos comunes al círculo en el que se desenvuelven. Pero, en lo que estamos hablando, es que frente al carácter funcional de estos objetos hay que buscar lo que se viene diciendo desde hace unos años: son objetos de prestigio. Este hecho viene al hilo de la ubicación de las tumbas en la necrópolis comparándola con la de Numancia (Jimeno 1996: 61-62). En esta necrópolis los ajuares mayoritariamente con adornos y objetos de prestigio (tumbas 38 con un báculo y tumba 32 con fíbula de caballito) se encuentran en la zona alta; mientras que las tumbas con armas y objetos de bronce se encuentran en la zona baja. Quizás en Villanueva de Teba pueda darse una situación parecida. En cambio, en la necrópolis de Ucero (Soria), en su fase similar a la citada de la Meseta Oriental y en fechas próximas a las nuestras, no aparecen espadas, únicamente puñales como en Villanueva de Teba. La importancia que tuvo el puñal explica que su sistema de soporte y transporte fuese exclusivo, constituyéndose en arma de ataque primordial, como ya nos indicaran algunos escritores romanos.

Hemos denominado a estas placas «tipo Hundersingen» por sus paralelos con aquellas placas hallstáttlcas europeas (Hallstatt D) estudiadas por I. Kilian-Dirlmeier (1972: 35-38, lám. 16 y 17). Tienen en común que son grandes, parecen corresponder a cinturones con un desarrollo rectangular y una decoración formada por una serie de bandas longitudinales, lisas en las alemanas y decoradas en las nuestras. El sistema de montaje europeo es distinto porque van sobre cuero y son láminas mucho más finas, pero en ambos casos son de gran anchura, dato que ya llamó la atención a Dechelette (1928: 723). Posiblemente, el hecho de ser más rígidas y pesadas, sea un componente ibérico en cuyo ambiente hay cintos de placas rígidas de esta manera. Pero en nuestro caso, la disposición de la decoración y los temas, exclusivamente geométricos, nos apuntan hacia influencias o reminiscencias del otro lado de los Pirineos donde la decoración densa y geométrica se dispone en bandas a metopas. Incluso algunas pudieran influir en nuestras piezas de tipo Bureba, como las placas de Panges (Côte-d 'Or).

Pero estas piezas del cinturón, de bronce con decoración de temas de triángulos rellenos de botoncitos, no son exclusivos de Villanueva de Teba pues conocemos algunos ejemplares más. Por un lado tenemos la pieza muy peculiar que se encuentra en la colección Fontaneda (Sanz, Escudero y Fontaneda, 1993: 82-84, fig. 2) cuyos autores que la han investigado la hacen proceder de un área próxima a Miraveche-Villanueva de Teba. Corresponde al extremo del tahalí en bronce con el garfio que aparece decorado en dos tipos de campos diferentes bordeados por una cenefa. Nos interesa aquí uno de ellos porque presentan cuatro hiladas de triángulos rellenos de botoncitos determinando un zig-zag en resalte o en chevron porque la decoración ha sido troquelada, como en los ejemplos de Villanueva de Teba. El otro campo corresponde a un tema cuasifigurado que encaja en un contexto artístico que estudian los autores en paralelo con otras piezas importantes de este contexto cultural meseteño. La pieza aparece rota en el arranque de otra composición donde se añadía otra placa de diferente material o de bronce que se sujetaba por los dos botones cuyas perforaciones aún se conservan; no es que allí estuviese el sistema de conexión con la placa siguiente. Es probable que el ensamblaje de esa pieza con las demás se hiciese como en Villanueva de Teba a través de un sistema de bisagra, como hemos venido explicando en la piezas de Villanueva de Teba. El ejemplar de la colección Fontaneda es más rico no solo por la decoración sino porque aparece también decorado con aplicaciones de láminas de oro, lo cual encaja en los contextos artísticos de yacimientos de una cronología desde finales del IV y durante el siglo III tanto del sur de la meseta como de la zona norte como el yacimiento de Miraveche con interesantes nielados y damasquinados de plata y cobre (lámina de placa con cazoletas damasquinadas 
con oro de la tumba 38? (Schüle, 1969: lám. 143, 14), el puñal y el tahalí de la tumba 31 ? (Schüle, 1969: lám. 13911 y 12) y una vaina inédita con rica decoración nielada) o el tahalí de Miranda de Ebro (Ruiz Vélez y Elorza, 1997: 579-586) decorado también con ricos nielados de plata.

La otra pieza que conocemos, permanece aún inédita y procede de una de las necrópolis de Soto de Bureba cuyo castro ya ha sido excavado registrando una ocupación en La Cerca y Los Llanos desde el Bronce Final hasta el Alto Imperio (Parzinger et alii, 1993: 315-354; Parzinger y Sanz, 2000). Cerca del poblado de la segunda Edad del Hierro y también de los cenizales o escombreras de La Negrera se encuentra la citada necrópolis la cual ha proporcionado algún tahalí característico de los puñales tipo Monte Bernorio en su fase formativa, bolas de piedra caliza, materiales diversos y la placa fragmentada que ahora nos interesa. Corresponde a una pieza muy curvada de $27,5 \mathrm{~cm}$ de longitud, partida en dos, $3,5 \mathrm{~cm}$ de anchura y rematada en garfio. Es de hierro y por el anverso presenta las dos aristas laterales elevadas que enmarcan un campo de cuatro bandas definidas por unos baquetones decorados con sogueado por el borde. En las camas que marcan esos baquetones se ha incrustado una lámina de bronce decorada con los triángulos rellenos de botoncitos alternativamente dispuestos definiendo una zig-zag o chevron en resalte. Es decir, es idéntica a las de nuestro Grupo C. Es probable que corresponda a un contexto cultural igual que asociado a ese tahalí de la fase formativa del puñal tipo Monte Bernorio nos puede estar indicando una necrópolis de larga duración desde finales del siglo IV hasta el siglo II a.C.

\section{Valoración cultural de los puñales de Villanueva de Teba.}

Desde los primeros descubrimientos de los puñales tipo Monte Bernorio, a finales del siglo XIX, por las excavaciones de R. Moro (Moro, 1891: 427-440) en Monte Bernorio hasta hoy, mucho se ha escrito sobre este modelo de puñal, señalando unos hitos que ya hemos visto y son los trabajos de E. Cabré, B. de Griño, C. Sanz Mínguez y F. Quesada. Este último autor, como E. Cabré, se refieren a toda la producción de puñales a nivel peninsular. Los dos anteriores se refieren exclusivamente a los puñales de tipo Monte Bernorio. Quesada incluye el puñal de Monte Bernorio-Miraveche en su tipo III al que corresponden los aparecidos en Villanueva de Teba. Los grupos II, III y IV de nuestra necrópolis no encajan en sus tipologías, siendo, en consecuencia, tipos nuevos en ese colectivo. Dicho autor distingue varias áreas geográfico-culturales en función de unos criterios de unidad geográfica, coincidiendo con divisiones geopolíticas de la antigüedad, siendo el Área 13, relativo al territorio autrigón que corresponde geográficamente al Alto Ebro. Es a esta zona a la que pertenece el yacimiento de Villanueva de Teba así como los de Álava y el norte de Palencia. Esta zona puede tener sentido en cuanto que parece haber alguna relación entre los puñales de la Bureba y los de algunos yacimientos alaveses como el de La Hoya y Carasta. La cuestión que queda pendiente es si esta relación es porque pertenecen a un mismo contexto, cosa poco probable, o porque debido a la proximidad, ha habido relaciones comerciales que se han traducido en el trasvase de algunos elementos formales como es patente en algunos puñales (Fillloy y Gil, 1996) o incluso la importación de algún ejemplar porque estamos seguros que en el norte de Burgos hubo importantes talleres, cosa que viene definida por la abundancia de ejemplares en Miraveche, Monte Bernorio o el encontrado en Sasamón (Gil Farrés, 1963: 14-16).

No vamos a entrar en la cuestión de la distinción formal entre espada y puñal desde los primeros momentos de la investigación cuando se establecían los $60 \mathrm{~cm}$. de longitud como umbral de distinción (Sandars, 1913: 260) para separar una espada de un puñal, o que la espada tiene forjadas en una pieza la empuñadura y la hoja, según la opinión de Chernorkian (1988: 137). Como dice Quesada (1997: 590) es muy difícil decir dónde acaban las espadas 
y dónde empiezan los puñales, pero establece un criterio de longitud para separarlos: los 26 $\mathrm{cm}$. de longitud en la hoja; por lo tanto los puñales tendrían menos de esa longitud, por debajo de $\operatorname{los} 25 \mathrm{~cm}$. Además, señala dicho autor que prácticamente todos miden menos de los 20 $\mathrm{cm}$. En nuestro caso podemos confirmar esa apreciación porque casi todos están por debajo de esos $20 \mathrm{~cm}$. salvo algún caso que hemos visto, tres de prospección que presentan $24\left(\mathrm{n}^{\mathrm{o}}\right.$ $4), 26\left(n^{\circ} 8\right), 27\left(n^{\circ} 5\right)$ y $28 \mathrm{~cm}\left(n^{\circ} 2\right)$.

Por otro lado, parece haber una clara diferencia entre los puñales del ámbito ibérico y del meseteño, no solo desde el punto de vista formal sino también cronológico. Los puñales ibéricos, (que también aparecen en la Meseta, exclusivamente en su zona oriental), más importantes son los de frontón exento (tipo I de Quesada) y los de antenas atrofiadas (tipo II de Quesada) con amplia base de la hoja y de forma triangular, poco aptos para el combate. A ellos habría que añadir los de tipo Alcacer-do-Sal, de empuñadura afacetada. Es difícil encontrar estas piezas en el resto de la Meseta, por no decir imposible. Estos puñales del ámbito ibérico son más antiguos, pues se remontan al siglo $\mathrm{V}$, que los típicos de la Meseta como el de Monte Bernorio, el dobleglobular o los mixtos de Quesada (tipos V - dobleglobular/frontón - y VI - antenas/dobleglobular) que aparecen desde el siglo IV. Es sintomático que, separando la frecuencia de espadas de las necrópolis de la zona oriental, emparentadas con el ámbito cultural de la Celtiberia original, en las necrópolis del Duero no aparecen espadas de los prototipos orientales, salvo las de gavilanes curvos de Miraveche que se complementan con algún ejemplar en la necrópolis de Palenzuela, pero no porque procede de la excavación sino de prospección (de Castro, 1971: 25, $\mathrm{n}^{\circ}$ 60). Esta espada no es de origen ibérico sino que se remonta al Bronce Final en las espadas de ricazos circulares tipo Ronda o tipo Alcalá del Río, que derivan del tipo Sa Idda. En consecuencia, podemos decir que la ausencia de espadas es una característica armamentística típica de la mayor parte de la Meseta. Esto podría dar un carácter especial al puñal en dicha zona porque en el mundo ibérico el puñal forma parte de una panoplia compleja (no existente en las Mesetas) ya que el papel ofensivo viene definido por las espadas (falcatas y de frontón) y las lanzas; entonces, el puñal sería un elemento de prestigio porque normalmente está presente en la tumbas más ricas. En las tierras del Duero, el puñal también aparece en las tumbas ricas, por lo tanto sería un elemento de distinción social y algunos autores piensan que por no aparecer espadas tendría, entonces, una función defensiva, no solo de prestigio. La panoplia meseteña es menos compleja que la ibérica y está formada básicamente por el puñal, la lanza, el escudo y el cuchillo, y no siempre todos estos elementos.

En Villanueva de Teba hemos encontrado veinticinco puñales repartidos en treinta y cinco tumbas (más las nueve hojas de prospección que no se contabilizan y la existencia de otros que proceden de operaciones furtivas), lo cual representa un tanto por ciento muy elevado $(71,4 \%)$ que está por encima de aquellas necrópolis que se presentan con mayor repertorio de armas como La Mercadera (Lorrio, 1990: 39-50; 1994, 229) en la que las tumbas con armas representan el $44 \%$ o en Ucero que llegan al $34 \%$. El resto de las necrópolis del alto Tajo y del alto Jalón no llegan ni mucho menos a estas cifras. Este hecho de la abundancia de tumbas con armas que, unido al de la ausencia total de espadas, parece indicarnos un cambio en esta área del norte de la Meseta que no se da en la zona oriental pero sí en el yacimiento de Ucero (García-Soto, 1988: 91) en el que en una fase cuarta han desaparecido las espadas de antenas atrofiadas de la fase tres, encontrándose exclusivamente puñales biglobulares. Sin embargo en la Meseta Oriental, en la fase $D$ de E. Cabré, de cronología idéntica a la de Ucero y a la nuestra, junto a los puñales de frontón y biglobulares, aparecen espadas de La Tène, de tipo Alpanseque y de tipo Arcóbriga, asociadas a cerámicas celtibéricas. Correspondería a la subfase IIB (siglo III a.C) de Lorrio (1994: 234-236, tabla II), conocida sobre todo por la necrópolis de Quintanas de Gormaz y Osma en las que se refleja la asociación espada-puñal, el desarrollo de los distintos tipos de puñal (frontón, biglobular y Monte Bernorio) y la aparición de las espadas de La Tène. 
Respecto al tanto por ciento y la función de los distintos ajuares, es interesante el análisis de Martín Valls (1986-87: 75-77) para las necrópolis de Las Cogotas (1.613 tumbas) y de La Osera (2.230 tumbas) en cuanto que distingue entre ajuares de guerreros con diversas categorías, de artesanos, femeninos y ajuares poco expresivos. En nuestro caso no parece darse esas circunstancias sino que, como ya señalamos anteriormente, los ajuares son muy homogéneos aunque la cantidad de piezas presentes sean más o menos las mismas. Nos remitimos a lo que señalamos anteriormente en la relación espacio físico de la necrópolis/ajuar para el caso de Numancia y que podría ser perfectamente aplicable a Villanueva de Teba. Esto puede indicarnos que estamos ante un grupo con unas formas de rito específicas por su pertenencia a un grupo con un estatus distinguido. La ausencia de espadas no pensamos que puede estar en función de una panoplia simple, como piensa Quesada, de cortos puñales y de lanzas. Habrá que ver que las formas de guerra que se practican en vida probablemente no sean las mismas que participan en el ámbito de la muerte donde la forma de enfrentarse al más allá es bien distinta.

En los puñales de Villanueva de Teba intentaremos establecer una relación tipológicocronológica en la que podemos determinar un terminus ante quem non que viene dado por el puñal tipo Monte Bernorio de la tumba 22 y por las piezas procedentes de prospección que corresponden a la fase de expansión de dicho puñal de Sanz Mínguez cuya cronología está dentro del siglo III con perduraciones hasta el siglo II. Es decir, el comienzo de la necrópolis de Villanueva de Teba habría que remontarlo al siglo II, pero ante la falta de otras evidencias diremos que lo retrasamos hasta el siglo III. No creemos encontrar criterios para especificar con más exactitud la cronología del punto de partida de la necrópolis. Es una rémora grande el hecho de que no aparezcan elementos celtibéricos en los ajuares los cuales podrían especificar con mayor exactitud ese origen, aunque no necesariamente por los estudios que hay hasta el momento. Esa ausencia es un caballo de batalla para establecer el parentesco con otras necrópolis de la Meseta; pero esto es otro tema que veremos más adelante.

Entonces, tenemos un primer tipo de puñal, nuestro Grupo I que es el tipo Monte Bernorio en sus etapas finales, fase de expansión de Sanz Mínguez, que va a dar paso a una serie de modelos que se sitúan cronológicamente posteriores como nos lo indican la propia evolución formal y la asociación de esos modelos nuevos a las placas tipo ibérico que desplazan totalmente a las de tipo Bureba ${ }^{1}$. El modelo típicamente meseteño evoluciona hacia el modelo del Grupo IV a través de una etapa intermedia que está representada por el segundo puñal de dicha tumba 22.

\section{ARMAS DEFENSIVAS: LOS ESCUDOS.}

Pocas piezas de escudos se han encontrado en la necrópolis, lo que contrasta con la cuantía y vistosidad de los puñales; además llaman la atención por su unidad morfológica pues prácticamente todos son de la misma tipología y no son muchos los elementos auxiliares del escudo que han aparecido

De prospección sólo se han recogido dos ejemplares casi enteros $\left(\mathrm{n}^{\mathrm{o}} 2\right.$ y 5$)$. El $\mathrm{n}^{\mathrm{o}} 2$ conserva gran parte de su forma y por eso se puede reconstruir la misma. Es de forma troncocó-

1 Recordamos que en el mundo de Miraveche las placas de cinturón habituales son las de tipo Bureba habiendo aparecido algún ejemplar de tipo ibérico y con decoración figurada. En Villanueva de Teba, las pocas de tipo Bureba han sido sustituidas por las de tipo ibérico pero no ya con decoración figurada sino con temas geométricos que entran dentro del gusto estético de los tiempos finales del indigenismo tendentes hacia la abstracción y reducción simbólica de los elementos decorativos que ya se ha estudiado tanto en otros elementos de bronce como en la cerámica, aunque en este caso es más problemático. 
nica con un diámetro de $11 \mathrm{~cm}$. El ala plana mide $2,4 \mathrm{~cm}$ de anchura. La copa tiene $5,8 \mathrm{~cm}$. de diámetro y $3 \mathrm{~cm}$. de altura. Conserva algo del cierre de la copa y es casi seguro que era de una sola pieza; es decir, no era el típico de Monte Bernorio con las lañas interiores y las estrías. Presenta cuatro agujeros para sujetar a la rodela. La pieza $n^{0} 5$ es un fragmento del perfil de la copa de otro umbo con el arranque del ala pero no puede saberse cómo remataba la copa y por los demás ejemplares, parece que era todo de una sola pieza. El resto son fragmentos ( $n^{\circ} 1,3$ y 7) que podrían corresponde a umbos, pero es difícil asegurarlo. En cambio, los $\mathrm{n}^{\mathrm{o}} 4$ y 6 son dos anillos de bronce, entero el primero con $14,4 \mathrm{~cm}$. de diámetro formado por una lámina de bronce de $2,4 \mathrm{~cm}$. de ancho, liso; el segundo conserva una cuarta parte, de $1,6 \mathrm{~cm}$. de ancho con tres estrías en cada lado. Estas piezas tenían un carácter marcadamente decorativo porque además presentan temas de esta índole. No está muy claro que puedan ser piezas asociadas al umbo; es decir, dispuestas alrededor de él porque su diámetro tendría que ser algo mayor al del umbo, pero no es así en algunos casos. El $n^{\circ} 4$ lleva una banda central de eses troqueladas de un trazo y dos acanalados a ambos lados.

\section{Los umbos.}

De excavación proceden cuatro ejemplares (tumbas. 6, 9, 16 y 25) (fig. 16); ninguno totalmente entero pero con suficientes datos como para deducir su forma total. En los dos primeros casos aparecen asociados a otros elementos de la caetra como los radios y los terminales de radio que nos permitirán reconstruir la disposición de esta arma defensiva. El umbo de la tumba 6 es de la misma forma que los demás, troncocónicos de 13,8 cm de diámetro y con la copa sin agujeros de 5,8 cm de diámetro, 3 de altura y completamente lisa, de una sola pieza. El ala disponía de cuatro grupos de doble perforación para el ensamblaje a la rodela. El de la tumba 9 también es troncocónico de $12,3 \mathrm{~cm}$ de diámetro con un ala de 3,5 $\mathrm{cm}$ de ancho. La copa está abierta por arriba, con las lañas en forma de cruz, aunque da la impresión de que eran tres en vez de dos. El diámetro de la copa es de $4,5 \mathrm{~cm}$ y por todo el perímetro del ala presenta una incurvación para quizás ensamblar mejor en la rodela. Éste y el $\mathrm{n}^{\mathrm{o}} 2$ de prospección son los únicos que presentan esta peculiaridad porque en los demás el ala es plana. La copa es totalmente lisa. El umbo de la tumba 16 nos puede indicar cómo eran los umbos típicos de esta necrópolis, troncocónicos y de una sola pieza. Tiene un diámetro de $12,5 \mathrm{~cm}, 5 \mathrm{~cm}$ de diámetro de la copa con $3,4 \mathrm{~cm}$ de altura. La copa está lisa y por la superficie superior presenta un tema en cruz acanalado. En los cuatro espacios intermedios van sendas perforaciones para un perno (conserva uno) y en el centro de la copa y del tema cruciforme va otro perno que se conserva, de cabeza aplanada. La presencia de estos pernos se entiende porque se rellenaba con otro objeto de materia orgánica, como ya señaló Kurtz (1987: 75 y 76). En el ala presenta cuatro perforaciones axiales, en grupos de dos como los dos casos anteriores. La copa presenta unas líneas incisas paralelas organizadas en tres bandas alrededor de ella. El umbo de la tumba 25 es de $13 \mathrm{~cm}$ de diámetro, 3,4 cm de ancho del ala y altura de la copa $2,5 \mathrm{~cm}$. El ala presenta los cuatro grupos de doble perforación pero la copa parece que era del tipo Monte Bernorio con los flecos, pero no parece disponer de lañas interiores. Sin embargo sí que está presente la decoración de una banda de líneas paralelas en la copa.

\section{Los terminales de radio.}

En la tumba 6 hay cuatro terminales de radio o tirantes a los que les faltan los tirantes propiamente dichos (los radios) (fig. 17). Aquellos son un poco convexos (como las de Las Cogo- 
tas) dejando un espacio de $0,4 \mathrm{~cm}$ de espesor, lo que quiere decir que la rodela era fina y ligeramente convexa. Son unas piezas de forma triangular de lámina que se vuelve sobre sí misma, con 9,5 cm de largo por 5,8 de ancho. Cuatro piezas idénticas se encontraron en la tumba 9 , de medidas casi iguales pero estas cuatro con decoración por la cara anterior formada por doble fila de líneas incisas formando un esquema sencillo. Este hecho de estar decoradas es un elemento de cronología avanzada. El espacio entre la lámina incurvada es de $6 \mathrm{~mm}$.

\section{Los tirantes.}

No está nada clara la existencia de tirantes en la necrópolis, unido al hecho de que no han sido muchos los ejemplares de escudos. Sin embargo podríamos considerar como tales a algunas piezas de las tumbas 6 y 11 (fig. 19). En el primer caso serían tres laminillas muy finas de bronce $\left(n^{\circ} 3-4\right)$ rematadas en los extremos por sendas perforaciones para un perno. Miden 5,2 x 0,4 cm y son de sección plana. Están decoradas con un espigado longitudinal inciso. También podrían serlo otras dos piezas de $6,4 \times 0,4 \mathrm{~cm}\left(\mathrm{n}^{\circ} 1-2\right)$ que presentan idéntica decoración a base de una hilada longitudinal de círculos concéntricos estampados. La interpretación que ha hecho el dibujante de estas piezas es que iban alrededor del umbo pero son rectas y no presentan ninguna incurvación por lo que no es probable que tuviesen esa función. El hecho de que ambas tengan la misma anchura, $0,4 \mathrm{~cm}$, puede hacernos pensar que tuviesen la misma función, ser tirantes metálicos del escudo.

En la tumba 11 aparecieron dos piezas de hierro de $6,8 \times 0,8 \mathrm{~cm}$, de sección triangular, como es el caso de la mayor parte de las secciones de estos tirantes de otras necrópolis. En el extremo (sólo se conservan la mitad de cada una de ellas) va un ensanchamiento con perforación conservando el perno con la cabeza aplanada, también de hierro. Estos dos ejemplares sí serían las piezas típicas de este género, a diferencia de las anteriores. Además el modelo de remache empleado es del mismo tipo del que aparece en los umbos analizados.

\section{Las abrazaderas.}

Sólo están presentes en la tumba 9 (fig. 18) representadas por cuatro piezas idénticas de 4,1 x 3,7 cm, de hierro, con los vástagos que se doblan para cerrar en doble curvatura dibujando un rectángulo. La anchura que abarca la abrazadera es de $1,6 \mathrm{~cm}$, medida que encaja con el grosor de la caetra. Presentan una decoración longitudinal de cuatro líneas paralelas incisas.

\section{Las anillas periféricas.}

También han aparecido algunas anillas periféricas de bronce que rodeaban el umbo, pero no está muy claro que pudiesen tener esta función, al menos en alguno de los casos; a no ser que el disco de bronce monte sobre el perímetro del umbo, cosa posible pero poco probable. Conocemos dos piezas de prospección, una entera y otra que conserva únicamente un sector de menos de un cuarto. El primer ejemplar presenta un diámetro de $14,4 \mathrm{~cm}$ y es un anillo de una anchura de $2,4 \mathrm{~cm}$ que tiene una rica decoración pues por todo el centro va una banda de eses de un trazo rodeada por doble acanalado a cada lado. La otra pieza tiene $7 \mathrm{~cm}$ de longitud conservada que podría llegar a un diámetro algo superior a los $7 \mathrm{~cm}$. Por el centro presenta un perfil convexo y en las dos alas laterales desarrolla sendas bandas de tres líneas incisas paralelas. Es decir, en ambos casos son piezas cuidadas que podrían entrar en el contexto de los tirantes decorados citados más arriba. De excavación sólo ha aparecido un 
anillo de bronce en la tumba 6 (fig. 17) que tiene un diámetro de $13,5 \mathrm{~cm}$ y conserva uno de los apéndices con perforación central para ser clavado a la rodela. Tiene una anchura de 1,4 $\mathrm{cm}$ y presenta un acanalado periférico por cada lado. Si esta anilla iba montada en el escudo debería ir periféricamente al umbo pero quizás no fuese así, lo cual quiere decir que estas piezas desarrollarían otro tipo de función.

\section{Las manillas.}

Las tumbas 4 y 9 (fig. 19) son las únicas que han dado una manilla. La primera es de hierro presentando una longitud de $10,8 \mathrm{~cm}$. En el centro tiene menor anchura, engrosándose la pieza hacia las alas, las cuales están rotas y por eso no conservan las perforaciones para el enganche. Presenta un perfil curvo, como es habitual pero por la forma cabría que fuese una de las placas de hierro de ese mismo diseño que aparece por el reverso en algunas placas de tipo Hundersingen; es decir, las placas que conforman el cinto del puñal. La segunda pieza no ofrece ninguna duda y corresponde a una lámina de bronce de recubrimiento de la manilla propiamente dicha que pudo ser de materia orgánica. Es decir, muy lejos de los tipos conocidos. Es de forma muy peculiar y recuerda las de estructura calada pero éstas son macizas. Las alas son de forma triangular y el cuerpo central de desarrollo recto presenta dos solapas laterales. Esta lámina se sujetaba al cuerpo de la manilla a través de tres perforaciones en las aletas, una en el centro del cuerpo y otra más en cada solapa. Está decorada con líneas incisas dobles constituyendo unos esquemas geométricos muy sencillos como se puede apreciar en el dibujo. Mide 12,5 cm de longitud, de la que solo se conserva la lámina de bronce que la cubría. La forma es similar a algunas de estructura triangular de Las Cogotas.

\section{Otras piezas.}

Incluimos en este apartado de la caetra unas piezas que pueden estar relacionadas con ella, aunque no con absoluta certeza porque plantean muchas dudas.

En primer lugar nos referiremos a dos de ellas procedentes respectivamente de las tumbas 6 y 9 (fig. 17). En el primer caso corresponde al $n^{\circ} 22$ y es una chapa de hierro con perfil en $\mathrm{V}$, de $9,8 \mathrm{~cm}$. de largo por 2,8 de alto. Es de forma trapezoidal. Por los laterales lleva sendas chapitas de cierre que confluyen hacia el centro. La de la tumba $9\left(n^{\circ} 56\right)$ es idéntica a ésta. Da la impresión de que son el remate de una pieza, a modo de pomo u otra circunstancia similar. Sanz Mínguez (1997: 216, fig. 195 n 1052), que encontró una pieza similar a estas en la necrópolis de Las Ruedas, la vincula al escudo de tipo Monte Bernorio desconociendo su función concreta.

Otras piezas interesantes proceden de la tumba 6 y consisten en unos diminutos discos de bronce ensamblados decorados con círculos concéntricos. En el centro va un perno de hierro que atraviesa la plaquita y probablemente eran elementos decorativos de la caetra o rodela. fig. 18).

\section{Valoración cultural.}

Un hecho significativo es que en todo el norte de la Comunidad de Castilla y León estos umbos de caetra son muy similares a lo largo de toda la segunda Edad del Hierro, no presentando muestras de la variada gama que aparece en el resto de la Meseta (sobre todo en el sur y este). 
En el círculo geográfico más inmediato a Villanueva de Teba conocemos 26 umbos de escudo. Todos presentan una gran uniformidad morfológica aunque con las correspondientes variaciones debidas en unos casos a su mejor calidad y en otras por ser variedades tipológicas de carácter local. De Sasamón (Gil Farrés, 1958-61: 15) procede uno hecho de hierro encontrándose actualmente en el M.A.N. Alcanza un diámetro de $11,5 \mathrm{~cm}$, conservando dos únicos fragmentos de la copa y del faldón; aquella con una decoración formada por una cenefa de incisiones paralelas y perpendiculares, y éste con orificios para enganchar a la caetra. De Ubierna ${ }^{2}$ conocemos tres ejemplares y un fragmento que puede ser de otro más. Son de forma idéntica al anterior aunque hay dos modelos diferentes: uno de ellos, el más grande, de $13 \mathrm{~cm}$ de diámetro, es totalmente liso con la parte superior cubierta, mientras que los otros dos carecen de este detalle. Además, el primero está rematado con dos remaches. Los tres presentan decoración incisa formada por bandas paralelas de líneas incisas y espigado longitudinal en el cono. La otra pieza es un aro que iría colocado sobre el umbo, como aparece en un ejemplar de Miraveche. De esta necrópolis (Schüle, 1969: lám. $137 \mathrm{n}^{\circ} 12,138 \mathrm{n}^{\circ}$ $11,139 \mathrm{n}^{\circ} 8,145 \mathrm{n}^{\mathrm{o}} 16,147 \mathrm{n}^{\circ} 13$ y 14, $149 \mathrm{n}^{\circ}$ 9) provienen siete de ellos que corresponden a tres modelos diferentes. Uno de ellos, formado por dos piezas: el umbo propiamente dicho y el aplique, como en el caso de Ubierna. El de Miraveche es de bronce con cuatro apéndices simétricos donde engancharían las cuatro abrazaderas de la caetra. Al segundo grupo pertenecen cinco ejemplares formados por una sola lámina con la parte superior cubierta. Lo característico de este grupo es la presencia de perforaciones tanto en el faldón como en la parte superior del sector cónico. Finalmente, del tercer grupo hay un único ejemplar similar al anterior pero que está abierto en el sector cónico donde se disponen dos planchuelas formando una cruz, característica de los umbos de tipo Monte Bernorio-Miraveche, según la tipología de Cabré, tipo 11. 2 de Kurtz o IIIC de Quesada. Tres ejemplares proceden de la necrópolis de Lara (Martínez Burgos, 1935: 20, lám. II, Luis Monteverde, 1958: 196, Schüle, 1969: lám. 155 n $^{\circ}$ 23,24 y 27) correspondiendo a un tipo totalmente distinto. Son piezas planas cuya forma resulta difícil de adivinar. Aparecen decoradas con motivos de círculos concéntricos en el posible límite de la pieza y en el centro. Son de bronce, a diferencia del resto de las que venimos estudiando y su correspondencia a umbos de escudo es más que dudosa. En la localidad de Villamorón (Schüle, 1969: lám. 157 n 16) se encontró otra muestra en hierro, de características morfológicas similares a las de Ubierna. La parte superior del sector cónico está hueca y en ella se dispone una banda en espigado inciso alrededor y paralela a la base. Finalmente, el castro de Monte Bernorio dio ocho ejemplares (Schüle, 1969: lám. 161, 8-15) que aunque parecen corresponder al mismo tipo, presentan algunas variaciones formales que conviene señalar. En primer lugar, el faldón no alcanza la anchura tan considerable de los ejemplares burgaleses. El sector cónico aparece más pronunciado y con una inclinación mayor; además, algunos de estos ejemplares, en vez de presentar el perfil recto, es ligeramente convexo. Todos son de hierro salvo uno que es de bronce, y dos que parecen tener aplicaciones de plata. Sólo presentan decoración dos ejemplares formando sendas bandas en el sector cónico.

Las características morfológicas y técnicas de estas piezas coinciden con las expresadas por Cabré para el modelo Monte Bernorio-Miraveche pero con pequeñas variaciones de escasa significación que responden a especificaciones de carácter local. En primer lugar señalamos que, salvo las de Lara y una de Monte Bernorio, todas están hechas en hierro. Las medidas coinciden con los ejemplares de Villanueva de Teba pues el diámetro oscila entre los 11 y los $15 \mathrm{~cm}$ y coinciden con las que da Kurtz (1987: 75) para Las Cogotas en torno a los $12 \mathrm{~cm}$. Son de forma circular distinguiendo dos sectores netamente diferenciados: por una

2 Los materiales de esta necrópolis proceden de las correspondientes campañas de excavación pero los umbos a los que nos referimos provienen de una excavación furtiva realizada mientras se hacían las oficiales. Ruiz Vélez, Abásolo y Pérez, 1998, en prensa; Ruiz Vélez, 2001, pp. 40-41. 
parte el faldón o ala, plano, de una anchura comprendida entre los 1,5 y los $3 \mathrm{~cm}$. en el que se sitúan cuatro u ocho perforaciones en grupos de dos, simétricamente, sirviendo de enganche a la caetra; por otra parte está el sector troncocónico que presenta peculiaridades en algunos ejemplares. En la mayoría son de paredes rectas, salvo alguno que es convexo. Siempre es de mayor anchura que el faldón excepto en el ejemplar de Ubierna. El remate final está cerrado en algunas piezas y abierta en otras; en este último caso sujeto con dos planchuelas en cruz. El ejemplar de Miraveche que presenta asociada otra pieza anular con apéndices, tiende más hacia la forma hemisférica que hacia la troncocónica, nítida en los demás ejemplares. Algunos de aquellos en los que el sector más estrecho del tronco está cerrado (Villanueva de Teba, Miraveche y Ubierna) presentan también algunas perforaciones cuya función resulta difícil de determinar. No se puede descartar la idea de que fuesen empleadas para aplicar una pieza encima de carácter decorativo y de forma vistosa.

Aunque desde el punto de vista formal todos se pueden englobar en un mismo grupo, por lo que venimos diciendo, vamos a diferenciar tres modalidades debido a variaciones formales de escasa significación.

a) En primer lugar, aquellos que recogen la forma troncocónica netamente definida, con ocho perforaciones en el ala, a veces cuatro. Serían los más específicos y los más numerosos. Pero podemos distinguir tres modalidades: una es aquella en la que la parte superior del tronco de cono está cerrada; una segunda en la que está abierta y libre; y otra en la que se disponen dos barras o tiras de hierro en forma de cruz y soldadas o rematadas a las paredes. A este primer grupo corresponden los ejemplares de Monte Bernorio, Villamorón, Sasamón, algunos de Ubierna y Miraveche y el de la tumba 9 de Villanueva de Teba.

b) Del segundo grupo tenemos dos muestras; una de Miraveche y otra de Ubierna en las que el umbo tiende hacia la forma hemisférica, además de tener sobre el faldón otra pieza anular con cuatro apéndices en los que enganchan las abrazaderas de la caetra. Pero debe tenerse en cuenta que este cerco está también presente en el primer grupo, caso de la tumba 6 de Villanueva.

c) Finalmente el grupo de Lara de los Infantes cuyos modelos no encajan en las tipologías presentes.

Estas variaciones que no responden a áreas geográficas concretas sino que se encuentran indistintamente en diversos yacimientos, responden a criterios técnicos diferentes en la forma de concebir la pieza, sin poder determinar si pertenecen a escuelas o talleres diferentes. Lo que sí es cierto es que comparado este bloque con todo el conjunto de la Meseta, los nuestros forman un conjunto homogéneo, bien diferenciado. Desde el ámbito de Ubierna hasta la cronología de esta necrópolis podemos darnos cuenta de la pervivencia del modelo, con pocas variaciones formales, particularmente en esta zona del norte de Castilla donde tres yacimientos marcan tres hitos cronológicos y culturales muy importantes: Ubierna, Miraveche y Villanueva de Teba; es decir unas cronologías cuyos cenits estarían respectivamente en los siglos V-IV, IV-III y II-I a. C.

Son varios los paralelismos que señalamos aunque debemos tener en cuenta otra serie de consideraciones cronológicas y tipológicas que nos limitaremos exclusivamente a plantear pues todavía son escasos los hallazgos siendo muchas, en consecuencia, las lagunas que se tienen. El que mejor estudió estas piezas fue J. Cabré (1939-40: 57-84) para el yacimiento de Las Cogotas; estudio que más adelante completó Kurtz (1987) en dos ocasiones. El primero estableció una seriación tipológica que tenía una implicación cronológica. En su catálogo una de las series más recientes es precisamente la que llama «fase de la cultura de Monte Bernorio-Miraveche-Cogotas» (Kurtz, 1987: 70-73, lám. XIV) en la que debemos integrar 
nuestras piezas debido a sus características formales. En nuestra necrópolis es una pena que no se hayan conservado la mayoría de los elementos del escudo, salvo en las tumbas 6 y 9 donde se han encontrado los tirantes, las abrazaderas y las grapas. Todas estas piezas que integran el grupo son muy simples destacando el cuerpo cónico que es común a todos los ejemplares y les diferencian de los demás grupos (Alpanseque A y $\mathrm{B}$, celtibérico A y $\mathrm{B}$, etc.) en los que es hemisférico o elíptico. Por otra parte algunas piezas tienen una ligera inclinación en el faldón, lo cual, unido a la modalidad de las abrazaderas de las tumbas 6 y 9 , nos hace concluir que la caetra era ligeramente convexa. Esta idea ya la apuntó Cabré en el citado trabajo. Nuestros ejemplares no alcanzan la vistosidad de los modelos del resto de la Meseta ni su belleza pero su concepción hace que resulten muy efectivos. El mapa de difusión de estas piezas lo tenemos en Schüle (1969: mapa 29) y Quesada (1997: fig. 299) aunque hay que añadir numerosos hallazgos procedentes de excavaciones posteriores. Parecidos a los nuestros en cuento a forma y tamaño, con el sector cónico abierto, hay en la necrópolis de las Cogotas con un ejemplar (Cabré, 1931: tumba 954, lám. LXXIV; Schüle, 1969: lám. $118 \mathrm{n}^{\circ}$ 2), otro en Osma (Bosch Gimpera, 1921-26: 173, fig. 302; Schüle, 1969: lám. $54 \mathrm{n}^{\circ}$ 3), otro en Quintanas de Gormaz (Schüle, 1969: lám. $40 \mathrm{n}^{\circ}$ 4) pero de forma semicircular, y en un área tan alejada como Córdoba (Schüle, 1969: lám. $81 \mathrm{n}^{\circ}$ 24) pero con ligeras variaciones. En las proximidades de nuestro yacimiento no hemos encontrado o no conocemos ningún ejemplar rematado en las típicas púas, como en las necrópolis de Las Cogotas (Cabré, 1931: sep. A lám. LXII, sep. 418 lám. LXVII, sep. 188 lám. LXX, sep. 356 lám. LXXVI) y La Osera (Cabré et alii, 1950: lám. XXX y LXXIV) donde los hallazgos son numerosos. Únicamente un ejemplar de Miraveche y el de la tumba 9 de Villanueva de Teba, con la parte superior abierta, conservan las dos láminas de hierro en forma de cruz; elemento el cual es típico de los ejemplares con púas. Pero quizás es más interesante el hecho de que no aparezcan piezas de otros modelos típicos de la Meseta, cuando las secuencias culturales tienden a estar más claras.

De los umbos estudiados en Villanueva de Teba podemos sacar algunas conclusiones respecto a tipología y cronología. Respecto a la tipología hemos de señalar que no es el más frecuente el tipo Monte Bernorio con la copa decorada y con flecos y lañas sino otro cuyo uso ya era habitual en Miraveche: el de copa maciza, compacta, sin laña y con la presencia de clavos en la parte superior de la copa. Estamos de acuerdo en las matizaciones de Valls y Esparza $(1992,263)$ que debe quitarse la denominación añadida de Miraveche-Cogotas a ese modelo por las razones que ellos señalan: en Cogotas es un modelo más de los que hay y en Miraveche no es ese modelo el más frecuente sino otro; razones que son seguidas por Sanz Mínguez (1997b: 449). Precisamente el modelo que domina en Villanueva de Teba es el hecho de una lámina entera que es justamente el más frecuente en Miraveche y que tipológicamente encaja en el tipo IIIB de Quesada (1997: 514) que coincide no solo en la forma sino en las dimensiones. Incluso ya en Miraveche aparece el umbo asociado a ese anillo de bronce que iría montado sobre la periferia del umbo. El modelo de Miraveche, liso, se proyecta en el yacimiento de Villanueva de Teba al que incorpora los elementos típicos señalados primero por Cabré y luego por Kurtz para los ejemplares de Las Cogotas: tirantes metálicos, terminales de radio y abrazaderas. Este modelo compacto parece que es el más específico de la zona de la Bureba contrastando con todas las tipologías que se encuentran en el resto de la Meseta, tema tratado por Cabré, Kurtz, Quesada y Sanz en las obras citadas. Aunque en los yacimientos aparecen diversos modelos, producto de las relaciones comerciales o de otra índole, es probable que haya algunos específicos de diferentes zonas, como es nuestro caso, pues el modelo troncocónico compacto, con clavos en la cabecera de la copa, abarca un amplio marco cronológico que iría desde el siglo IV de Miraveche hasta el siglo II de Villanueva de Teba. Es quizás por ello por lo que debemos poner en consideración la opinión de Nicolini (1969: 177) de que la caetra de los lusitanos era de una manera, la de los vetones de otra y la del resto de la Meseta de otra. Lo que sí es claro es que los umbos de escudo de la Bureba no tiene que ver con los de El Raso de Candelada (Fernández Gómez 1986: 801-804) 
que corresponden fundamentalmente a los tipos IIA y IIIA de Quesada. Por otro lado, como ya apuntó Kurtz (1997: 75), el interior de la copa estaría relleno con alguna pieza de materia orgánica. En el caso de la mayoría de los ejemplares de Villanueva de Teba, el tipo compacto, es evidente y la razón está en la presencia de los clavos en la cara superior de la copa.

Respecto a las manillas, de los dos ejemplares aparecidos en Villanueva de Teba, el primero de la tumba 4 le ponemos en duda (aunque podría encajar con la manilla encontrada en la tumba 66 de Padilla de Duero) (Sanz Mínguez, 1997a: 452, fig. 141); no así el de la tumba 9 que además representa una modalidad específica no en cuanto a la forma sino en la manera de disponer sus elementos. El ejemplar de la tumba 9, tipológicamente está emparentado con el tipo calado, habitual en la Meseta, en el que las aletas del modelo ibérico han sido reducidas al mínimo. Sería el modelo V de Quesada (1997: 507-508, fig. 289), plano y calado sin aletas con solapas para abrazar la madera que constituía la manilla propiamente dicha. Este modelo es el que aparece asociado al umbo Monte Bernorio (modelo IIIC de Quesada) y estaría presente en el alto Ebro (La Bureba) y en el valle medio del Duero como en la zona vetona; no así en la zona oriental de la Meseta. La manilla de Villanueva de Teba significa una evolución definida porque la manilla de madera es forrada por una lámina fina de bronce decorada con una serie de líneas incisas, en este caso, que entra en el contexto artístico que aparece en los puñales, particularmente en las vainas.

En cuanto a cronología, debemos tener en cuenta dos hechos. Por una parte, estas piezas aparecen en la Meseta asociadas a espadas de La Tène y otros modelos de finales del Hierro, fíbulas de la misma cronología, falcatas y espadas tipo Arcóbriga (periodo D de las necrópolis de la zona oriental de la Meseta); todo lo cual nos lleva a fechas posteriores a comienzos del siglo III a. C., aunque Sanz Mínguez defiende una cronología de la primera mitad del siglo IV (Sanz Mínguez, 1997a: 452) pero se refiere a la peculiar manilla de la tumba 66 de Las Ruedas de Padilla de Duero. Estos modelos de Villanueva de Teba coinciden con los de la segunda fase de Arcóbriga, con el tronco también cerrado y con grandes clavos, fechados allá en los siglos III y II, y corresponden al tipo IIIB de Quesada que son casi exclusivos en Miraveche cuya cronología es del siglo IV y III (Ruiz Vélez, 2001: 82-83) pero que como hemos visto siguen utilizándose en Villanueva de Teba. Pero debemos tener en cuenta otro hecho. Hemos visto más arriba que hay paralelismos con otras necrópolis muy alejadas en el tiempo. Nos referimos concretamente a Ubierna que hay que retrotraerla a finales del $\mathrm{V}$ o inicios del IV. Con esto queremos señalar la pervivencia de un modelo de raíz indígena y que perdura a lo largo de la segunda Edad del Hierro con cierta identidad, sin duda debido a su sencillez y efectividad aunque en nuestra necrópolis, como es normal debido a su cronología, se encuentran los modelos más significativos porque son de los últimos en estas tierras. En consecuencia, debemos pensar que es un objeto que aparece en fechas relativamente tempranas y que debido a su forma tan sencilla gozó de larga perduración con pocos cambios sustanciales en su morfología.

Junto al umbo destacan las abrazaderas, presentes en las tumbas 6 y 9 que presentan una disposición triangular formada por doble lámina que se vuelve por el otro lado. Cerraba la caetra y se unía a los tirantes que enganchaban en el umbo. Estas abrazaderas son distintas a las encontradas en Las Cogotas, dadas a conocer por Cabré (1939-40: lám. XIV) y estudiadas luego por Kurtz (1986-87: 445-458).

\section{PUNTAS DE LANZA}

Las puntas de lanza, igual que otros objetos como los puñales o las placas andaluzas, aparecen en numerosas tumbas que, como decíamos más arriba, nos indican el grado de coherencia y uniformidad de estos ajuares funerarios. Esto nos señala la brevedad del arco cro- 
nológico en el que se desarrolló esta necrópolis; es decir, tuvo una vida muy corta a tenor del estudio tipológico y las escasas o nulas evoluciones en los materiales. Pero no es el arma más repetitiva y representativa de la panoplia en nuestra necrópolis a diferencia de todas las demás, tanto del ámbito ibérico como del meseteño. Está menos representado que los puñales aunque hemos de resaltar que su presencia sí es abundante.

En Villanueva de Teba no hemos encontrado ninguna lanza maciza o soliferra; sólo las puntas que irían insertada en vástagos o astiles de madera; además de algunos regatones. En consecuencia, vamos a seguir con las divisiones establecidas comúnmente para distinguir tres categorías formales en función de las dimensiones. La jabalina incorporaría aquellas puntas más pequeñas y que una ver armada no era de más de $2 \mathrm{~m}$ de longitud; entre 1,5 y 2 m. En nuestro caso sólo podríamos hablar de un ejemplo, el de la tumba 13, y con reservas pues nos atrevemos a señalar que esta pieza no está representada en nuestro yacimiento. Sanz Mínguez (1997: 421) apunta que las jabalinas son armas para atacar de punta, por eso tienen puntas de dimensiones más reducidas, y las lanzas sirve como arma punzante y como cortante; de ahí la importancia del filo en las puntas metálicas. Cuando tienen en torno de 2,5 $\mathrm{m}$ de longitud total serían ya lanzas según Brunaux y Rapin (1988: 85-88); y en esta catalogación tiene mucho que ver el diámetro del tubo que en nuestro caso está entre los 3 y los $3,9 \mathrm{~cm}$ lo cual nos hace matizar más la pertenencia de todas las piezas de Villanueva al apartado de las lanzas. Para las picas pasarían, aunque no con mucho, ese diámetro y no creemos que en el ambiente de esta necrópolis estas piezas existiesen.

De excavación proceden 21 ejemplares de punta de lanza (figs. 20-23) y 5 regatones (fig. 24), repartidos en 18 tumbas $(48,64 \%)$ de las 35 totales. Es decir, prácticamente la mitad de ellas ofrecen esta arma ofensiva. Además señalamos que es normal encontrar una pieza en cada tumba, salvo la $\mathrm{n}^{\circ} 6$ que tiene dos, la 13 también dos, la 17 con tres, la 25 con tres, la 26 con dos regatones, la 31 con dos puntas, la 33 con dos y la 34 que tiene otras dos. De excavación son 28 piezas; en total 49 en toda la necrópolis, cifra muy similar a la de Las Ruedas. Estas tumbas con más de una pieza representan el 38,88 \% del total. Como de prospección proceden otras 21 piezas, no se pude descartar que la mayoría de las tumbas tuviesen dos ejemplares al menos. Lo que sí es también significativo es que de los once regatones procedentes de excavación, tres provienen de la tumba 26 (fig. 24) que no ofreció punta de lanza, otro de la 34 que tampoco dio punta de lanza y de la tumba 1 con otro regatón. Esto podría apuntar hacia la idea de Kurtz (1987: 55) de que estos regatones son auténticas puntas de lanza, idea que no nos parece muy probable porque este apéndice posterior del asta de la lanza servía como elemento auxiliar de esa arma ofensiva para rematar acciones bélicas y en muchos casos servía además para azuzar al caballo ya que debe tenerse en cuenta que los jinetes de esa época, como otros pueblos de la Protohistoria, utilizaban una única espuela, elementos ambos (lanza y espuela) que se complementan perfectamente para un primer ataque al enemigo. Esta misma opinión la comparte Sanz Mínguez (Sanz Mínguez 1997: 421) para Las Ruedas de Padilla de Duero.

Todos los ejemplares son de hierro y presentan una misma estructura: la hoja maciza y el tubo hueco, a veces con estrangulamiento basal aunque esto es circunstancial, más parece consecuencia del deterioro que han padecido algunas piezas pues están muy oxidadas como es habitual en el hierro (fig. 22). En cualquier caso los filos son siempre rectos y no disponen de estrías periféricas. Los perfiles son rectos, sin ningún estrangulamiento. Las dimensiones parecen muy uniformes dentro de los distintos grupos, oscilando entre los 19 y los $30 \mathrm{~cm}$ de longitud total pero la mayoría tienen entre 22 y $28 \mathrm{~cm}$. La longitud del tubo oscila entre los 7 y $\operatorname{los} 9,5 \mathrm{~cm}$. La anchura de la hoja también es uniforme, ente 2,5 y $3,5 \mathrm{~cm}$, salvo la $\mathrm{n}^{\mathrm{o}} 12 \mathrm{de}$ prospección y una de la tumba 17 (fig. 23) que tienen 2 y $2,4 \mathrm{~cm}$ respectivamente. En este último caso, los $26,5 \mathrm{~cm}$ de longitud le hacen tener una apariencia más estilizada. Por el con- 
trario, el segundo ejemplar de la tumba 13 representa el otro extremo. Es una hoja de $7 \mathrm{~cm}$ de ancho lo que le hace ser el único ejemplar achaparrado del conjunto. Hemos llevado a un eje de coordenadas (fig. 25) conjugando los parámetros longitud total - \% de la longitud del tubo y se manifiesta una gran uniformidad, a diferencia de Las Ruedas (Sanz Mínguez, 1997: 423, fig. 224), en la que Sanz Mínguez establece una tipología de cinco grupos articulando también la forma de la hoja (laurel, sauce o triangular) y la sección. Nuestras piezas que ofrecen unas características muy comunes podrían corresponder a sus grupos III y IV que pertenecen en su mayoría al perfil de hoja de sauce y a unas medidas concretas, que es nuestro caso, aunque en Villanueva de Teba esa hoja de sauce unas veces es más ancha y otras mucho más fina. Por otro lado la sección de las puntas de esta necrópolis es casi siempre bicóncava, no losángica con nervadura como en Las Ruedas.

Los regatones (fig. 24), once de excavación y seis de prospección, miden entre 4,5 y 10,2 $\mathrm{cm}$ de largo. Todos son del mismo modelo, es decir, el cuerpo es la simple prolongación del tubo. El uso de estas piezas sería múltiple pues por una parte servirían de contrapeso a la punta y equilibrar su función; por otra serviría para apuntalar el arma en el suelo y poder reutilizarla más rápidamente; también se utilizaría para rematar al enemigo que ya estaba abatido; y finalmente, como dice Quesada (1997: 307-308), para arma de ataque cuando la punta de la lanza hubiese sido quebrada por el enemigo.

La presencia de las puntas en la tumbas es cuantiosa y no se puede decir que vaya asociada a ajuares ricos o pobres. En este caso, en cuanto que todos los ajuares son ricos, debemos señalar que la punta de lanza es un complemento más de la panoplia guerrera.

Las puntas de lanza las hemos dividido en dos grandes grupos atendiendo a la forma de la hoja pero siempre dentro del modelo que Sanz Mínguez llama de hoja de laurel ya que la de hoja de sauce presentan unas peculiaridades que no están presentes aquí. El primer grupo es el de hoja lanceolada o de forma de almendra; y el segundo, de forma triangular o cuasitriangular cuya base tiende a ser perpendicular al eje de la pieza. Además, en cada grupo distinguimos dos subgrupos: cuando la sección es biconvexa o lenticular, y cuando es de forma losángica, es decir, de cuatro mesas con nervadura central que son escasos en el yacimiento. De todas formas conviene señalar que el elevado grado de oxidación no permite ver los posibles acanalados que pudieron tener, cuando sí que son perceptibles en algunos ejemplares (fig. 20).

Del PRIMER GRUPO, VARIANTE A, es decir, de hoja almendrada y sección lenticular, son los ejemplares de las tumbas 6,12 , los dos de la 13 , el de la 14,15 y 18 , los tres de la 25 , el de la 27 y el de la $30 ;$ y los $n^{\circ} 2,4,5,6,7,8,10,12,13,14$, y 18 de prospección; es decir, la mayoría de las piezas, pues de un total de 43, 24 son de este tipo $(55,81 \%)$. La VARIANTE B está representada únicamente por un ejemplar de excavación, el de la tumba 16 y por tres de prospección, $\mathrm{n}^{\circ} 15,20$ y 21 , representando el $9,3 \%$.

La VARIANTE A del SEGUNDO GRUPO está representada por los $\mathrm{n}^{\circ} 3$ y 17 de prospección y por los de las tumbas 10, 19 y los dos de la 31. En total seis $(13,95 \%)$. La VARIANTE B también es escasa con los $\mathrm{n}^{\mathrm{o}} 16$ y 19 de prospección, el tercer ejemplar de la tumba 17 y los dos de la $31(11,62 \%)$. Vemos que su incidencia es pequeña en todo el contexto.

Un grupo aparte lo forman los $n^{\circ} 1$ y 2 de la tumba 17 y el $n^{\circ} 16$ de prospección, integrables en el segundo grupo, variante $\mathrm{B}$, pero que llevan una acanaladura a cada lado de la nervadura central. Estarían muy próximos a un ejemplar de Miraveche (Schüle, 1969, lám. 140 $\mathrm{n}^{\mathrm{o}} 7$ ). El segundo ejemplo de la tumba 1 , el de la tumba 21 y los $\mathrm{n}^{\mathrm{o}} 1$ y 11 de prospección están incompletos, conservando únicamente el tubo y el arranque de la hoja.

El dominio grande del modelo de sección lenticular, decisivo en ambos grupos, resulta muy expresivo en toda la necrópolis, aproximándonos al mundo de Miraveche pero sobre todo a la cuarta fase de las necrópolis de la Meseta Oriental, en particular a los yacimientos 
de Gormaz y Osma en los que este tipo de puntas abundan. Es decir, parecen ser uniformes estas circunstancias formales en los momentos finales del indigenismo. Estos materiales no tienen nada que ver con sus parientes del círculo suroriental de la Meseta ni con el área de la desembocadura del Tajo. Otro elemento común a las necrópolis es la gran diferencia entre el número de puntas de lanza y el de regatones, cuando se entiende que debería ser similar. Pero esto es común a todos los yacimientos como observa Kurtz (1987: 68) para las Cogotas, Fernández Gómez (1986: 800) para El Raso, Lorrio (1990: 44) para el ámbito de la Celtiberia original o Quesada (1989: 43) para el mundo ibérico.

En nuestro caso deberíamos señalar que el dominio de las secciones bicóncavas frente a las rómbicas que parecen ir asociadas a nervadura central $\left(\mathrm{n}^{\circ} 14,16\right.$ y 20 de prospección; tumba 12 con nervadura; y las que tienen dos acanalados paralelos centrales como es el caso de la tumba 26 - segundo ejemplar -, y los dos ejemplares de la tumba 34) nos están indicando un proceso de sustitución de las segundas por las primeras o que los talleres de esta zona preferían desarrollar esas secciones porque las consideraban más idóneas para sus intereses porque debe tenerse en cuenta que la afirmación de que la presencia de nervaduras o acanalados producen un efecto mortífero más rápido no está demostrado. Las tres puntas de la tumba 17 son de sección rómbica y sin nervadura central, teniendo en cuenta que esta tumba es peculiar en cuanto que el ajuar está duplicado porque probablemente fue una tumba doble. Curiosamente no hemos encontrado en Villanueva ejemplares de un modelo que consideran cántabro y que está presente con dos ejemplares en la tumba 28 de Las Ruedas (Sanz Mínguez,1997: 76 y 425, fig. $67 \mathrm{~J}$ y K); cántabro porque aparece en Monte Bernorio (Cabré, 1920: lám. II; González Echegaray y García Guinea, 1963: fig. 46; Schüle, 1969: lám. 162); pero no está presente en Villanueva de Teba.

\section{LA PANOPLIA GUERRERA DE VILLANUEVA DE TEBA}

Conocemos, con profundidad, la panoplia guerrera de algunos pueblos de la Península Ibérica a lo largo de la segunda Edad Hierro. Esto es debido a los decisivos trabajos de investigación de algunos investigadores como Quesada (1997; 2002: 1-34; 2002: 35-64) para el ámbito ibérico, los de Lorrio (1984: 212-257; 1997: 147-198; 2002: 65-86) para el ámbito celtibérico, Sanz Mínguez (1984: 25-46; 1990b: 172-187; 1997b: 426-448; 2002: 87-134) para el mundo vacceo, Peralta (2000: 188-200) para el mundo cántabro. Por otro lado están desde hace tiempo los importantes trabajos sobre armas de esta fase y que se iniciaron con análisis a cargo de Juan Cabré (1931: 221-241; 1939-40: 57-84), Morenas de Tejada (1916: 169-175); les siguieron J. Cabré y E. Cabré (1933: 37-45); o ella misma (1948: 186-190; 1982: 151-162; 1988: 123-126; 1990: 205-224); ella con Morán Cabré (1979a: 763-774; 1979b: 10-26); Cuadrado (1963: 13-60); Kurtz (1985: 13-23); Lenerz de Wilde (1986: 273280); Monteagudo (1952: 116-119); Sandars (1913), Stary (1982: 114-144) y tantos otros que podemos encontrar en la bibliografía especializada de las primeras publicaciones citadas. El trabajo de recopilación de Schüle (1969) fue fundamental con un interesante estudio en el que algunas de sus propuestas todavía están vigentes.

En los ámbitos ibérico y celtibérico en el sentido estricto encontramos, debido al elevado número de datos conocidos, una seriación más o menos importante de las variaciones morfológicas en la panoplia guerrera de las gentes de la segunda Edad del Hierro. El contenido de la armamentística en todos los pueblos de la Península Ibérica estuvo muy desarrollado debido al carácter peculiar de aquellas sociedades, tanto del ámbito ibérico como del celtibérico, alcanzando una gran variedad de formas y un dinamismo que explican la evolución de los modelos de armas. Todo esto conllevó una enorme inventiva local, como apunta Quesada (1997: 595), que queda reflejado en algunos hechos importantes como en las vistosas empu- 
ñaduras (pomos, cruz) con unos rasgos que no tienen parangón con otras zonas de dentro y fuera de la Península. Es el caso, precisamente, de Villanueva de Teba como se ve en los puñales que no presentan paralelos con sus coetáneos los biglobulares o de otro tipo. Son un unicum al que nos tienen acostumbrados otras necrópolis en otros aspectos como es el caso de la necrópolis de Palenzuela con sus miniaturas las cuales también están presentes en Las Ruedas. Con las lanzas ocurre otro tanto. Así se explica la gran variedad de pequeños detalles que explican la extensa tipología que establece Quesada (1997: 343-427) para este tipo de arma de ataque (lanza) o arrojadiza (jabalina), si bien las lanzas del ámbito céltico o celtibérico no alcanzan las peculiaridades de las ibéricas.

Por otro lado, redundando en lo que decíamos antes, esta variedad y continua evolución impuesta por una sociedad en la que los enfrentamientos internos y los externos son frecuentes, determinan una hibridación de los modelos y tipos (entre las propias espadas, entre las espadas y los puñales, etc.) que se ve acentuada por el carácter artesano y local de las producciones con especialistas que incluso se desplazan de una zona a otra para atender las demandas de, primero, una aristocracia guerrera y luego unas elites ecuestres de mayor espectro social que acaban exigiendo talleres especializados para la elaboración de unas armas de lujo para los más poderosos o unas producciones arraigadas que se convierten en objetos de exportación a otras zonas como ocurre con algunos puñales de tipo Monte Bernorio-Miraveche o con las espadas de gavilanes curvos de Miraveche que llegan a las necrópolis de Palenzuela y de Padilla de Duero. Esta profusión de talleres explica el marco local y comarcal de algunos modelos de armas y otro más amplio regional para las producciones de mayor calidad. Un estudio de las decoraciones de damasquinados con hilos de plata, oro o cobre de los puñales de tipo Monte Bernorio, además de otros elementos de análisis permitirán conocer la procedencias de muchas armas y elaborar un marco de relaciones comerciales en estas tierras.

Para el conocimiento de la panoplia guerrera tenemos dos inconvenientes, como señala Lorrio (1997: 147), que son, por un lado, una serie de carencias que vienen impuestas por las exigencias del rito funerario que determina que en el ajuar haya unas piezas y no otras, según las etapas y las culturas. Por otro lado, el propio deterioro del yacimiento que, por causas naturales o por acciones antrópicas conscientes o inconscientes, se altera su estado original. Estos aspectos impiden llegar al conocimiento de la panoplia real por cuanto aportan datos con una significación relativa de lo que fue el conjunto armamentístico. Su presencia en las tumbas no es sólo por el carácter militar de esos instrumentos sino por su significado ritual que pasa a ser más importante. Sin embargo, la información sobre este aspecto no procede únicamente de las necrópolis. En los poblados también se hallan armas y a veces con un importante repertorio. No es el caso de Soto de Bureba que no ha aportado ninguna arma durante el proceso de excavación. Este castro es el único poblado excavado en La Bureba pero más al sur en el castro de Hontoria del Pinar (Ruiz Vélez et alii, 2000: 375-382-385, fig. 7, 1 y 2) se encontraron dos empuñaduras de puñales biglobulares, concretamente en una vivienda con aparejos artesanales y que hemos fechado en el siglo I a.C. quizás en momentos de violencia militar como pudieron ser las guerras sertorianas. En Sasamón (Gil Farrés, 1963: 14-16) se encontró también un puñal de tipo Monte Bernorio-Miraveche. Además, en ocasiones se descubren depósitos de armas como el de Quintana Redonda en Soria en el que se encontró un casco o el más reciente de Alfaro (Marcos Pous, 1996: 148, fig. 12, 2; Iriarte et alii, 1996: 166-171 y 173-194). También hay que tener en cuenta los hallazgos aislados, las representaciones iconográficas tanto en escultura como en cerámica, que son importantes para muchos detalles y las fuentes escritas de historiadores y geógrafos romanos coincidiendo con los grandes conflictos que se desarrollaron en la Península Ibérica con la segunda Guerra Púnica. Estos dos últimos bloques son importantes para los postreros momentos de la armamentística prerromana.

Conocemos muy bien la panoplia y su seriación cultural y cronológica para algunas áreas, como ya habíamos señalado más arriba. Para el ámbito celtibérico han sido decisivos 
los trabajos de Lorrio (1994: 212-257; 1997: 147-148) y los de Quesada (1997: 593-625) para el mundo ibérico y también céltico y celtibérico. Ellos serán los referentes para el análisis de la panoplia guerrera de nuestra zona (fig. 27).

La panoplia celtibérica, porque es la más próxima y mejor conocida respecto a la de nuestra área, es muy uniforme independientemente de que haya evolucionado desde finales del VII hasta el siglo I a.C. La espada y/o el puñal, las puntas de lanza, el cuchillo, el escudo, la coraza y cota de malla, el casco, a veces elementos de honda, arco, grebas, son los objetos integrantes de la panoplia guerrera integral pero nunca aparece completa. La espada/puñal, las puntas de lanza, el umbo del escudo, el cuchillo son las piezas recurrentes en las tumbas. Dependiendo de etapas y del grado social de cada enterramiento el ajuar es más rico o más pobre. Lo más normal es que aparezca un elemento de cada tipo de objeto aunque en algunos casos se nos presentan duplicados; salvo las puntas de lanza que es más variable el número siendo el arma por excelencia que es seguido de cerca por el cuchillo (fig. 28).

La panoplia de Villanueva de Teba es muy sencilla y coherente con el hecho de que responde a una necrópolis de una vida bastante corta aunque tengamos que dar un arco cronológico grande a toda ella. Ofrece unas cifras que son comunes a otras necrópolis, por lo tanto, no introduce nada nuevo excepto las cuestiones tipológicas que ya expusimos anteriormente. Cuatro (incluimos el regatón con la lanza) son los elementos integrantes de la panoplia total: el puñal, la punta de lanzalel regatón, el cuchillo y el escudo. Las puntas de lanza son los más representadas pues aparecieron 27 ejemplares, más 10 regatones.

Las puntas de lanza significan el $39 \%$ de los objetos de la panoplia y los regatones el 15 $\%$ que al considerarlos un conjunto suponen más del $50 \%$ del total. En nueve tumbas aparece una sola punta de lanza sin embargo en ocho se encontraron dos o tres ejemplares. Ésta es una característica común a todos los ámbitos culturales de la Península.

Los puñales quedan en segundo lugar con 24 ejemplares que representan el $31 \%$ del total; aparte del hecho de que aparecen en 21 tumbas de un total de 35, resulta que es un dato muy elevado. Es posible que la casi totalidad de las tumbas tuviesen un puñal teniendo en cuenta los ejemplares y los fragmentos encontrados en prospección. Otro detalle de los puñales es que casi siempre aparece un único ejemplar en cada tumba, concretamente en dieciocho de ellas; sin embargo en las tumbas $\mathrm{n}^{\mathrm{o}} 17,22$ y 27 son dos los ejemplares encontrados. En la tumba 17 porque hay duplicidad de algunos elementos del ajuar, pero las otras dos no hay razón aparente salvo la explicación de la peculiaridad del rito. Pero esta característica es bastante común en las necrópolis celtibéricas.

El tercer elemento de la panoplia es la caetra que aparece representada en seis tumbas lo que significa el $9 \%$ de la panoplia. El umbo está presente únicamente en cuatro tumbas y en las demás a través de los elementos auxiliares como los tirantes, las grapas o una manilla que es el único caso de toda la necrópolis que recuerda las manillas de aletas del ámbito ibérico, sin embargo los umbos son, en especial, meseteños. La tumba 9 es la que aportó mayor número de elementos del escudo pues están prácticamente todos los que son de metal ya que el resto, de madera y cuero, por ser materia orgánica, se ha perdido. Podemos decir que es una pieza completa y por lo tanto reconstruir por entero la caetra de la necrópolis.

Finalmente, citamos el cuchillo que curiosamente está muy escasamente representado pues sólo aparece en las tumbas 6, 8, 22 y 26 con un ejemplar en cada una de ellas. Significa el $6 \%$ de la panoplia. Es, por lo tanto, poco representativo. Tipológicamente presenta los rasgos comunes a este tipo de piezas con su perfil curvo siendo un elemento de origen ibérico que aparece desde los primeros momentos de la panoplia guerrera en todos los ámbitos. Algunos autores no son partidarios de integrarlo en ella pero es coherente porque están asociados a las armas, además de estar presente en la tumba y no como elemento doméstico sino como objeto de pleno derecho con el resto de las piezas. Al estar integrado en el ajuar, se le 
ha querido interpretar como elemento de la panoplia guerrera, según piensan Mohen (1980: 66-67) y Kurtz (1987: 34-35), y antes que ellos los Cabré y Molinero (1950: 69), pero debemos pensar que también pudo tener usos domésticos, como piensa Fernández Gómez (1980: 805) pues aunque forma parte de los ajuares o conjuntos guerreros pudo tener una función estrictamente utilitaria, en opinión de Sanz Mínguez (1997: 420). Pudo desempeñar, como parece más razonable ambas funciones, quizás aludiendo al carácter y uso tradicional histórico de tal instrumento. La funcionalidad doméstica viene impuesta por la tipología y la tradición histórica pero debemos tener en cuenta cómo en algunas ocasiones aparece asociado a las espadas pues las conteras de éstas presentan un cajetín para guardar este instrumento. Este dato, además, aparece en las fuentes clásicas (Lorrio, 1993: 321). Por otro lado, su aparición en ambientes domésticos asociado a contextos del hogar con parrillas y tenazas en Las Ruedas, su función aparece definida en tal sentido, más cuando en algunos tipos el mango se remata en una anilla para ser colgado.

En la gráfica correspondiente podemos (fig. 26) ver la importancia de la presencia de uno, dos, tres o cuatro elementos de la panoplia. Es escasa la de un elemento, casi siempre la punta de lanza, y también escasa la de cuatro elementos porque únicamente aparece en una tumba; es decir la panoplia completa de la necrópolis. Este último detalle es coherente con el planteamiento de que al ser más completa o compleja, hay menos representación. Es más abundante, con catorce tumbas, la que tiene dos elementos que coincide con el puñal y la punta de lanza que son los más abundantes en toda la necrópolis. Con tres elementos sólo aparece indicada la panoplia en cuatro tumbas. En cualquier caso, es importante el hecho de que la panoplia está representada en 23 tumbas de las 35 lo cual significa un tanto por ciento muy alto, concretamente el $65,5 \%$, respecto a las demás necrópolis que nunca se han dado este caso de tanta presencia. Entonces, podemos decir que dos elementos son los más llamativos de esta necrópolis en cuanto a armas se refiere:

1.- gran importancia de la panoplia guerrera no por la riqueza de su contenido sino porque es un elemento relevante de toda la necrópolis que está presente en muchas tumbas.

2.- corresponde a un grupo social de carácter ecuestre con un indicador significativo que responde a dos variaciones tipológicas el bocado del animal (de uso y de castigo) . Esto se debe a que no sólo interesa el caballo como «instrumento de guerra» (si es correcta la expresión) sino que implica un proceso de preparación como es el hecho de aparecer bocados de castigo que son empleados para la doma del animal; lo cual quiere decir que domaban caballos.

No incluimos los arreos de caballo en la panoplia porque tienen tratamiento y significado aparte. Están íntimamente unidos al carácter guerrero pero implican un matiz porque los materiales anteriores significan unos guerreros de infantería frente a los que incorporan los arreos que serían de caballería. Ya indicamos más arriba que esta afluencia de arreos de caballo en las tumbas, hacen que interpretemos esta necrópolis como un grupo de equites de una sociedad de los momentos finales del mundo indígena en La Bureba. En el poblado de Los Llanos de Soto de Bureba ya dijimos más arriba que aparecieron huesos de caballo, no como animal de carne sino de tiro y para la guerra (Parzinger y Sanz, 2000: 378). Las fuentes clásicas hablan de la importancia de este animal en las guerras sertorianas (según Livio) y como animal para las carreras en el circo romano (Ammiano). La iconografía de las estelas clunienses indígenas de época romana son indicadores de esta importancia, en este caso guerrera que es a la que nos referimos nosotros.

Vamos a comparar esta situación de la panoplia de Villanueva de Teba con algunos yacimientos emblemáticos de otras zonas que conocemos con cierto detalle. Nos referiremos a 
la de las Ruedas para el ámbito vacceo, a la de La Mercadera para el ámbito arévaco y a la de Las Cogotas para los vetones. Hemos de señalar que en todos los ejemplos el arco cronológico y cultural referenciado es mayor que en el yacimiento que nosotros estudiamos y es importante tener esto en cuenta porque la panoplia no es la misma en las distintas fases desde el siglo V hasta el I a.C. como han demostrado perfectamente Lorrio y Quesada en las seriaciones cronológicas que han hecho dichos investigadores. Es interesante la relación de necrópolis celtibéricas en las que se especifica la cantidad de enterramientos con armas y sin ellas (fig. 27) lo cual nos indica la importancia del elemento guerrero en dicha necrópolis.

En el caso de la necrópolis de Las Ruedas (Sanz Mínguez, 1997: 470, fig. 232) de Padilla de Duero, de las 66 tumbas encontradas, 28 han aportado elementos de la panoplia; es decir el $42{ }^{\prime} 4 \%$. Es una proporción elevada; de las más elevadas de la segunda Edad del Hierro pero no llega al 68'5\% de la de Villanueva de Teba que es elevadísima. Ya dijimos más arriba por qué. La panoplia de las Ruedas está integrada por cinco elementos, frente a los cuatro de la nuestra: espada (1 ejemplar), puñal (15), puntas de lanza (14), caetra (17) y cuchillo (4). La relación entre espada-puñal está vinculada en cierta manera al mundo de Villanueva de Teba porque no hay espadas y sí muchos puñales. En Las Ruedas la única espada está relacionada con una tumba, la 28 , que pertenece al grupo de mayor rango de la necrópolis. Distinta es la presencia de la caetra que es escasa en nuestra necrópolis pero más abundante allí con 17 ejemplares. Por otro lado es diferente el desarrollo de las categorías de la panoplia en cuanto al número de elementos integrantes. En Las Ruedas, de las 28 tumbas con armas, 16 presentan un único elemento de la panoplia. A partir de ahí se va reduciendo: 9 tumbas con dos elementos, 2 con tres, 1 con cuatro y 0 con cinco elementos. En nuestro caso el grupo más numeroso es el que presenta dos elementos, generalmente puñal y punta de lanza que van muy bien para unas tropas de naturaleza ecuestre como hemos visto anteriormente. Los arreos de caballo en Las Ruedas sólo están presentes en 3 tumbas frente a las 15 de Villanueva cuya representación es mayor porque son casi la mitad el número total de tumbas. Además los tres casos de Las Ruedas están asociados a una lanza en un caso, a una lanza y cuchillo en otro y un caso que es único sin elementos de la panoplia. Vemos, pues, que hay unas diferencias importantes en la relación entre ambas necrópolis.

En el caso de la Mercadera (Lorrio, 1990: 39-40; 1997: 173-176, fig. 70) seguimos la opinión de Lorrio cuya necrópolis es el caso más específico para entender la Fase II o etapa de plenitud (V-finales del III) de la panoplia celtibérica, cronología que no coincide con la nuestra pues Villanueva de Teba es sincrónica de la Fase III de Lorrio (fines del III-I a.C.) cuando las condiciones de la panoplia cambian hacia menos, frente a la de Villanueva de Teba que va hacia más armas en las tumbas sin ser espectaculares como las de la fase II. De un total de 100 tumbas, 44 presentan armas, lo cual representa una relación inferior a la de Villanueva de Teba. Pero presenta una gran variabilidad en los equipos armamentísticos (Lorrio, 2000: 173) puesto que se puede establecer una cierta estandarización en los equipos de armas y esto sí que es una característica de Villanueva de Teba que en nuestro caso se entiende por la cronología tardía y los cambios de rito que introducen los momentos finales coherentes con los cambios sociales que ha habido. El conjunto más abundante de La Mercadera es el que únicamente presenta la punta de lanza como panoplia, con un $45 \%$ de las tumbas con armas. Puede haber de una a tres puntas de lanza. En esto se parece a Villanueva de Teba. El siguiente grupo en representación es el que tiene tres elementos: espada, punta de lanza y escudo que aparece en el 13,6 \% de las tumbas. El tercer grupo, con un 11,4 \%, presenta dos elementos: espada o puñal y punta de lanza. Con espada o puñal, es decir un elemento, están el 9,1\% de las tumbas que parece ser que corresponde con los momentos más avanzados de la necrópolis. Con dos elementos están también las tumbas de dos elementos pero que corresponden con un escudo y una, dos o tres puntas de lanza. Lorrio (2000: 176) no incluye el cuchillo entre los elementos del ajuar aunque aparece en tumbas de gue- 
rrero pero también en tumbas con adornos. Los arreos de caballo son abundantes y asociados siempre a tumbas ricas. Vemos pues que hay ciertas concomitancias con Villanueva de Teba respecto a los arreos de caballo y en el número de elementos integrantes de la panoplia aunque haya una distancia cronológica importante.

Las necrópolis de Las Cogotas y de La Osera (Cabré, 1932; Cabré et alii, 1950; Martín Valls, 1986-87: 75-78) ofrecen una mayor diversidad y diferencias con las vistas hasta ahora. En Las Cogotas se encontraron 1.613 tumbas distribuidas en cuatro zonas de las que 224 únicamente presentan ajuar $(15,48 \%)$. Martín Valls distingue cuatro categorías: ajuares de guerreros, ajuares probablemente de artesanos, ajuares posiblemente femeninos y otros. Respecto a los ajuares guerreros significan el $18,3 \%$ y corresponden a cuatro tipos: los de carácter suntuario cuyas armas presentan nielados de plata pero no están asociadas a arreos de caballo; el segundo grupo es el que presenta arreos de caballo asociados a puntas de lanza, cuchillos, puñales y escudo, con un caso en el que aparece una espada; el tercero el de los ajuares completos porque tienen lanza, cuchillo, puñal, tahalí y escudo pero no espadas ni arreos de caballo; finalmente los que presentan uno o dos elementos que siempre es lanza, cuchillo o navaja, no las armas anteriores. En La Osera se encontraron 2.230 tumbas distribuidas en seis zonas. La más importante fue la zona VI con 517 tumbas de las que 250 presentaron ajuar (48,35 \%). Martín Valls (1986-87: 76-77) establece el mismo tipo de cuatro categorías para esta necrópolis: ajuares guerreros, artesanos, femeninos y otros. Del primer grupo, 65 tumbas (26\%) presentan ajuar de guerrero de las cuales algunas son excepcionales porque tienen espadas con damasquinados de plata, lanzas, escudo y arreos de caballo. Una de esas tumbas no tenía espada en cambio sí ocho placas ibéricas de bronce con ricos damasquinados de plata. Dentro de los guerreros hay un segundo grupo con espadas damasquinadas y armas pero no tienen arreos de caballo. El tercer grupo es con el ajuar completo o la panoplia completa sin nielados. El siguiente es parecido pero sin arreos de caballo y finalmente el grupo de los guerreros con ajuar más sencillo con lanza, cuchillo, navaja y a veces escudo o puñal.

En ambas necrópolis podemos ver que hay una clara jerarquización no sólo entre los ajuares guerreros sino en los demás atribuidos a artesanos y femeninos. Esto es una característica que corresponde a los momentos de mayor expansión de lo que Lorrio llaman la fase de plenitud de la panoplia guerrera. Esta etapa es la que está presente en nuestra zona por la necrópolis de Miraveche. Entonces, las fases II y III de Lorrio en la panoplia celtibérica están representadas en las tierras de la Bureba, respectivamente, por las necrópolis de Miraveche y Villanueva de Teba con las características específicas que les diferencian a ambas zonas geográficas y que hemos venido definiendo para el segundo caso nuestro, el de Villanueva de Teba que representa a toda una etapa, de los momentos finales del mundo indígena en las tierras altas del Ebro.

En el caso de Miraveche, bien siguiendo la distribución que publicó Schüle (1969: lám. 136-153), bien la organización que hicimos nosotros según las fichas del Museo (Ruiz Vélez 2001: 73-78), la panoplia no varía significativamente lo cual es de entender. Las variaciones están dentro de un contexto similar a los de las necrópolis vetonas en cuanto a los ajuares guerreros se refiere porque dentro de las variaciones entre los distintos elementos de la panoplia hay que tener en cuenta la existencia de los objetos con nielados de plata y cobre y la presencia de arreos. Por otro lado, no todas las piezas nieladas o damasquinadas están incluidas en la distribución de Schüle. La panoplia guerrera está integrada siempre por más de un tipo de elementos siendo los más destacados los que presentan cuatro y cinco elementos, lo cual nos indica la importancia de esa panoplia y que nos permite asociarla al mundo de los vettones, numéricamente hablando. Las tumbas excepcionales serían las que incorporan los damasquinados de plata como la tumba 31 que tienen cuatro elementos su panoplia; la 36 tiene, curiosamente, sólo dos elementos pero con gran cantidad de adornos y uno de los po- 
cos casos con bocado de caballo; la 60 con cuatro elementos en la panoplia pero con damasquinados y adornos además de una hermosa placa ibérica de cinturón, que a pesar de los nielados es pobre y la 79 con dos elementos. En estos casos todos presentan una espada de gavilanes curvos y una con bocado de caballo de los tres que existen en la necrópolis. Es precisamente éste uno de sus rasgos más definidos, la escasa representación de los arreos de caballo. Eso quiere decir que corresponde a esa etapa de la panoplia en la que se corresponde con las aristocracias guerreras, o segunda fase de Lorrio. La panoplia de Miraveche está formada por cinco elementos: espada de gavilanes curvos o Tipo VIII de Quesada, puñal tipo Monte Bernorio-Miraveche, punta de lanza/regatón, cuchillo y umbo de escudo. Las dos tumbas que presentan más elementos son la 33 y la 44 que no son las que disponen un ajuar muy vistoso. Sin embargo las que ofrecen un ajuar extraordinariamente variado y numeroso son las tumbas $31,36,38$ y 60 de Schüle que curiosamente son las que más ajuar disponen en la nueva distribución resultado del estudio de las fichas del archivo del Museo de Burgos. El número de elementos de la panoplia es de cuatro salvo la $n^{\circ} 36$ que es de dos. Este número es casi idéntico al de la nueva distribución salvo la tumba 31 que dispone de todos los elementos de la panoplia: espada de gavilanes curvos, puñal de Monte Bernorio, puntas de lanza (3) y regatón, cuchillos (3) y umbo de caetra. Tres tumbas presentan placa de tipo Bureba $(22,79$ y 80$)$ que en la necrópolis de Las Ruedas es un elemento de prestigio. Aquí no coincide con los ajuares que presentan damasquinados salvo la tumba 60 que tiene la placa ibérica de cinturón con el tema del jabalí y el tetrasquele o estrella de mar.

En conclusión, como hemos señalado más arriba, las necrópolis de Miraveche y Villanueva de Teba representan la evolución de la segunda Edad del Hierro en la Bureba coincidiendo con los dos momentos cuyos elementos formales de su cultura vienen definidos por los registros arqueológicos de ambas necrópolis. La primera fase, caracterizada por los ajuares de Miraveche, correspondería cultural y cronológicamente (más o menos) con la Fase II de Lorrio (1994: 230-236; 1997, 156-188) (V-IV y la mayor parte del III) que coincide con los momentos en los que en esas zonas domina una aristocracia guerrera que va evolucionando hacia los caracteres específicamente arévacos que caracterizan a una sociedad en la que el elemento guerrero está más difundido entre los grupos sociales diferentes, característica que definirá a la etapa siguiente. En el ámbito ibérico Quesada (1997: 609-615) indica una segunda etapa o Fase Antigua caracterizada por una «panoplia aristocrática» desde finales del VI hasta finales del V que evoluciona en la época plena hacia una panoplia más generalizada. Serían los paralelos más claros con Miraveche.

Inmediatamente se produce una reducción de la limitación del poder; nuevos sectores adquieren la condición de guerreros definidos por la presencia del caballo debido a una distribución menos monolítica de la riqueza. Corresponderían a las fases IIB y los comienzos de la fase III de Lorrio (1994: 234-236; 1997: 183-188), y a los momentos finales de la fase plena o de panoplia generalizada y los comienzos de la fase avanzada o de panoplia renovada de Quesada (1997: 611-618). Evidentemente, el propio desarrollo de estas fases en la Bureba adquiere unas dimensiones distintas a las que acabamos de referenciar. Faltan por definir los orígenes de este ambiente cultural que podría arrancar desde los asentamientos castreños con tumbas tumuliformes tipo La Polera de Ubierna (Ruiz Vélez et alii, 1998; Ruiz Vélez, 2001: 13-48) y el castro y la necrópolis de Lara de los Infantes (Luis Monteverde, 1958-59: 191199; Ruiz Vélez, 2001: 49-62). 


\section{BIBLIOGRAFÍA CITADA}

ABÁsolo, J.A. et alii (1982): Arqueología burgalesa, Burgos.

ABÁsolo, J.A. (1985): La época romana, en A. Montenegro (dir.) «Historia de Burgos. I Edad Antigua», Burgos, 285-392.

Álvarez, A.; Cebolla, J.L.; BlanCO, A. (1990): Elementos metálicos de tipo celtibérico. La colección Pérez Aguilar, II Simposio sobre los celtíberos. Necrópolis celtibéricos, Zaragoza, pp. 287-304.

BoHIGAS, R. (1986-87): La Edad del Hierro en Cantabria. Estado de la cuestión, Actas del Coloquio sobre la Edad del Hierro en la Meseta Norte, Zephyrus XXXIX-XL, Salamanca, pp. 119-138.

BrunauX, J.L.; Rapin, A. (1988): Gournay II. Boucliers et lances. Dépots et trophées, París.

CABRÉ, J. (1916): Una sepultura de guerrero ibérico de Miraveche (Burgos), A.E.A.yA. III, Madrid, pp. 1-16.

CABRÉ, J. (1920): Acropoli y necropoli cántabras de los celtas berones del Monte Bernorio, Revista de Arte Español V, Madrid, pp. 5-34.

CABRÉ, J. (1928): Decoraciones hispánicas I, AEAyA IV, pp. 97-110.

CABré, J. (1930): Excavaciones de Las Cogotas. Cardeñosa (Ávila). I El Castro, MJSEA 110, Madrid.

CABRÉ, J. (1931): Tipología del puñal en la cultura de las Cogotas, AEAyA VI, Madrid, pp. 221-241.

CABRÉ, J. (1932): Excavaciones de Las Cogotas. Cardeñosa (Ávila). II La necrópolis, MJSEA 120, Madrid.

CABRÉ, J. (1939-40): La caetra y el scutum en Hispania durante la segunda Edad del Hierro, B.S.A.A. XXII-XXIV, Valladolid, pp. 57-84.

CABRÉ, E. (1948): Los discos-coraza en ajuares funerarios de la Segunda Edad del Hierro en la Península Ibérica, IV C.A.S.E., pp. 186-190.

CABrÉ, J.; CABré, E. (1933): Datos para la cronología del puñal de la cultura de las Cogotas, AEAyA 25, pp. 37-45.

CABRÉ, E. (1948): Los discos-coraza en ajuares funerarios de la Segunda Edad del Hierro en la Península Ibérica, IV C.A.S.E., pp. 186-190.

CABRÉ, E. (1952): El simbolismo solar en la ornamentación de las espadas de la II Edad del Hierro céltica en la Península Ibérica, APL III, pp. 100-135. 123-137.

CABRÉ, E. (1975): Dos tumbas datables de la necrópolis de Alpanseque (Soria), APL XIV, pp.

CABrÉ, E. (1982): Notas para el estudio de las espadas tipo Arcóbriga, Homenaje a J. Cabré Aguiló, Zaragoza, pp. 151-162.

CABRÉ E., (1990): Espadas y puñales de las necrópolis celtibéricas, II Simposio sobre los celtíberos. Necrópolis Celtibéricas, Zaragoza, pp. 205-224.

CABRÉ, E.; BAQUedANO, M.I. (1990): La guerra y el armamento, en «Los celtas en la Península Ibérica», Número Monográfico de Revista de Arqueología, pp. 58-71.

CABRÉ, E.; MorÁn CABRÉ, J.A. (1979): Aportación al estudio de las espadas «Alcácer do sal». Una nueva serie descubierta en la necrópolis de La Osera (Chamartín de la Sierra, Ávila), XV Congreso Nacional de Arqueología, Lugo 1977, Zaragoza, pp. 763-774.

CAMPILlo, J. (1999): La romanización y la transición al medievo en la comarca mirandesa, Estudios Mirandeses XIX, Miranda de Ebro, 5-69. 
CAStro GarcíA, L. de (1971): La necrópolis de Pallantia, Palencia.

CHERnORKIAN, R. (1988): Les armes métaliques dans L'Art Protohistorique de l'Occident Méditerraneén, Marsella.

CuAdrado, E. (1963): Puñales de antenas en territorio ibérico, Zephyrus XIV, pp. 13-60.

Escudero, Z. (1988): El Soto de Medinilla. Cultura celtibérica, Revista de Arqueología 89, pp. 32-41.

ESCUDERO, Z. (1995): Nuevos estudios sobre el poblado vacceo de El Soto de Medinilla (Valladolid), en Delibes, Romero, Morales, edtr. «Arqueología y medio ambiente. El $1^{\circ}$ Milenio a.C. en el Duero Medio», Valladolid, pp. 179-217.

FERNÁNDEZ Gómez, F. (1986): Excavaciones arqueológicas en El Raso de Candeleda I (El castro) y II (La necrópolis), Ávila.

FERNÁNDEZ IBÁÑEZ, C. (1999): Placa de tahali para la suspensión de las dagas en el ejército romano: entre la República y el Imperio, Homenaje al Prf. Dr. García Guinea, Sautuola VI, Santander, pp. 335-345.

FILlOY, I. (1990): Tahalies y otros elementos de anclaje en la necrópolis celtibérica de La Hoya (Laguardia, Álava), II Simposio sobre los celtíberos. Necrópolis celtibéricas, Zaragoza, pp. 241-246.

FILloy, I.; GIL, E. (1996): Las armas de las necrópolis celtibéricas de Carasta y La Hoya. Tipología de sus puñales y prototipos del pugio, X ROMEC, Montpellier, septiembre.

FILloy, I.; GIL, E. (1996): Las armas de las necrópolis celtibéricas de Carasta y La Hoya (Álava, España), II Simposio sobre los celtíberos. Necrópolis celtibéricas, Zaragoza, pp. 241-246.

García Bellido, A. (1933): Sobre el probable origen del puñal español posthallstáttico llamado de Miraveche o del Monte Bernorio, Investigación y Progreso VII, pp. 144-146.

García-Soto Mateos, E. (1989): Tumbas con puñales de tipo Monte Bernorio en la necrópolis de S. Martín de Ucero, Actas del II Symposium de Arqueología Soriana II, Soria, pp. 367-388.

GARCÍA LledÓ, F.J. (1986-87): La técnica de construcción de algunas espadas de antenas de la Meseta, Zephyrus XXXIX-XL, pp. 311-320.

GIL FARRÉS, O. (1963): Armas posthallstátticas del siglo III a.C., MMAPr.. XIX-XXII, Madrid, pp. 14-16.

Griño, B. de (1986-87): Los puñales de tipo Monte Bernorio-Miraveche, Coloquio La Edad del Hierro en la Meseta, Zephyrus XXXIX-XL, pp. 297-306.

Griño, B. de (1989): Los puñales de tipo Monte Bernorio. Un arma de la Segunda Edad del Hierro en la Cuenca del Duero, vol. I y II, BAR International Series 504.

Houston, G.W. (1974): The New Milestones from Padilla de Abajo, in the province of Burgos, Durius 4, 423-424.

Iriarte, A.; García, M.L.; Filloy, I.; Gil, E.; SeSMA, J. (1996): El depósito de armas de La Azucarera (Alfaro, La Rioja), Cuadernos de Arqueología de la Universidad de Navarra 4, pp. 166-171 y $173-194$.

Kiliam-DirlmeIER, I. (1972): Die Hallstattzeilichen Gürtelbleche und Blechgürtel Mitteleuropas, P.Br. XII, München.

Jimeno MARTínez, A. (1996): Numancia: relación necrópolis-poblado, AEArq. 69, Madrid, pp. 57-76.

KURTz, W. (1985): La coraza metálica en la Europa Protohistórica, B.A.E.A.A. 21, pp. 13-23. 
KURTZ, W. (1986-87): El armamento en la necrópolis de Las Cogotas (Cardeñosa, Ávila), Zephyrus XXXIX-XL, pp. 445-458.

KURTZ, W. (1986-87): Los arreos de caballo en la necrópolis de Las Cogotas (Cardeñosa Ávila), Zephyrus XXXIX-XL, pp. 459-472.

KURTZ, W. (1987): La Necrópolis de Las Cogotas. Volumnen I: Ajuares. Revisión de los materiales de la necrópolis de la Segunda Edad del Hierro en la Cuenca del Duero (España), BAR International Series 344 .

LENERZ DE WILDE, M. (1986): Art celtique et arms ibériques, Aquitania supplem. 1, pp. 273-280.

LENERZ DE WiLde, M. (1991): Iberia Céltica. Archäelogische Zeugnisse Keltische Kultur auf der Pyrenäen-halbinsel, Stuttgart.

LORRIO, A.J. (1990): La Mercadera (Soria): organización social y distribución de la riqueza en una necrópolis celtibérica, II Simposio sobre los celtíberos. Necrópolis celtibéricas, Zaragoza, pp. 39-50.

LORRIO, A.J. (1994): La evolución de la panoplia celtibérica, Madrider Mitteilungen 35, pp. 212-257.

LORRIO, A.J. (1995): Los Celtibéricos: etnia y cultura, Tesis Doctoral inédita, Universidad Complutense, Madrid.

LORRIO, A.J. (1997): Los celtiberos, Universidad Complutense, Madrid.

LORRIO, A.J. (2000): Grupos culturales y etnias en la Celtibérica, Cuadernos de Arqueología de la Universidad de Navarra 8, pp. 99-179.

LORRIO, A.J. (2002): Problemas de cronología en la panoplia celtibérica, en P. Moret y F. Quesada, La Guerra en le mundo ibérico y celtibérico (siglos VI-II a.C.), Collection de la Casa de Velázquez, vol. 78, Madrid, 65-86.

Luis MonteVerde, J. (1958-59): Los castros de Lara (Burgos), Zephyrus IX, pp. 191-199.

Luis Monteverde, J. (1858a): Panorama arqueológico de Burgos en la Edad del Hierro, BIFG 142, XXXVII, Burgos, pp. 45-47.

Luis MonteVerde, J. (1966-68): La colección Monteverde de Burgos, NAHisp. X-XII, pp. 225-234.

Llanos OrTiZ de Landaluze, A. (1990): Necrópolis del Alto Ebro, II Simposio sobre los celtíberos. Necrópolis celtibéricas, Zaragoza, pp. 137-148.

Marcos Pous, A. (1996): De situ Gracurris. Desde el siglo XVI hasta las excavaciones inéditas de 1.969, Cuadernos de Arqueología de la Universidad e Navarra 4, pp. 107-171.

Martín Valls, R. (1984): Prehistoria palentina, en J. González (dir.), «Historia de Palencia. I Edades Antigua y Media», Palencia, pp. 34-46.

MARTín VALLS, R. (1985): Segunda Edad del Hierro. Las culturas prerromanas, en «Historia de Castilla y León. 1 La Prehistoria del Valle del Duero», Ámbito, Valladolid, pp. 100-133.

MARTín VALLS, R. (1986-87): La Segunda Edad del Hierro: consideraciones sobre su periodización, Zephyrus XXXIX-XL, Salamanca, pp. 59-86.

MARTín VALLS, R. (1986-87): La Segunda Edad del Hierro: consideraciones sobre su periodización, Zephyrus XXXIX-XL, Salamanca, pp. 59-86.

MARTín VAlls, R.; EsPaRZA, A. (1992): Génesis y evolución de la cultura celtibérica, Actas de la Reunión sobre Paletnología de la Península Ibérica (Madrid 1.989), Madrid, pp. 259-279.

Martínez Burgos, M. (1958-61): Museo Arqueológico de Burgos, MMAProv. XIX-XXII, Madrid, pp. 129-137.

Martínez Martínez, C. (1992): El armamento celtibérico en la necrópolis de Carratiermes, Actas del II Symposium de Arqueología Soriana, Homenaje a T. Ortego, Soria, pp. 559-570. 
Monteagudo, L. (1952): Espadas de La Osera y Arcóbriga, A.E.Arq. XXV, pp. 116-119.

MoHen, J.P. (1980): L’Age du fer en Aquitaine, du VIIIe. au IIIe. siècle avant Jesú-Christe, MSPF XI.

Morenas de TAJAdA, G. (1916a): Hallazgos arqueológicos en España. La necrópolis ibérica de Gormaz, Revista Por esos mundos, enero, pp. 169-175.

MORO, R. (1891): Exploraciones arqueológicas, BRAH XVIII, pp. 427-440.

NiCOLINI, G. (1969): Les bronzes figurés des sanctuaires ibériques, Bibliotheque de l'Ecole des Hautes Etudes Hispaniques, fasc. XLI, París, pp. 163-171.

NiCOLINI, G. (1977): Bronces ibéricos, Madrid.

PARZINGER, H.; SANZ, R.; RUIZ, VÉLEZ I. (1993): Die deutsch-spanischen Ausgrabungen in der Bureba (Prov. Burgos), Germania 71, Mainz am Rhein, pp. 315-354.

PARZinger H., SANZ R., Ruiz VÉlez I., (1998): El yacimiento arqueológico de Soto de Bureba (Burgos), I Congreso de Arqueología Burgalesa, Burgos, en prensa.

PARZINGer, H.; SANZ, R. (2000): Das Castro von Soto de Bureba. Archäelogische und historische Forschungen zur Bureba in vorrömischer und römischer Zeit, Instituto Arqueológico Alemán, Berlín.

PERAlta LABRADOR E., (2000): Los cántabros antes de Roma, Madrid.

QueSADA SANZ, F. (1989): Armamento, Guerra y Sociedad en la necrópolis ibérica de «El Cabecico del Tesoro» (Murcia, España), B.A.R. Internacional, Series 502, (I y II). Oxford.

QueSADA SANZ, F. (1997): El armamento ibérico. Estudio tipológico, geográfico, funcional, social y simbólico de las armas en la Cultura Ibérica (S. VI-I a.C.), Monographies Instrumentum 3, 1 y 2, Montagnac.

Quesada SANZ, F. (2002): La evolución de la panoplia, modos de combate y tácticas de los iberos, en P. Moret y F. Quesada, La Guerra en el mundo ibérico y celtibérico (siglos VI-II a.C.), Collection de la Casa de Velásquez, vol. 78, Madrid, 35-64.

ROMERO, F.; SANZ MíNGUEZ, C. (1992): Representaciones zoomorfas prerromanas en perspectiva cenital. Iconografía, cronología y dispersión geográfica, Actas del II Symposium de Arqueología Soriana. Homenaje a T. Ortego Frías I, Soria 1.989, Soria, pp. 453-471.

Ruiz VÉlez, I. (1976): La Segunda Edad del Hierro en la cuenca del río Arlanzón (Burgos), Memoria de Licenciatura inédita, Universidad de Valladolid.

RUIZ VÉLEZ, I. (2001): El ritual funerario en las necrópolis burgalesas de la Edad del Hierro, Discurso de ingreso en la Academia Burgense de Historia y Bellas Artes. Institución Fernán González, Burgos.

Ruiz Vélez, I.; ElorZa GuINEA, J.C. (1991-92): Tahalí damasquinado en plata de Miranda de Ebro (Burgos), Zephyrus XLIV-XLV, Salamanca, pp. 579-586.

RUIZ VÉleZ, I.; EloRZA GUINEA, J.C. (1997): Los puñales de la necrópolis protohistórica de Villanueva de Teba (La Bureba, Burgos), BIFG 215, Burgos, pp. 273-303.

RuIZ VÉleZ, I.; EloRZA, J.C.; ABÁSOlo, J.A. (2000): La necrópolis de Villanueva de Teba (Burgos): las placas de tipo ibérico, Estudios en Homenaje al profesor Dr. M.A. García Guinea, Instituto de Prehistoria y Arqueología Sautuola, Sautuola VI, Santander, pp. 297-306.

RuIZ VÉlez, I.; ABÁSOlO, J.A.; EloRZA, J.C., (1998): La necrópolis protohistórica de Villanueva de Teba (La Bureba, Burgos), I Congreso de Arqueología Burgalesa, en prensa.

Ruiz VÉlez, I.; SANZ, R.; PARzINGer, H. (2003): La necrópolis de la segunda Edad del Hierro del poblado de Soto de Bureba (Burgos), BIFG, 225, Burgos, 293-321. 
Ruiz Vélez, I.; Rodríguez, A.; CASTILlo, B. (2000): Instrumental profesional en el poblado celtibérico de «El Castro», en Hontoria del Pinar (Burgos), BIFG 221, Burgos, pp. 365-399.

Sanz Mínguez, C. (1986): Variantes del puñal de tipo Monte Bernorio en el valle medio del Duero, BSAA LII, pp. 25-46.

SAnZ MíngueZ, C. (1989): Padilla de Duero. Investigaciones arqueológicas 1.985-1.989, Peñafiel.

SANZ MíngueZ, C. (1990): Rituales funerarios en la necrópolis celtibérica de Las Ruedas, Padilla de Duero (Valladolid),II Simposio sobre los celtíberos. Necrópolis celtibéricas, Zaragoza, pp.159-170.

SANZ MínguEZ, C. (1990a): Metalistería prerromana en la cuenca del Duero. Una propuesta secuencial para los puñales de tipo Monte Bernorio, BSAA LVI, pp. 172-187.

SAnZ MíngueZ, C. (1991) Broches tipo Bureba. Tipología, cronología y dispersión, BSAA LVII, pp. 93-130.

SANZ MíngueZ, C. (1992): Fíbulas anulares hispánicas con cabecera de puente remachada, BSAA 32, pp. 39-42.

SAnz Mínguez, C. (1993): Uso del espacio en la necrópolis vaccea de Las Ruedas, Padilla de Duero (Valladolid): Cuatro tumbas para la definición de una estratigrafía horizontal, en Romero, Sanz, Escudero, «Arqueología vaccea», Valladolid, pp. 371-396.

SANZ MíngUEZ, C. (1997a): Los vacceos: cultura y ritos funerarios de un pueblo prerromano del valle medio del Duero. La necrópolis de Las Ruedas, Padilla de Duero (Valladolid), Memorias. Arqueología en Castilla y León 6, Valladolid.

SAnZ MíngueZ, C. (1997b): Bronces prerromanos de la Meseta Norte en el Museo LÁZARO GALDIANO, GOYA, 256, MADRID, 241-252.

SANZ MíngueZ, C. (2002): Panoplias prerromanas en el centro y occidente de la submeseta norte peninsular, en P. Moret y F. Quesada, La guerra en el mundo ibérico y celtibérico (silgos VI-II a.C.), Collection de la casa de Velázquez, vol. 78, Madrid, 87-134.

Sanz Mínguez, C.; Escudero, Z.; FontanedA, C. (1993): Tres piezas de metalistería prerromana en la colección Fontaneda (castillo de Ampudia, Palencia), BSAA LXII, pp. 79-93.

Schüle, W. (1969) Die Meseta-kulturen auf der Iberischen Halbinsel, Madrider Forschungen 3, Berlín, 2 vol.

Smith P., MuÑoz, E. (1984), La ocupación de las cuevas en la Edad del Hierro, Boletín Cántabro de Espeleología 4, Santander, pp. 129-139.

Zamora CanelladA, A. (1987): Segovia en la Antigüedad, en S. Tomás Arribas, «Historia de Segovia», Segovia, pp. 20-55. 


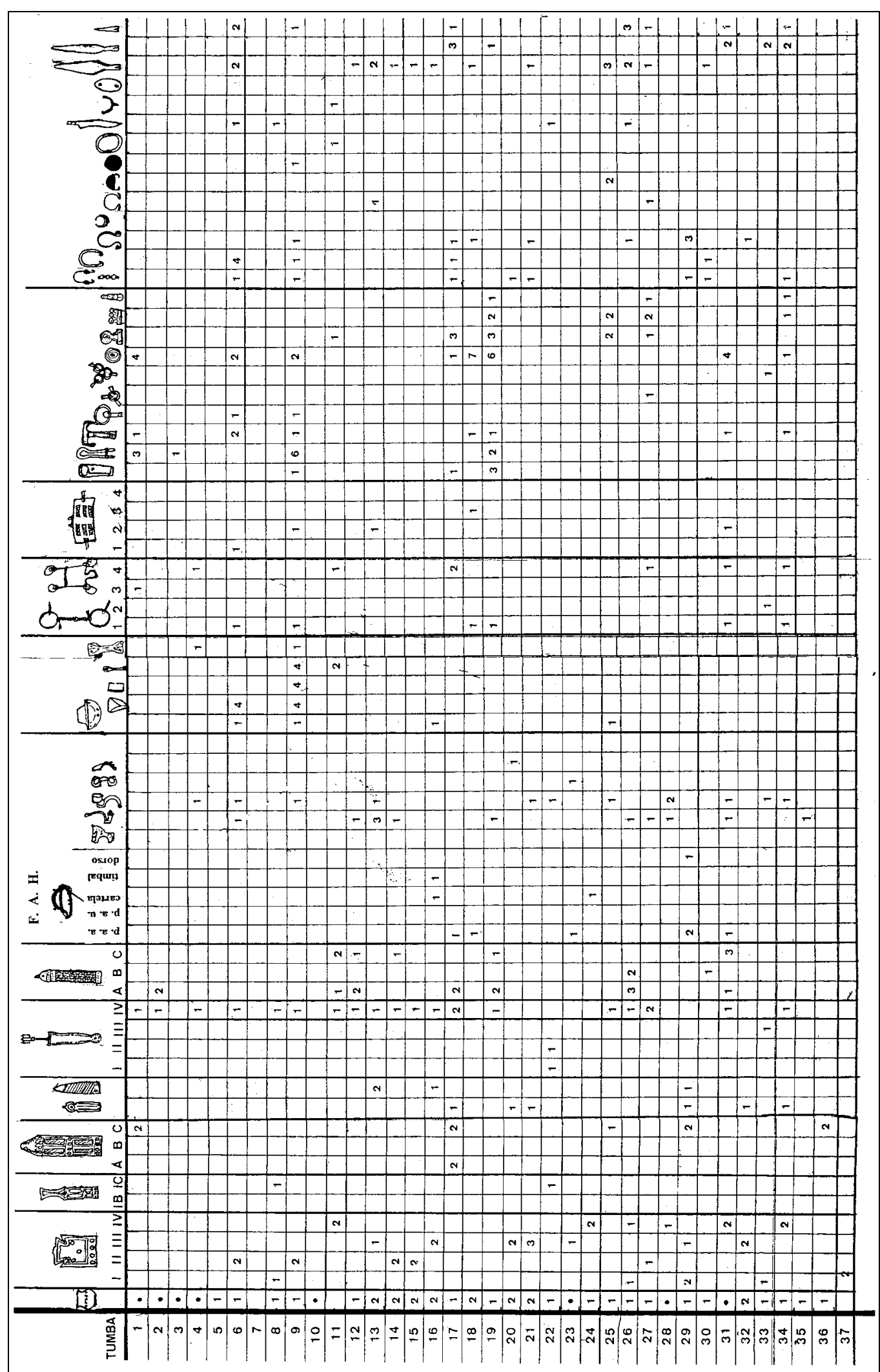

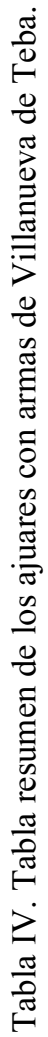




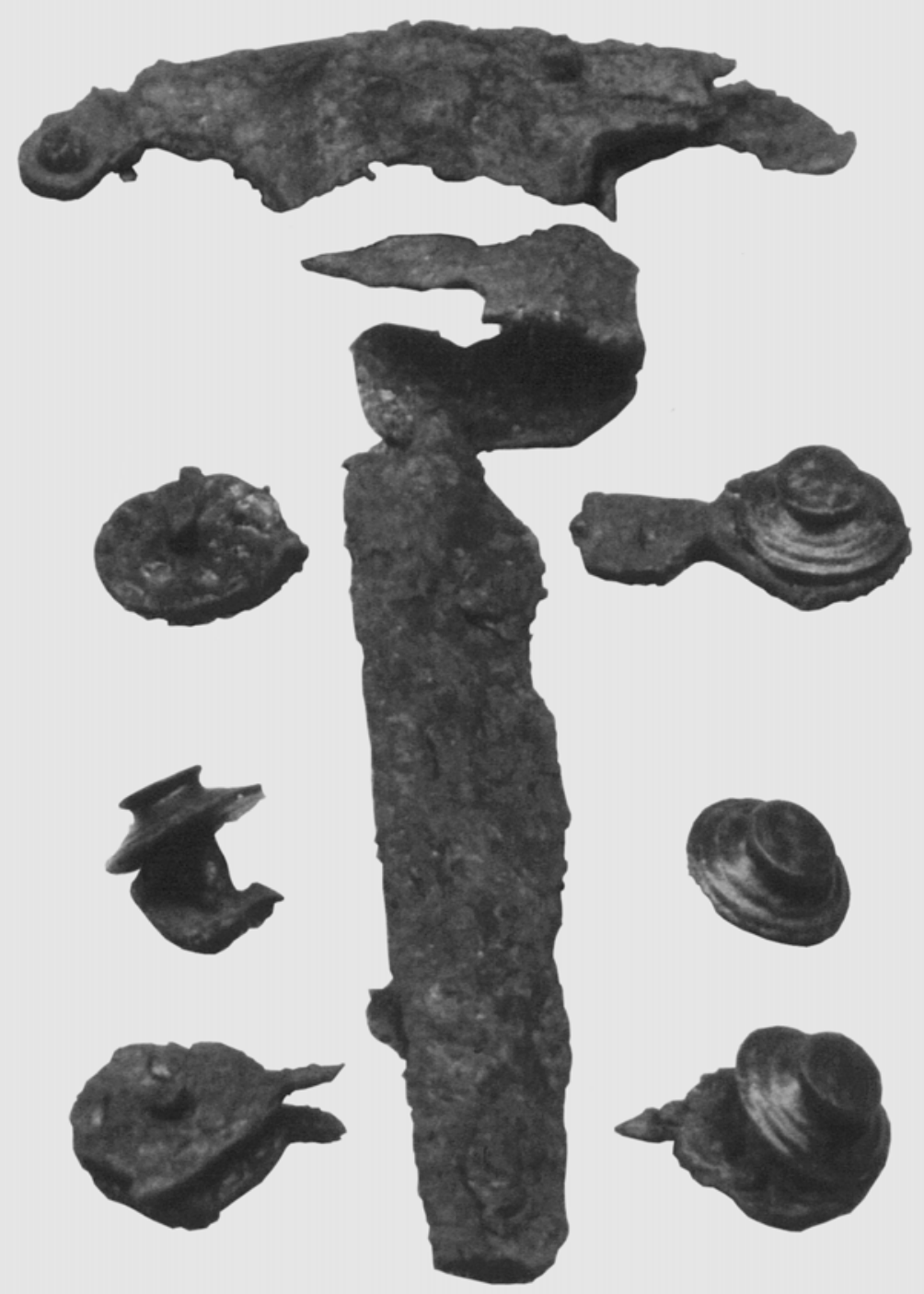

Lám. I. Puñal tipo Monte Bernorio, tumba 22. 


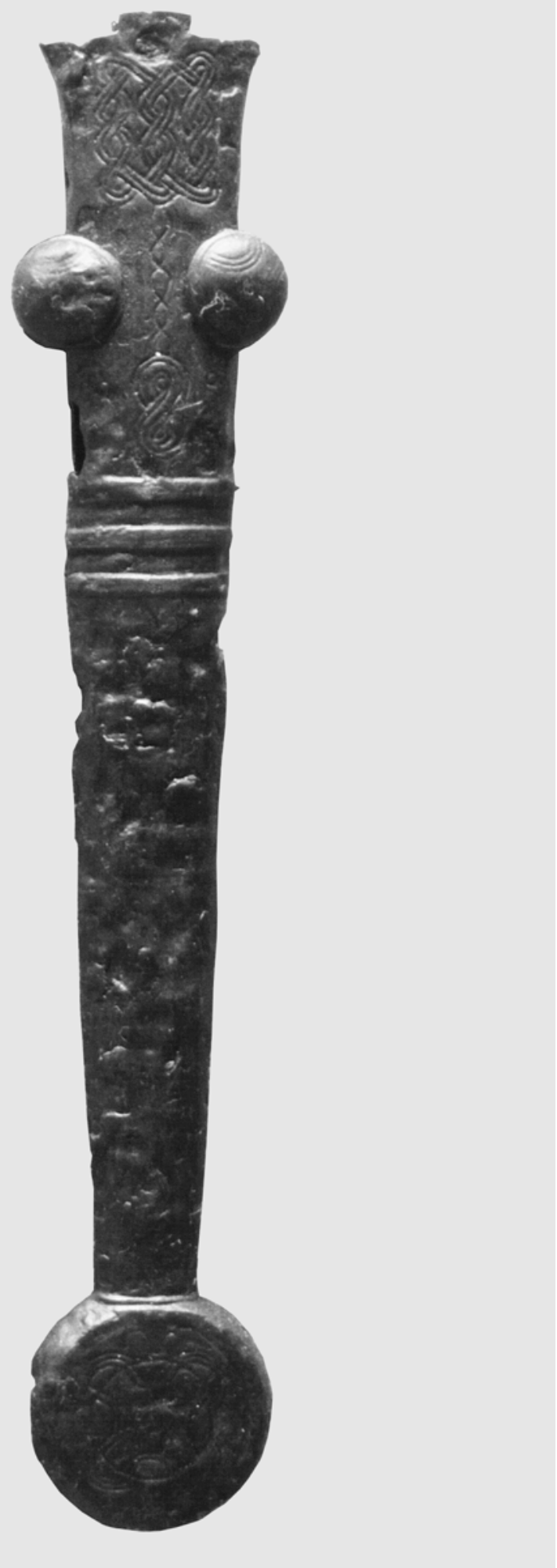

Lam. II. Vaina Monte Bernorio de prospección. 


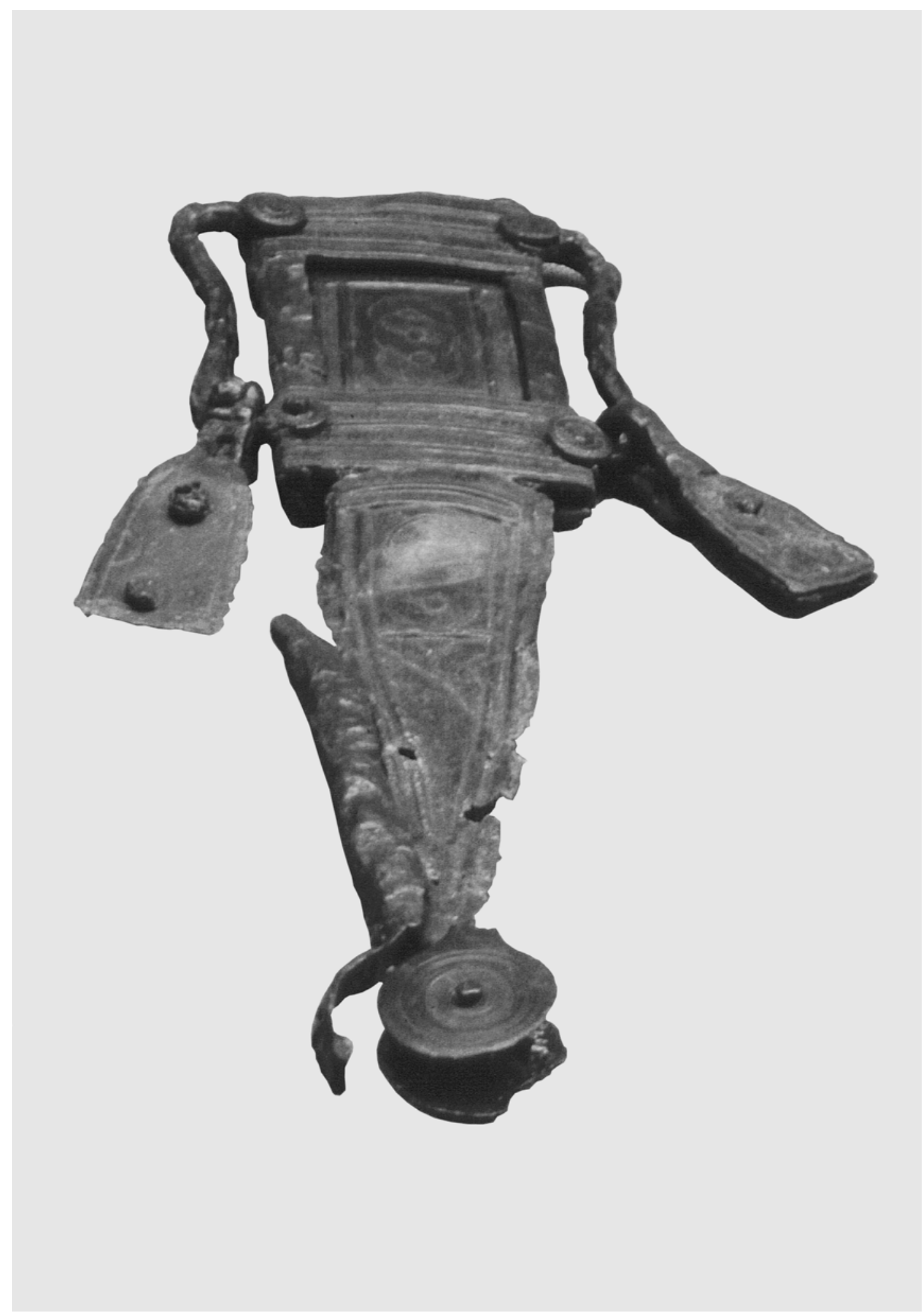

Lám. III. Puñal tipo III de la tumba 33. 


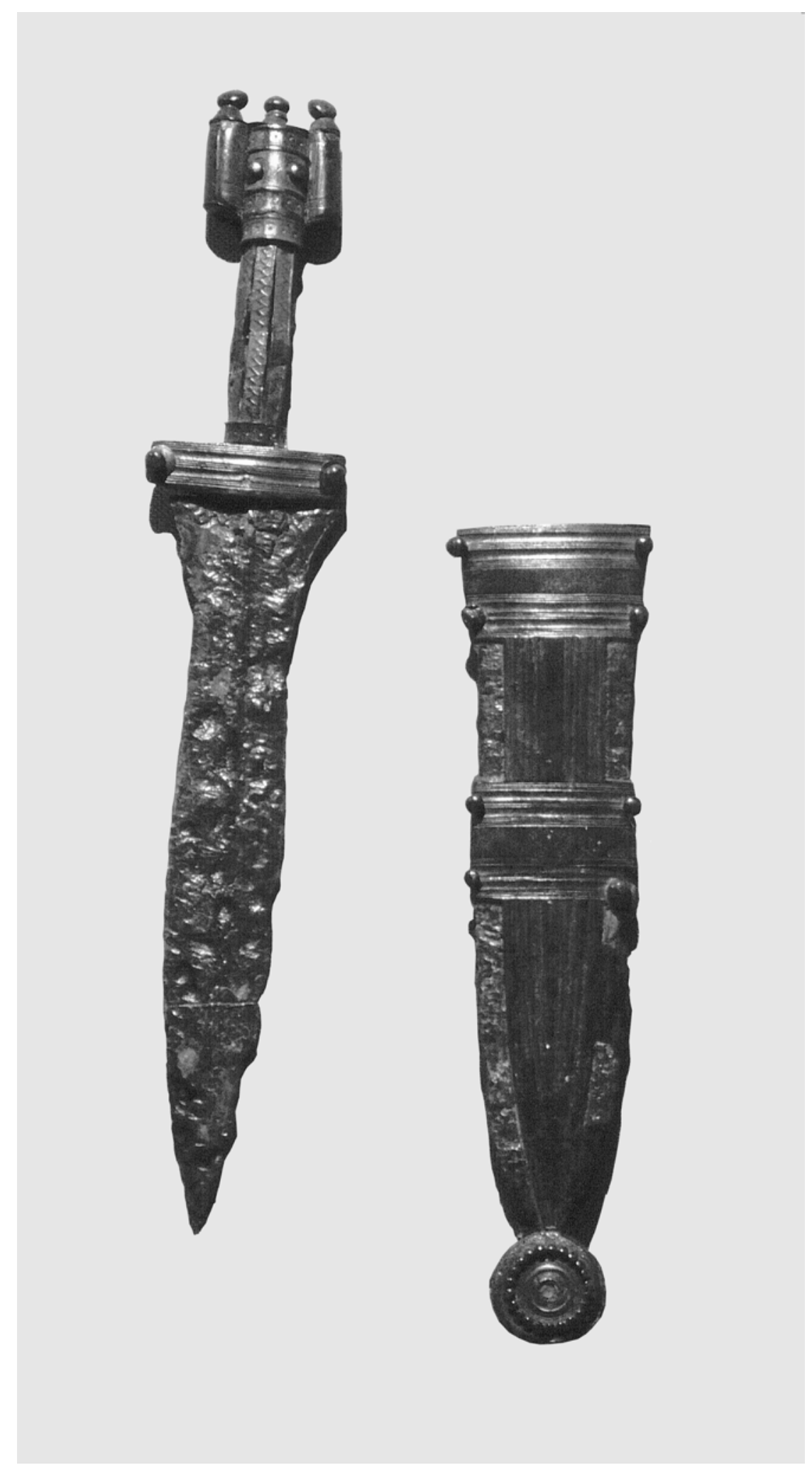

Lám. IV. Puñal tipo IV de la tumba 11. 


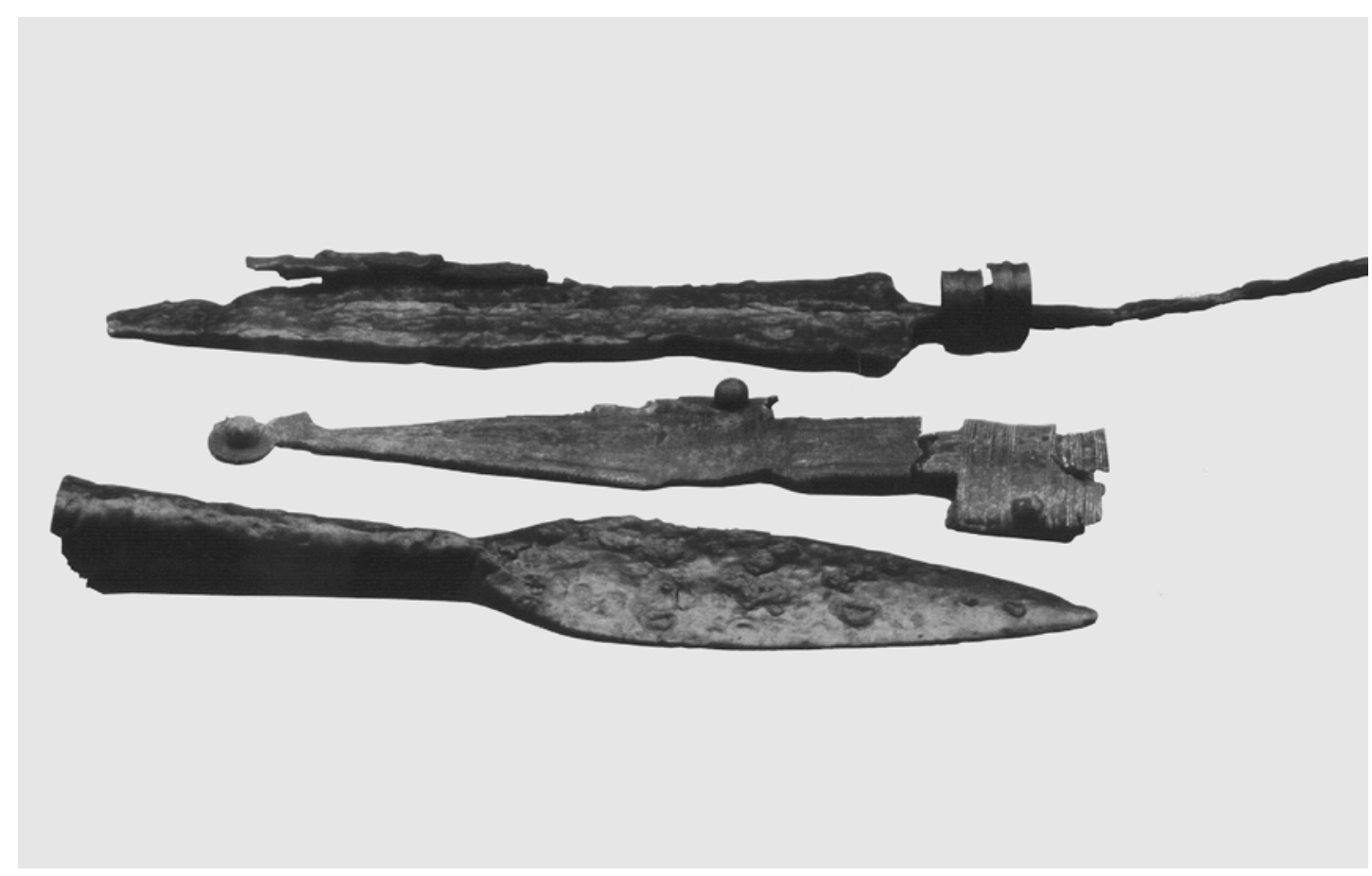

Lám. V. Puñal tipo IV de la tumba 15.

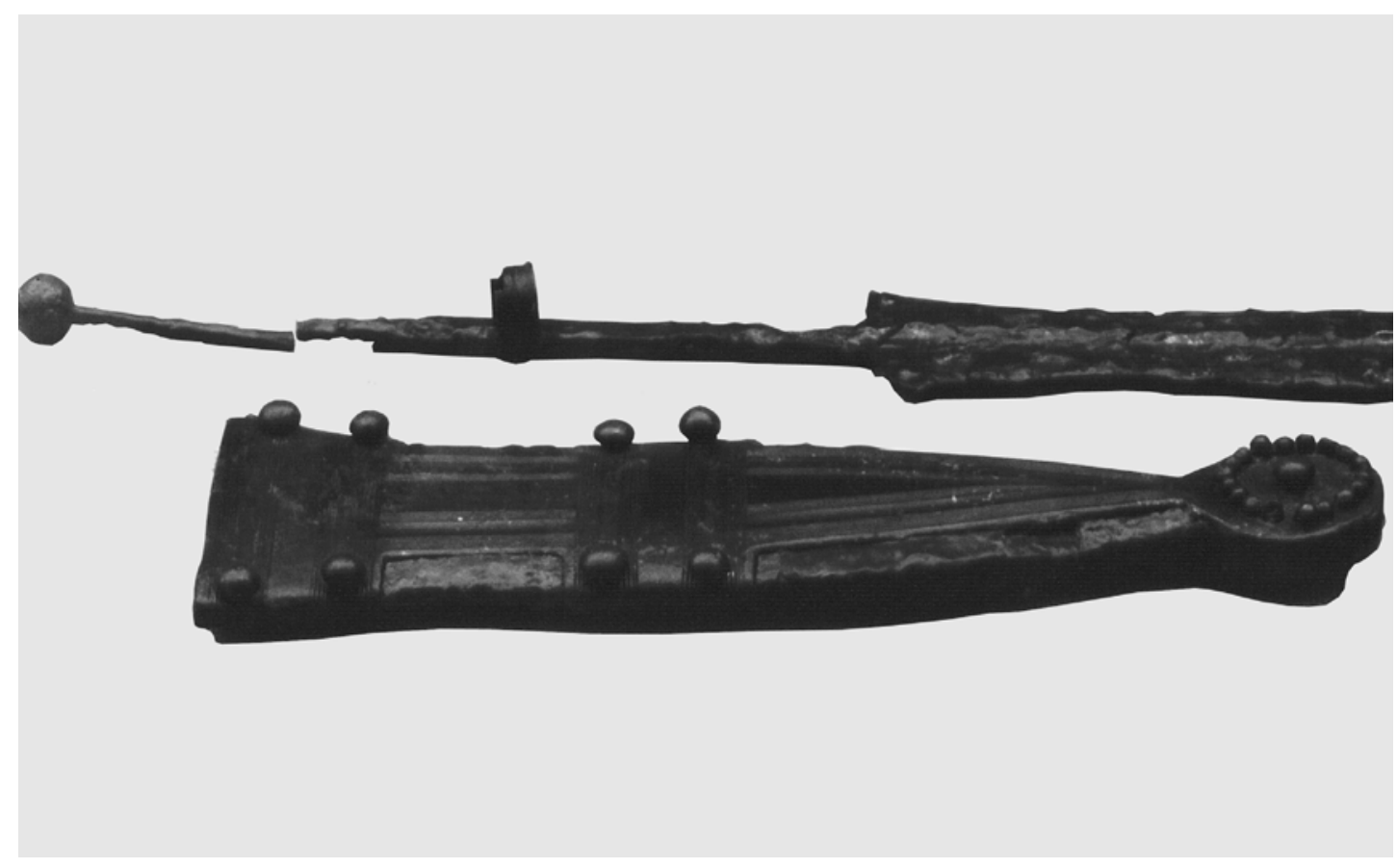

Lám. VI. Puñal tipo IV de la tumba 17. 


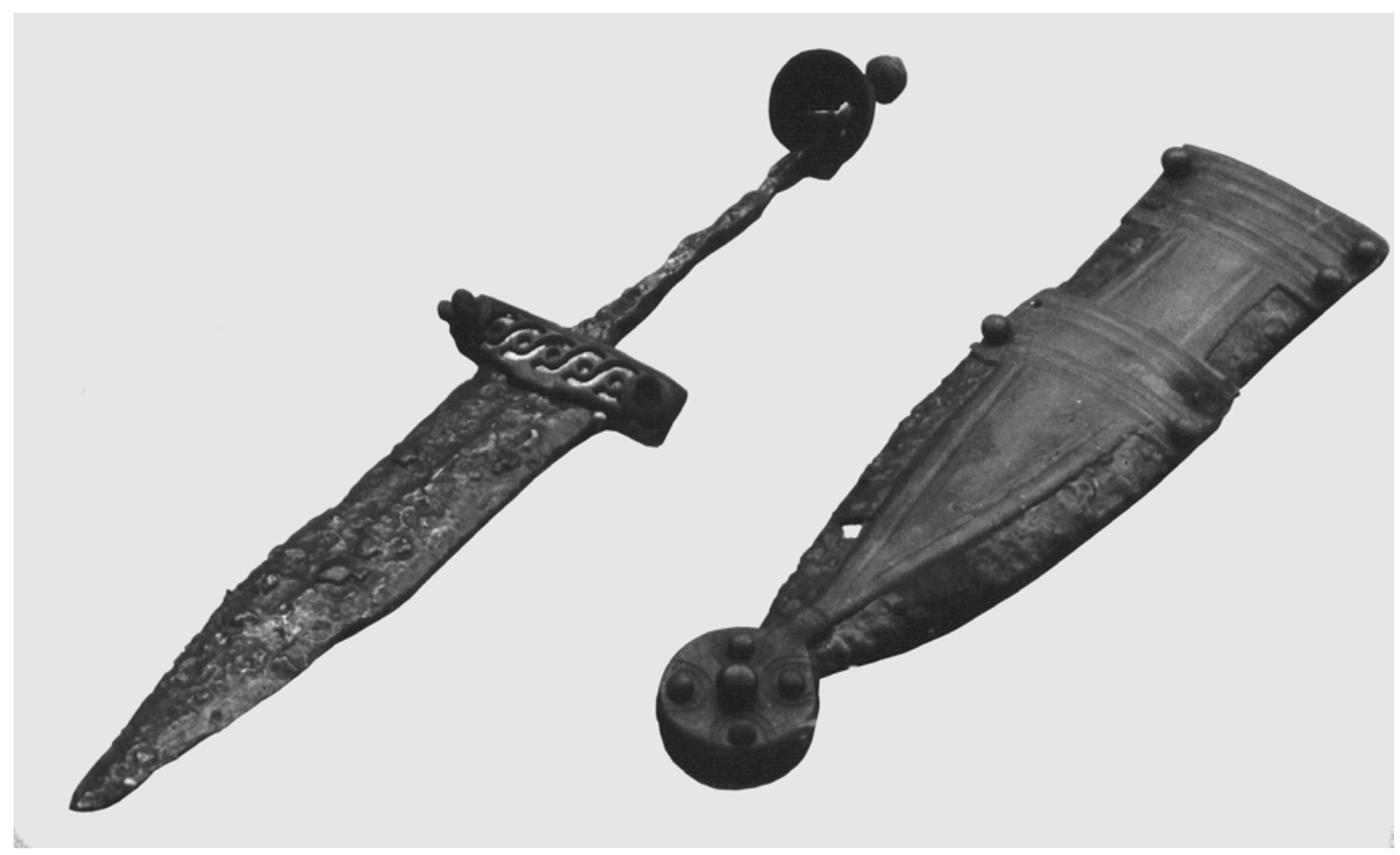

Lám. VII. Otro puñal tipo IV de la tumba 17.

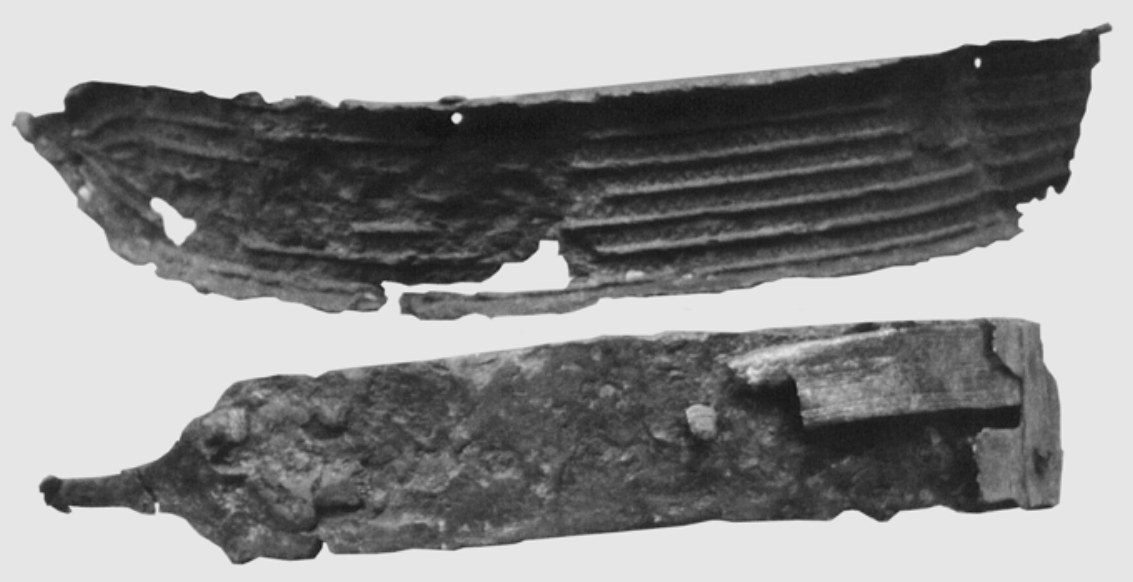

Lám. VIII. Placas de cinturón de la tumba 22. 


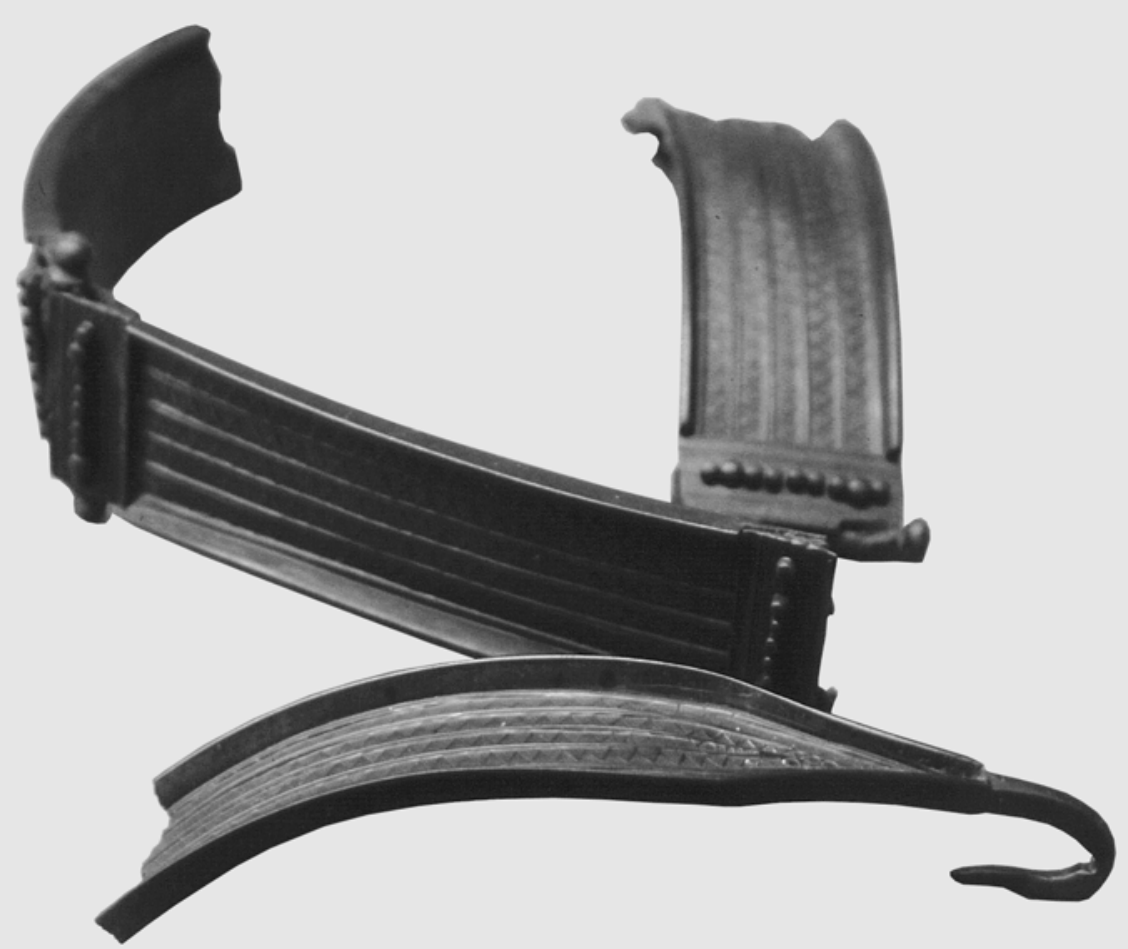

Lám. IX. Placas de cinturón de la tumba 26. 


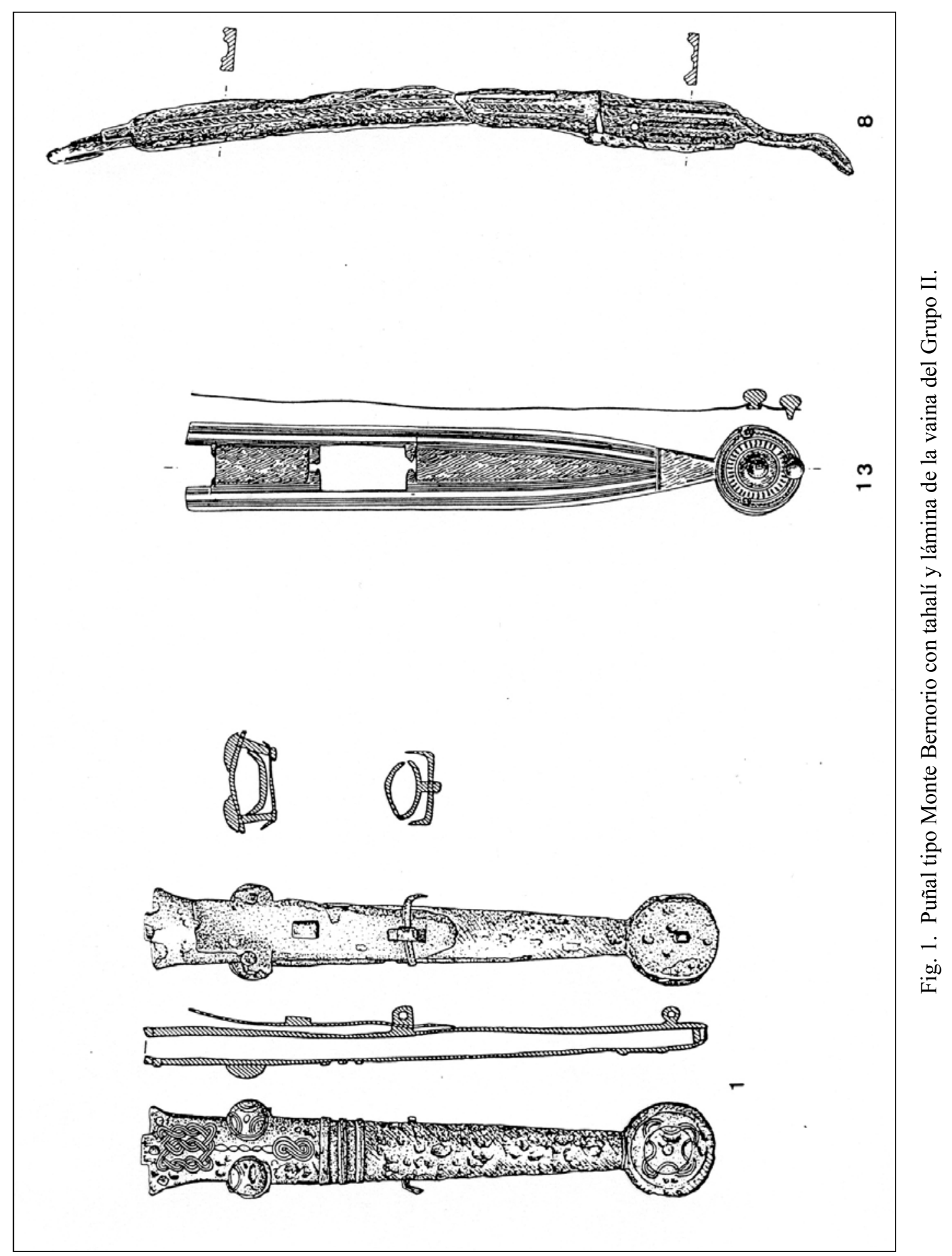




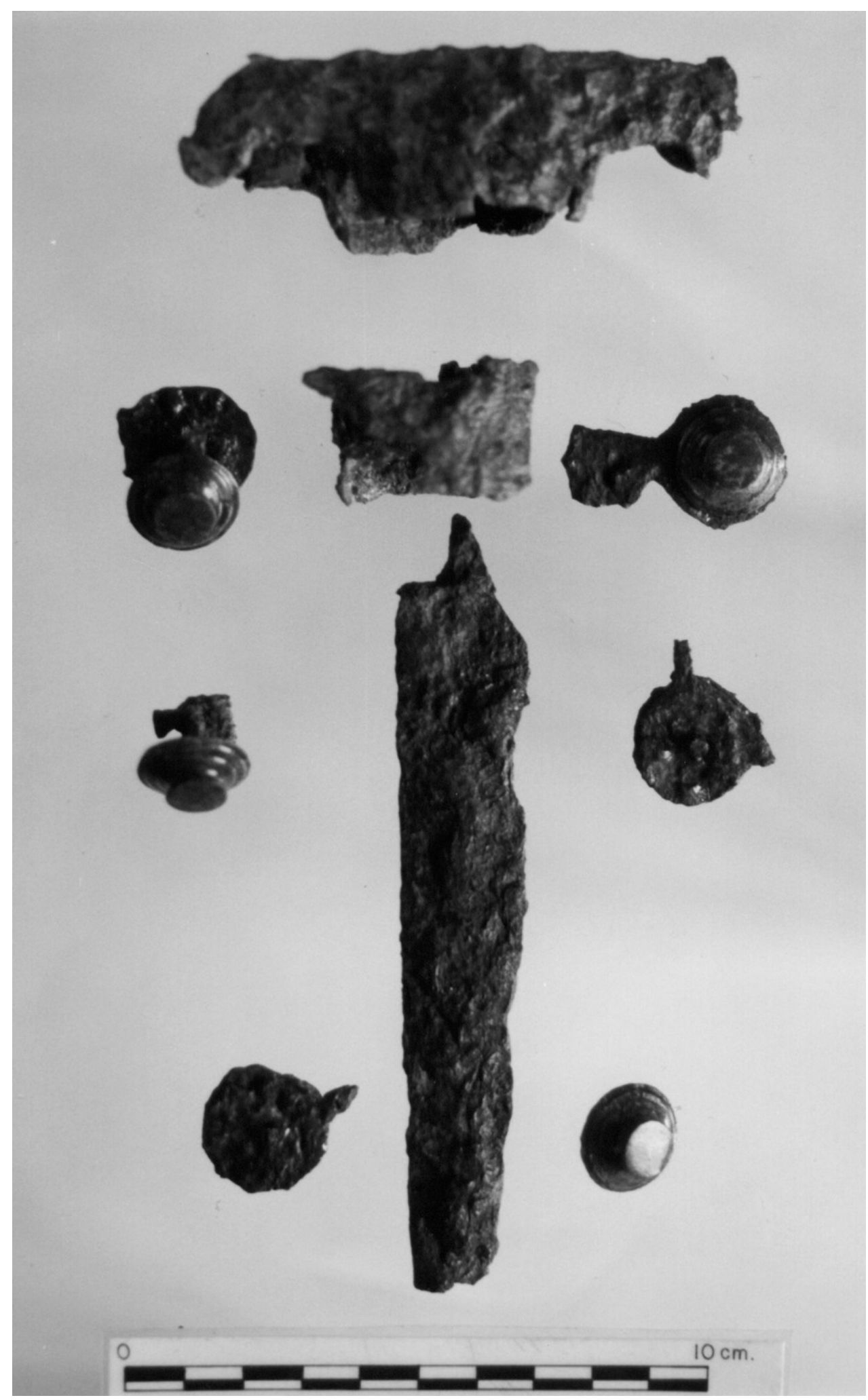

Fig. 2. Puñal tipo Monte Bernorio de la tumba 22. 


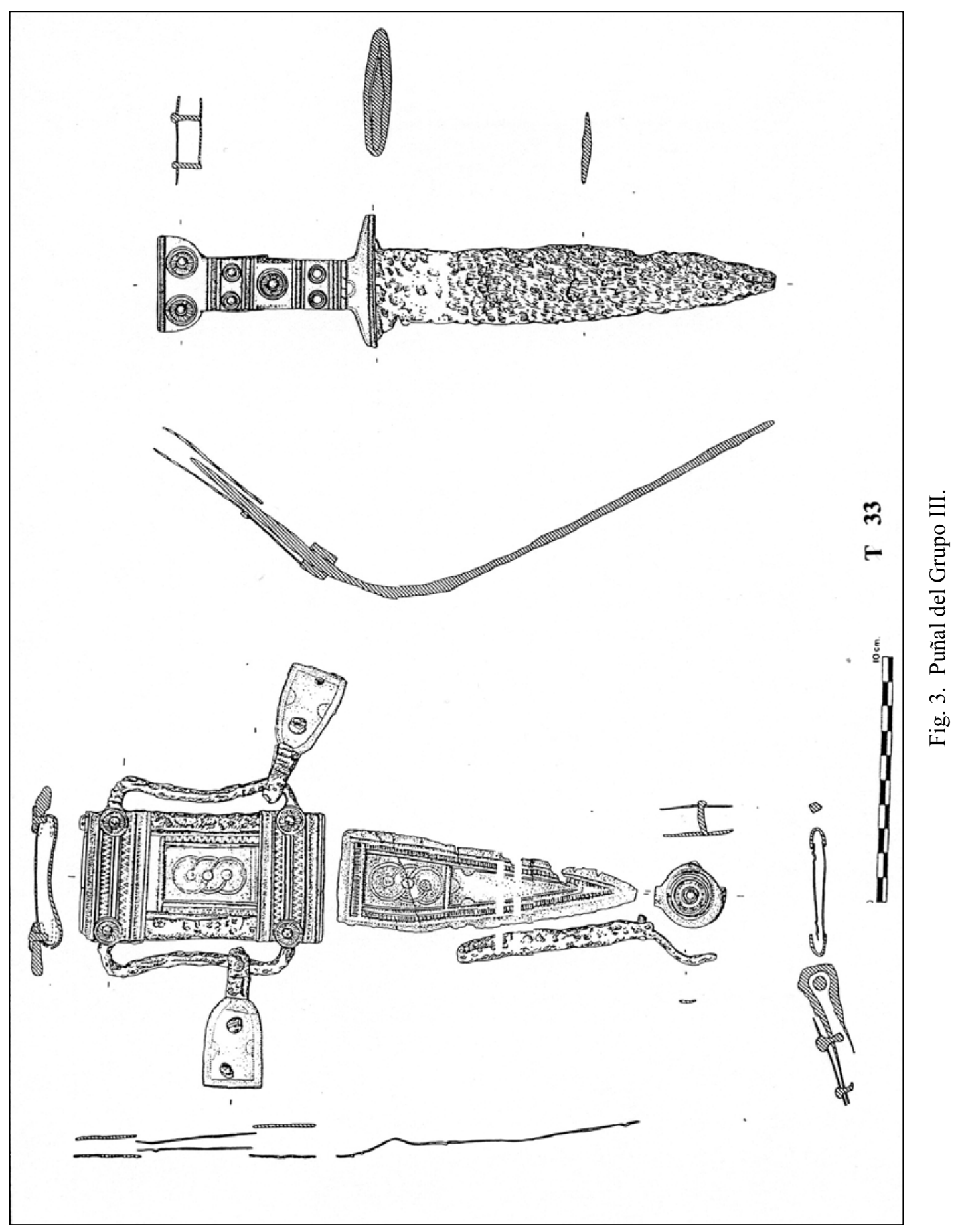




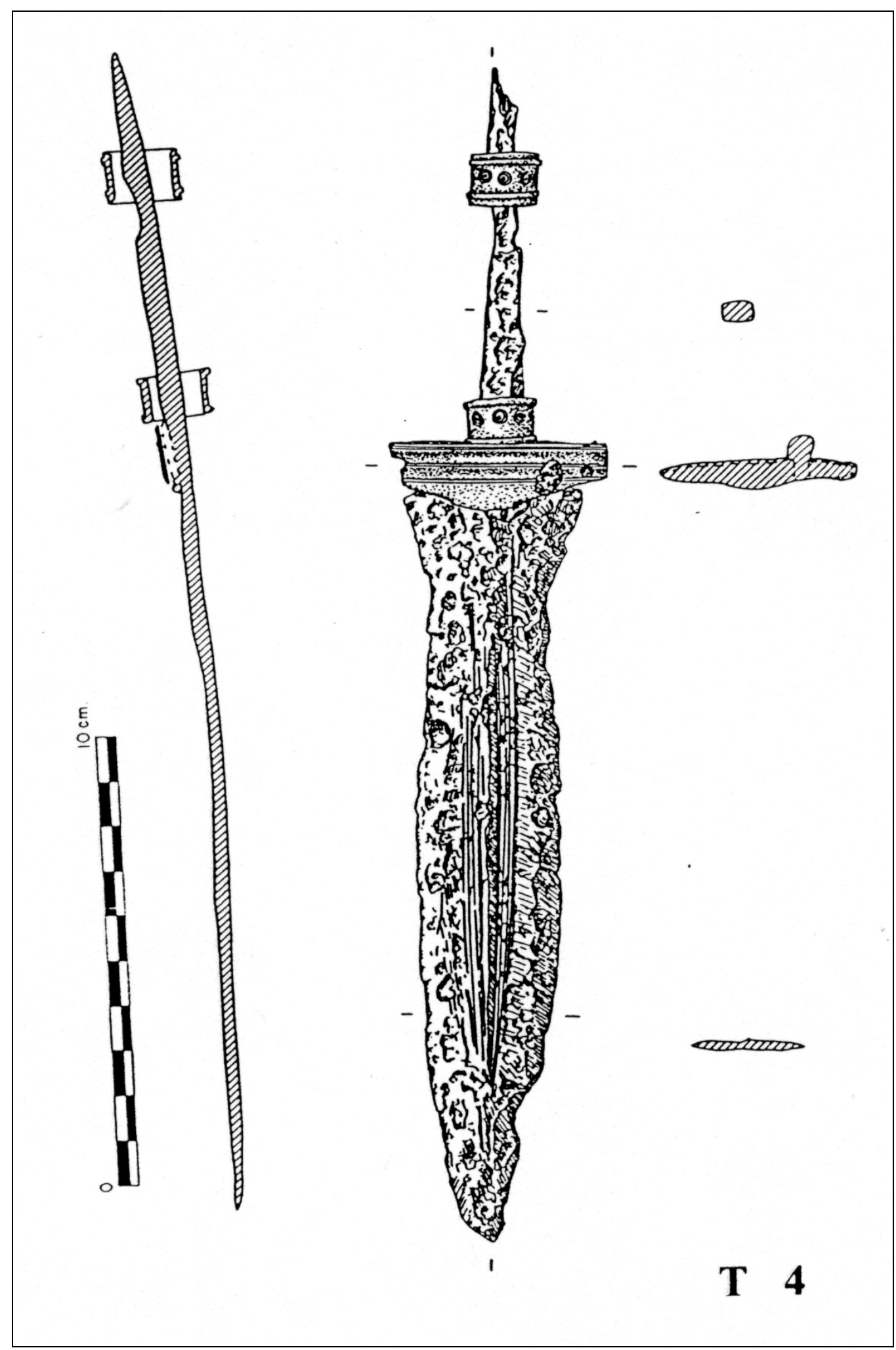

Fig. 4. Puñal del Grupo IV, tumba 4. 

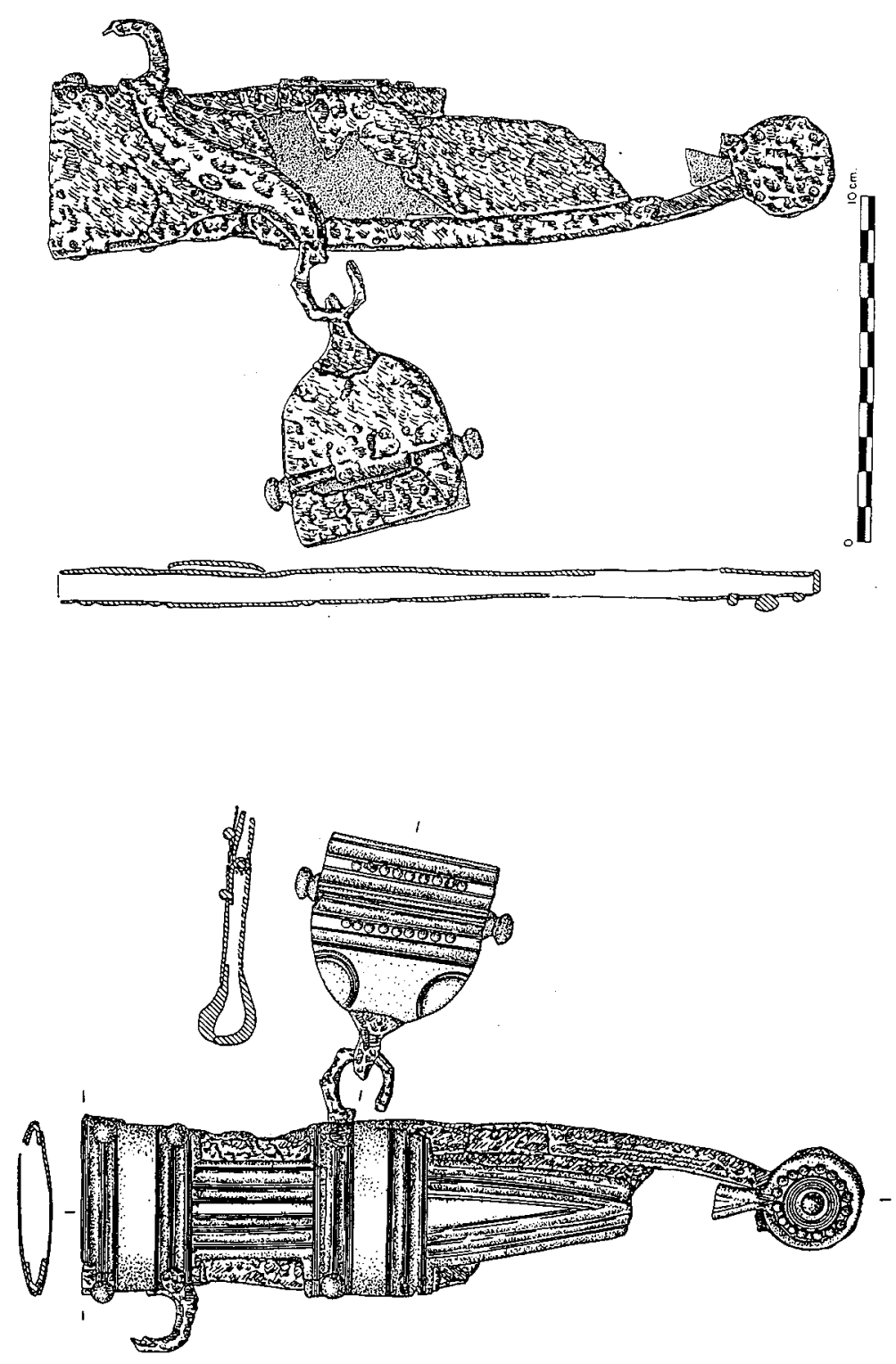

草 


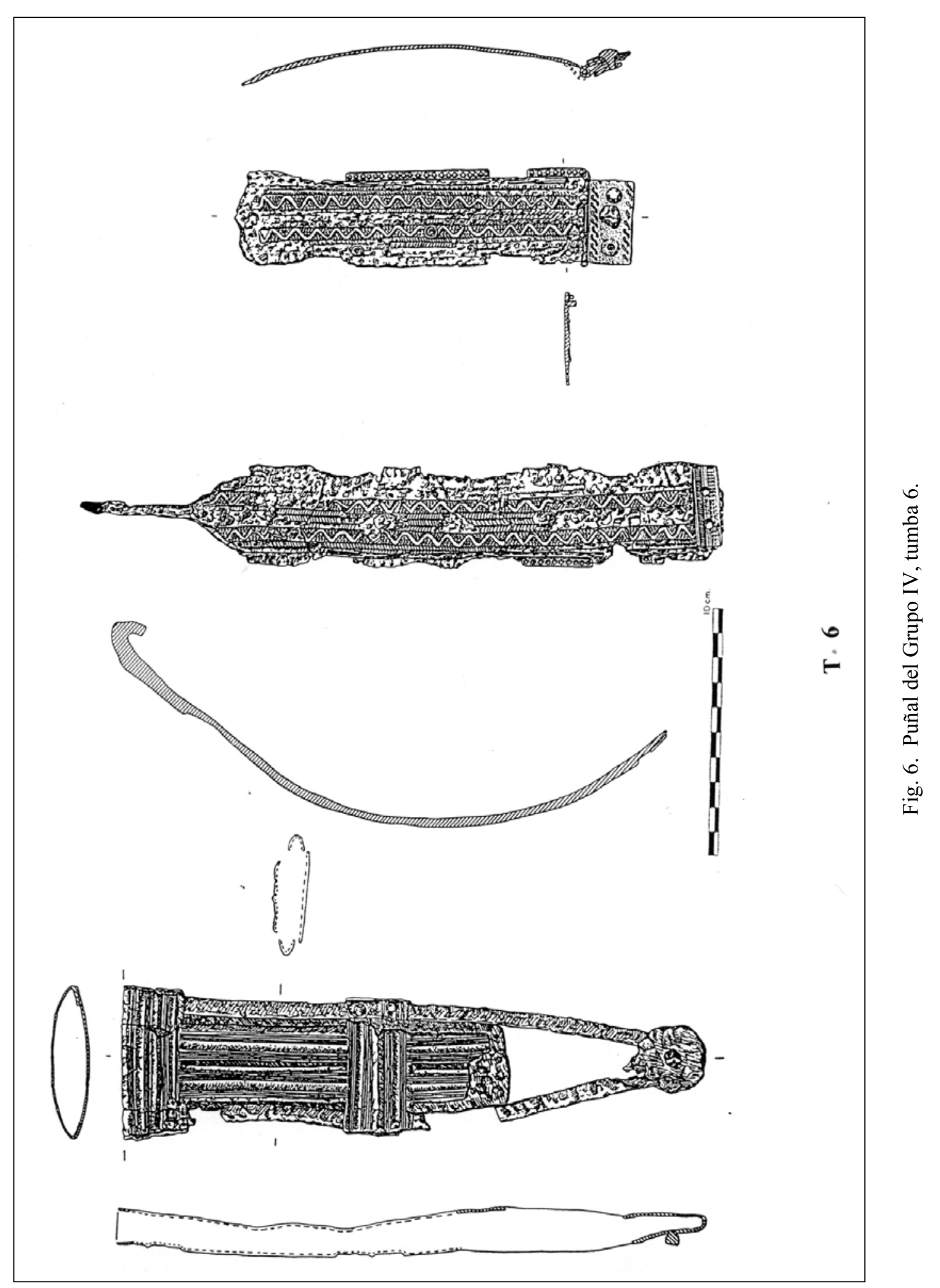




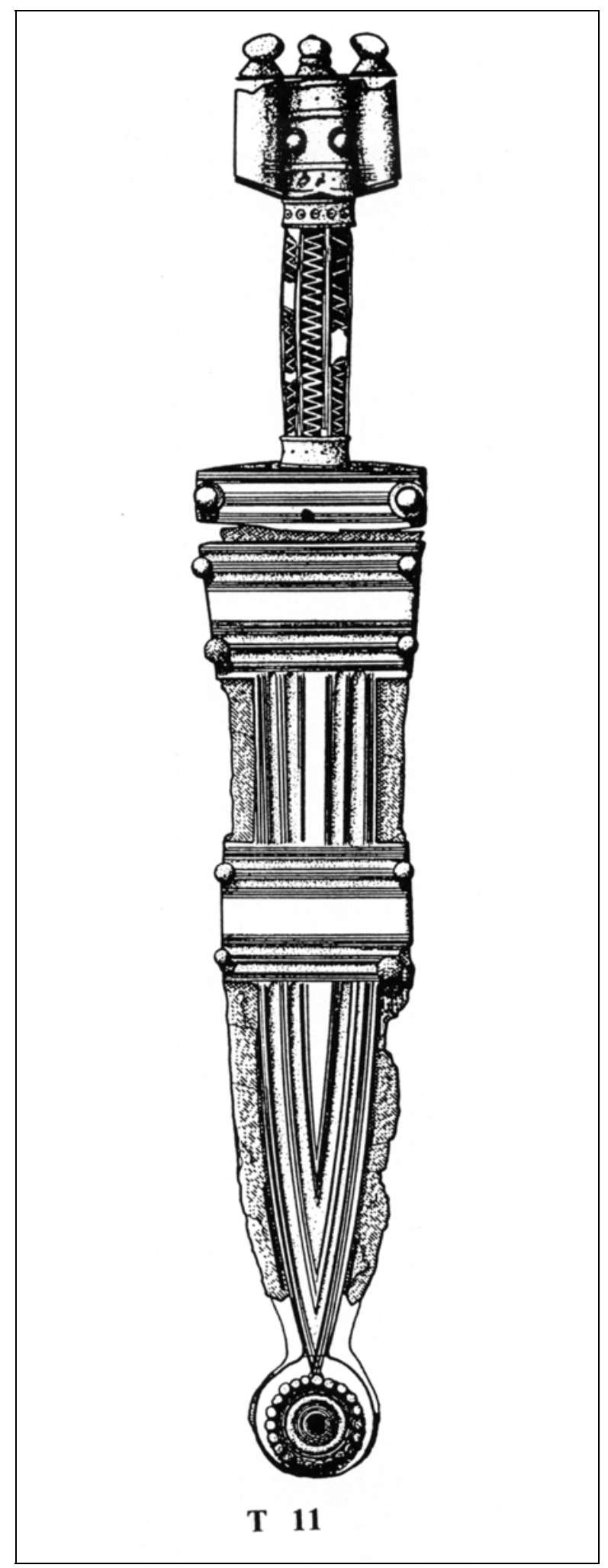

Fig. 7. Puñal del Grupo IV, tumba 11. 


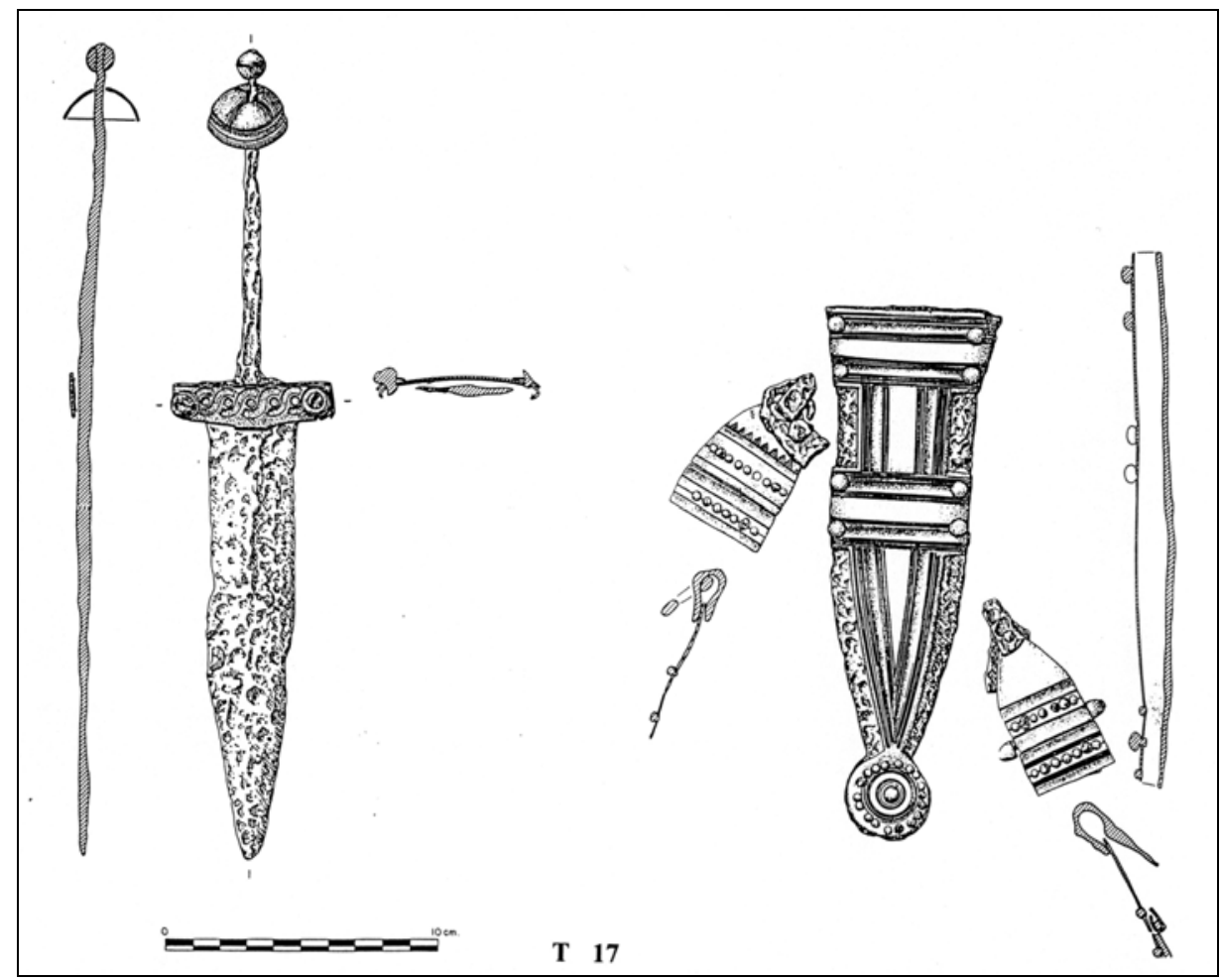

Fig. 8. Puñal del Grupo IV, tumba 17.

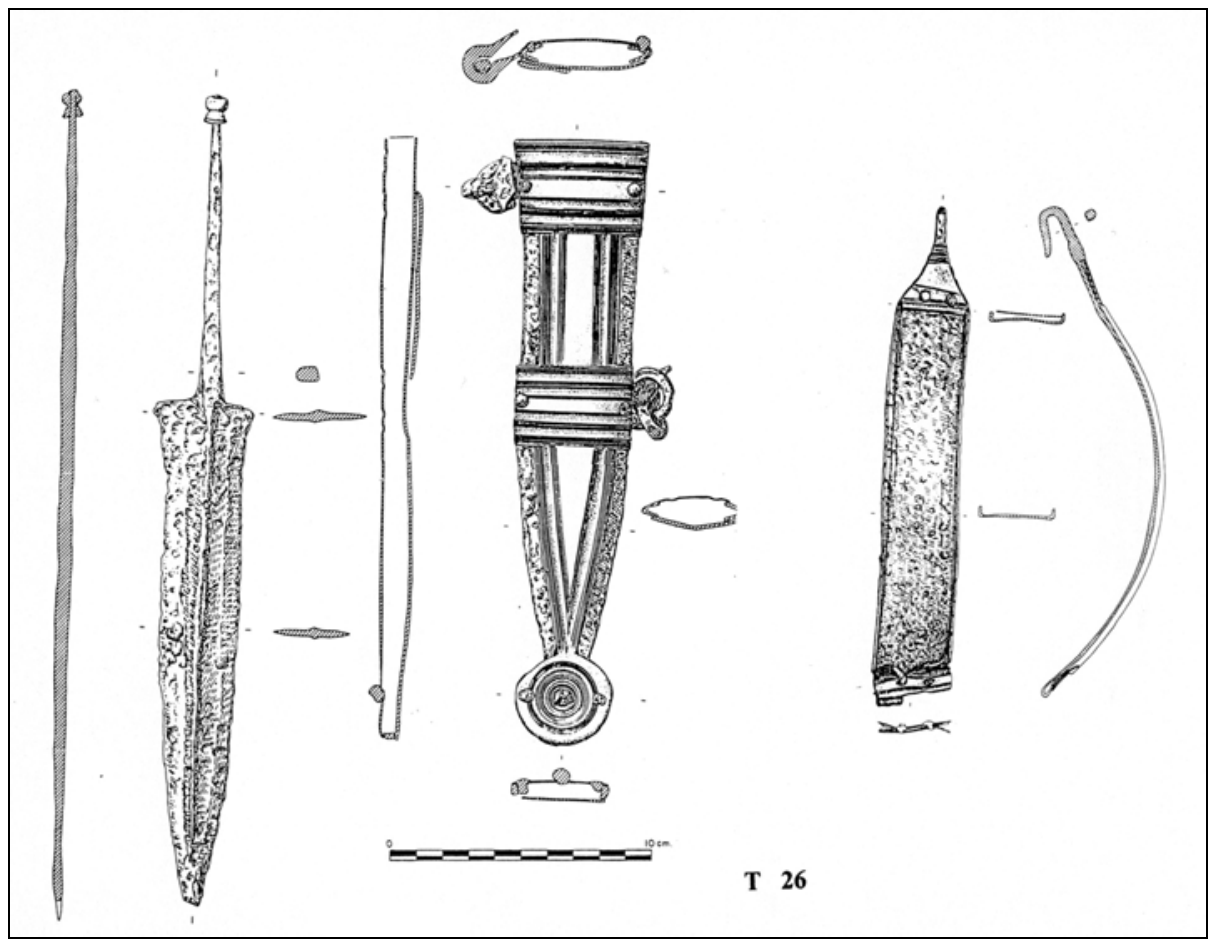

Fig. 9. Puñal de Grupo IV, tumba 26. 


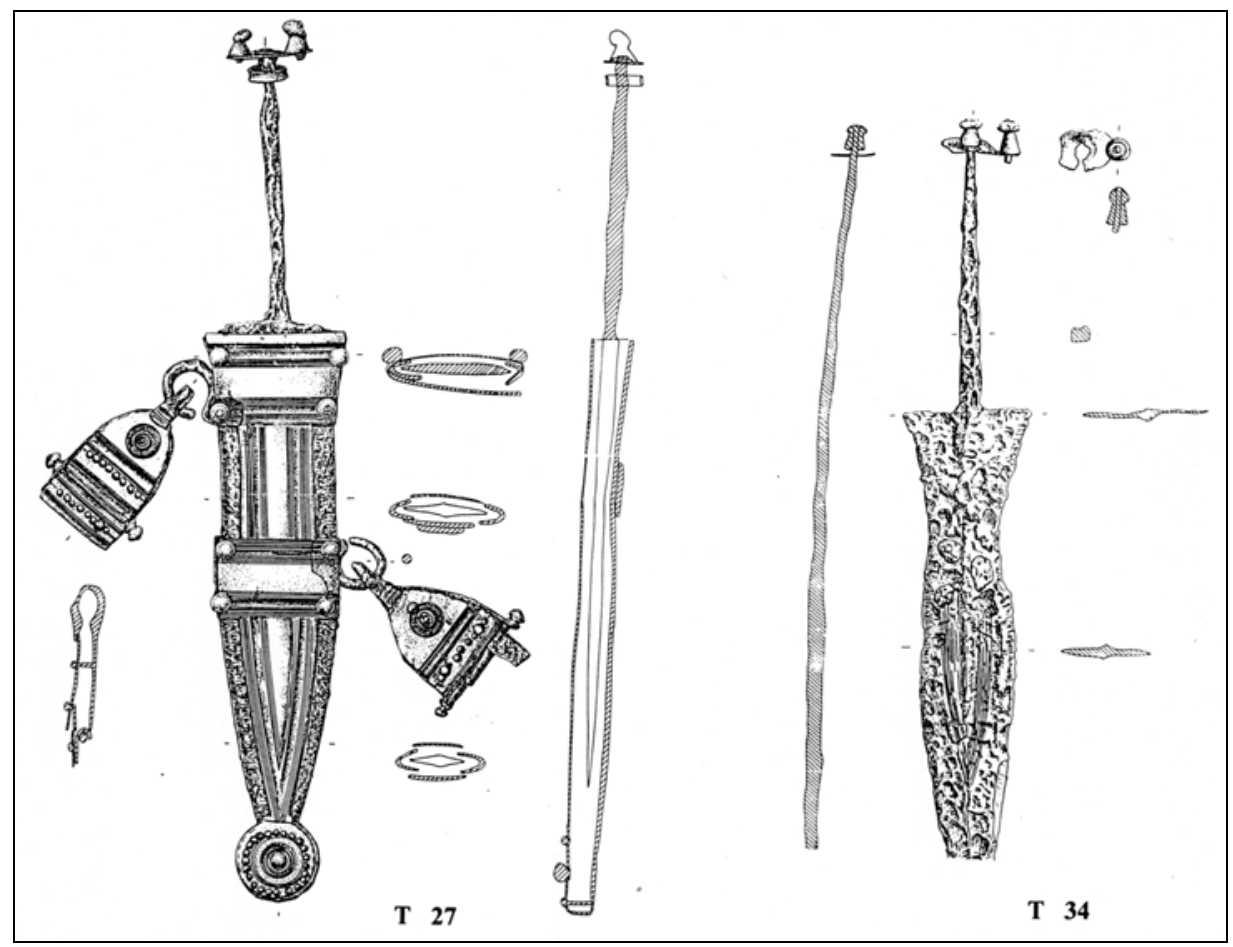

Fig. 10. Puñal del Grupo IV, tumbas 27 y 34 .

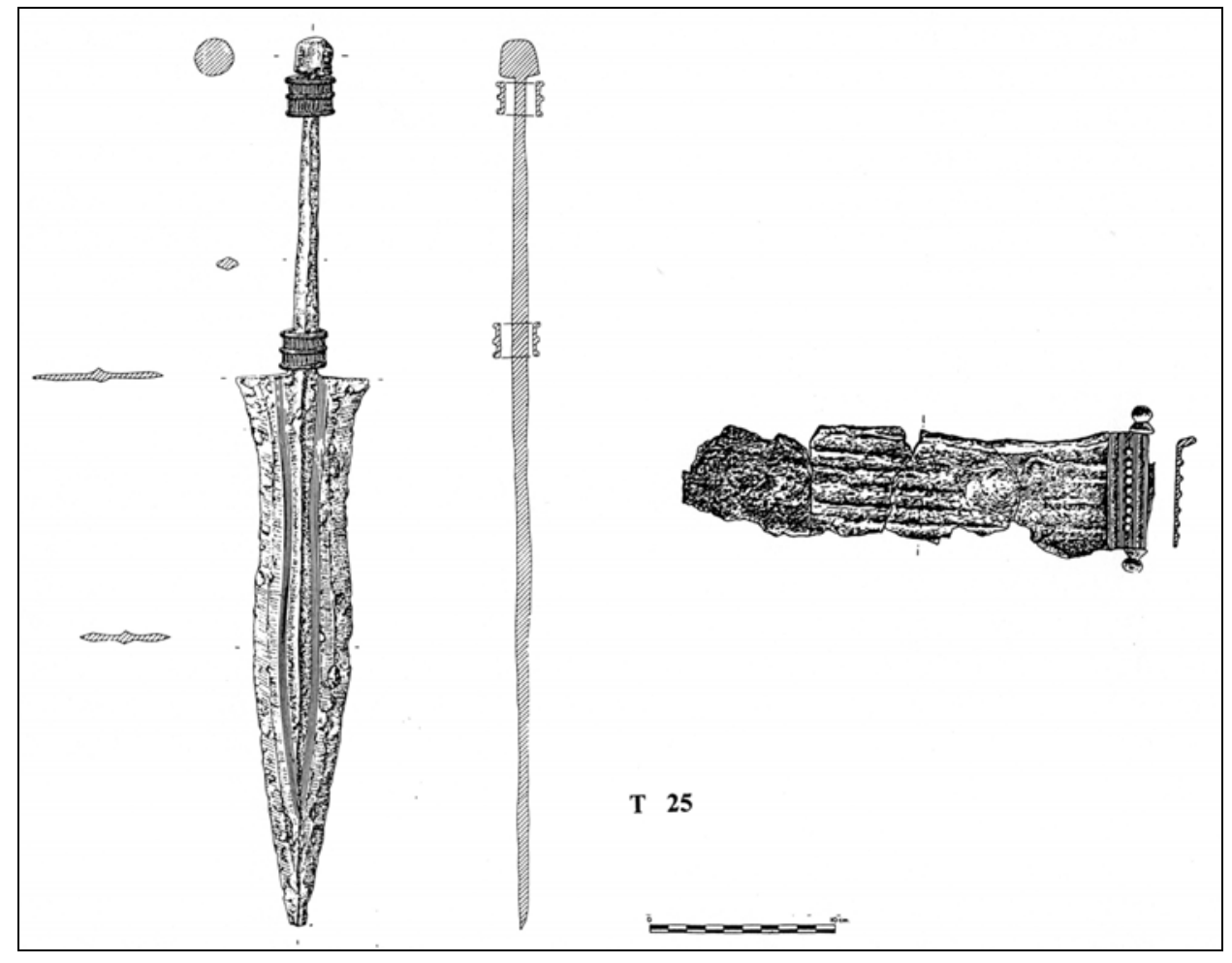

Fig. 11. Puñal del Grupo IV, tumba 25. 


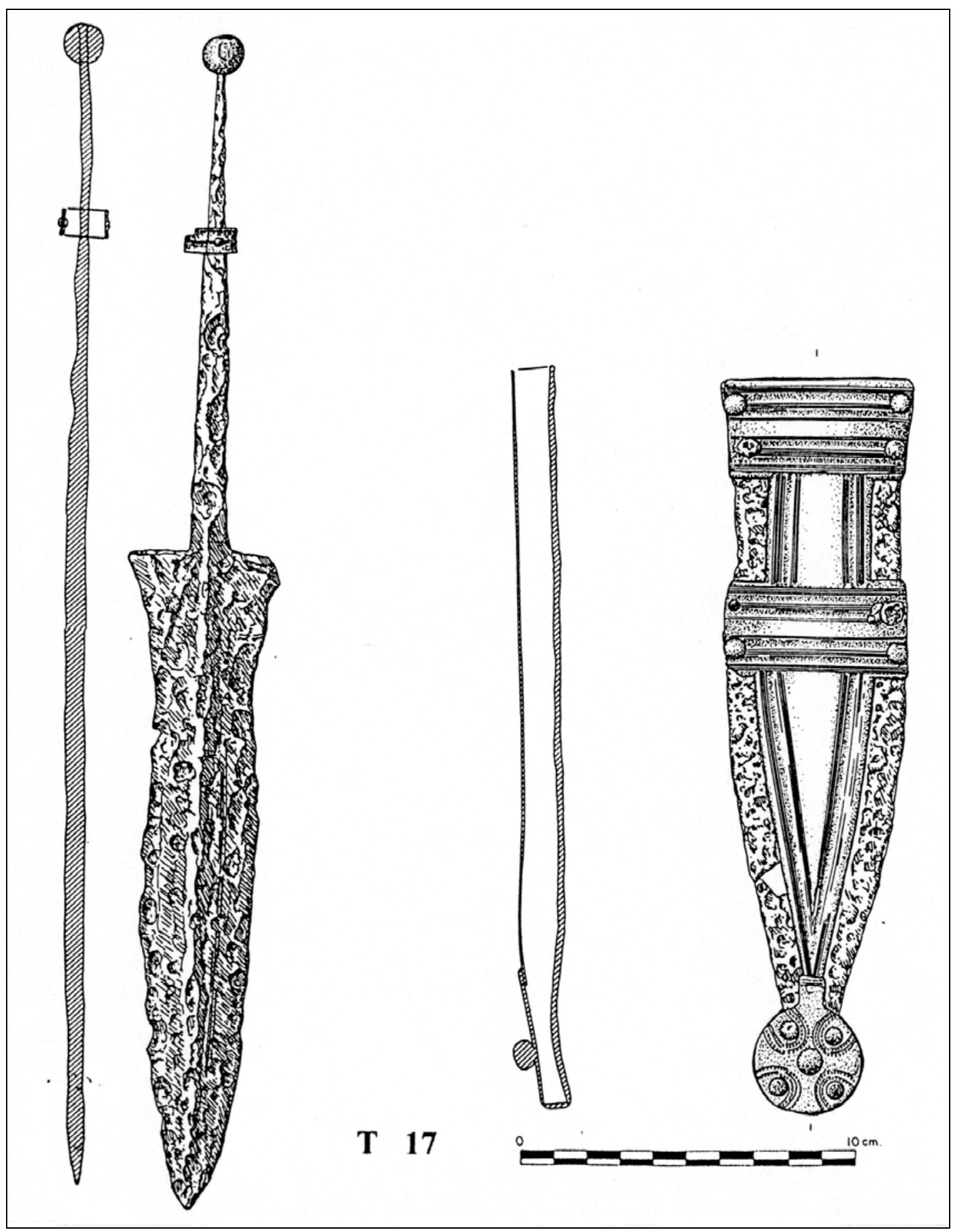

Fig. 12. Puñal de la tumba 17. 


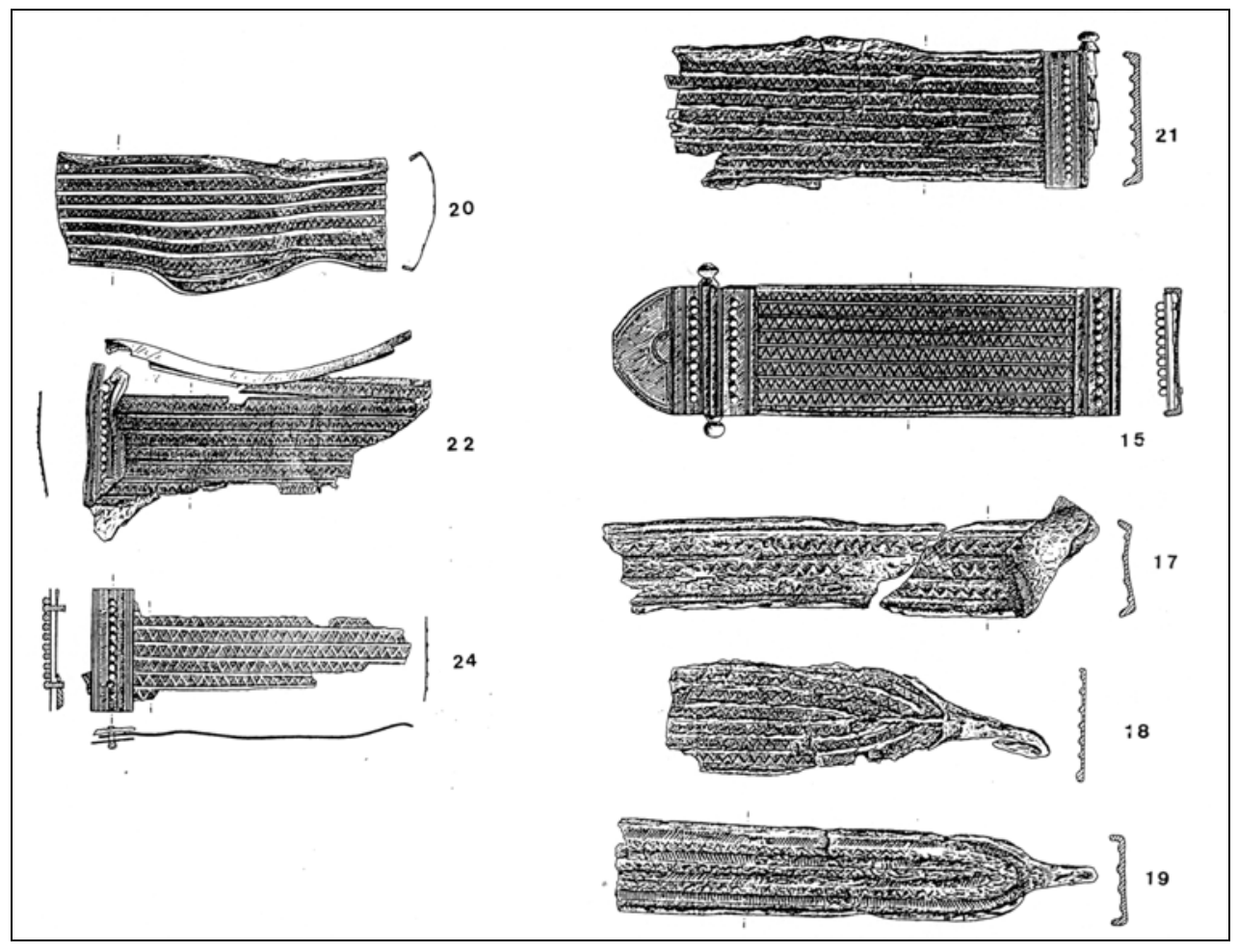

Fig. 13. Placas del cinturón del puñal.

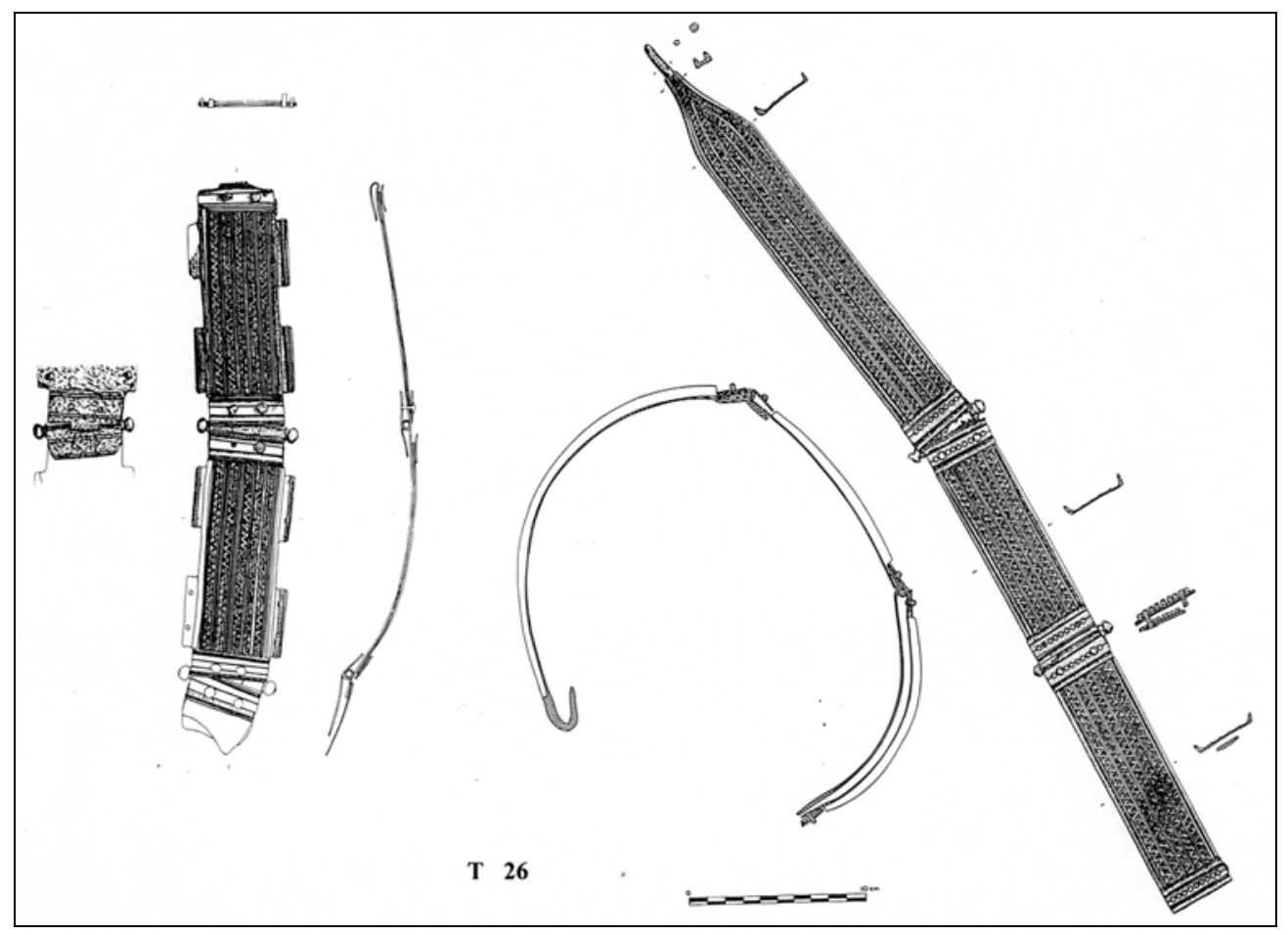

Fig. 14. Placas del cinturón de la tumba 26. 


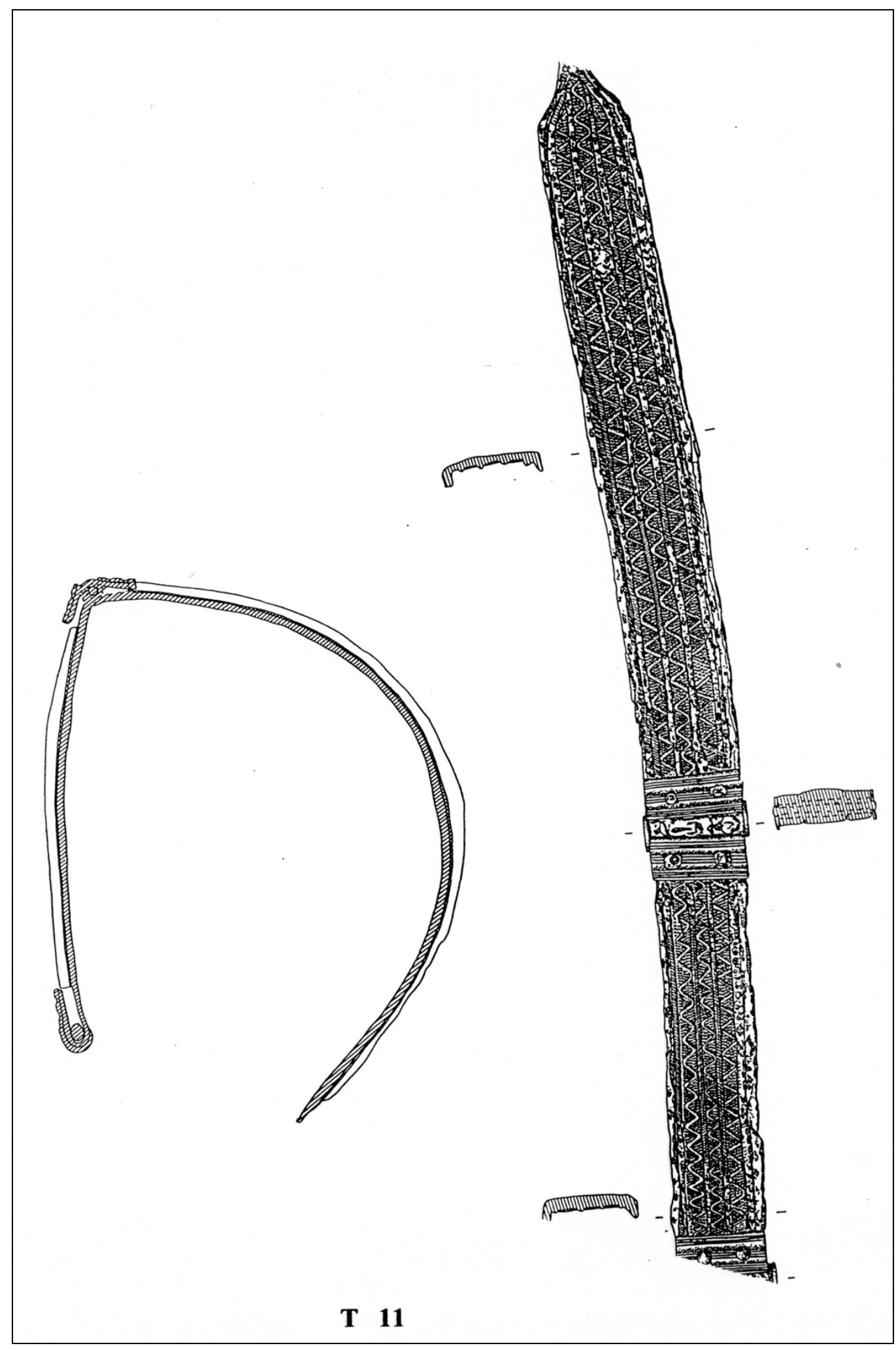

Fig. 15. Placas del cinto de la tumba 11. 


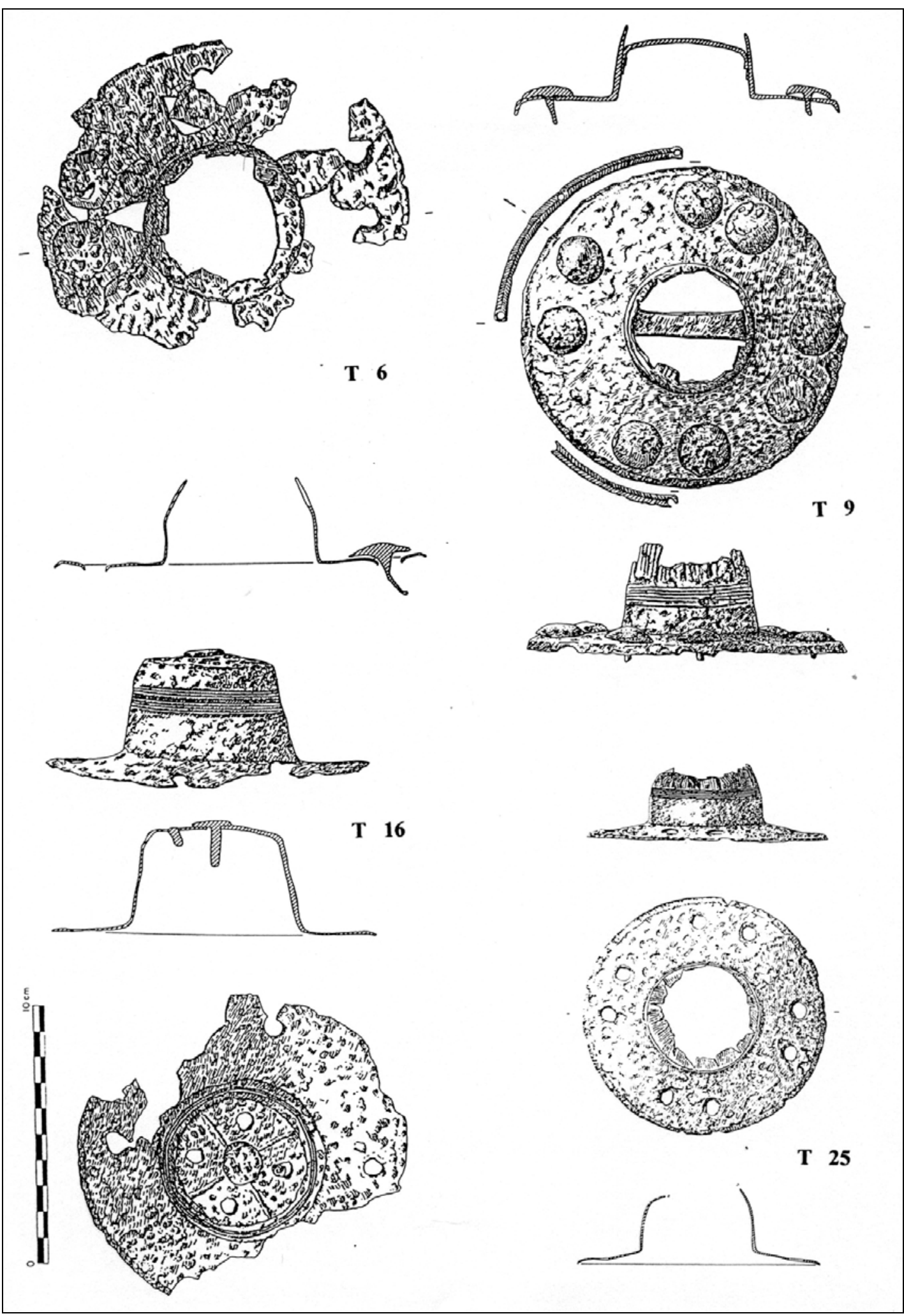

Fig. 16. Umbos de diferentes tumbas. 


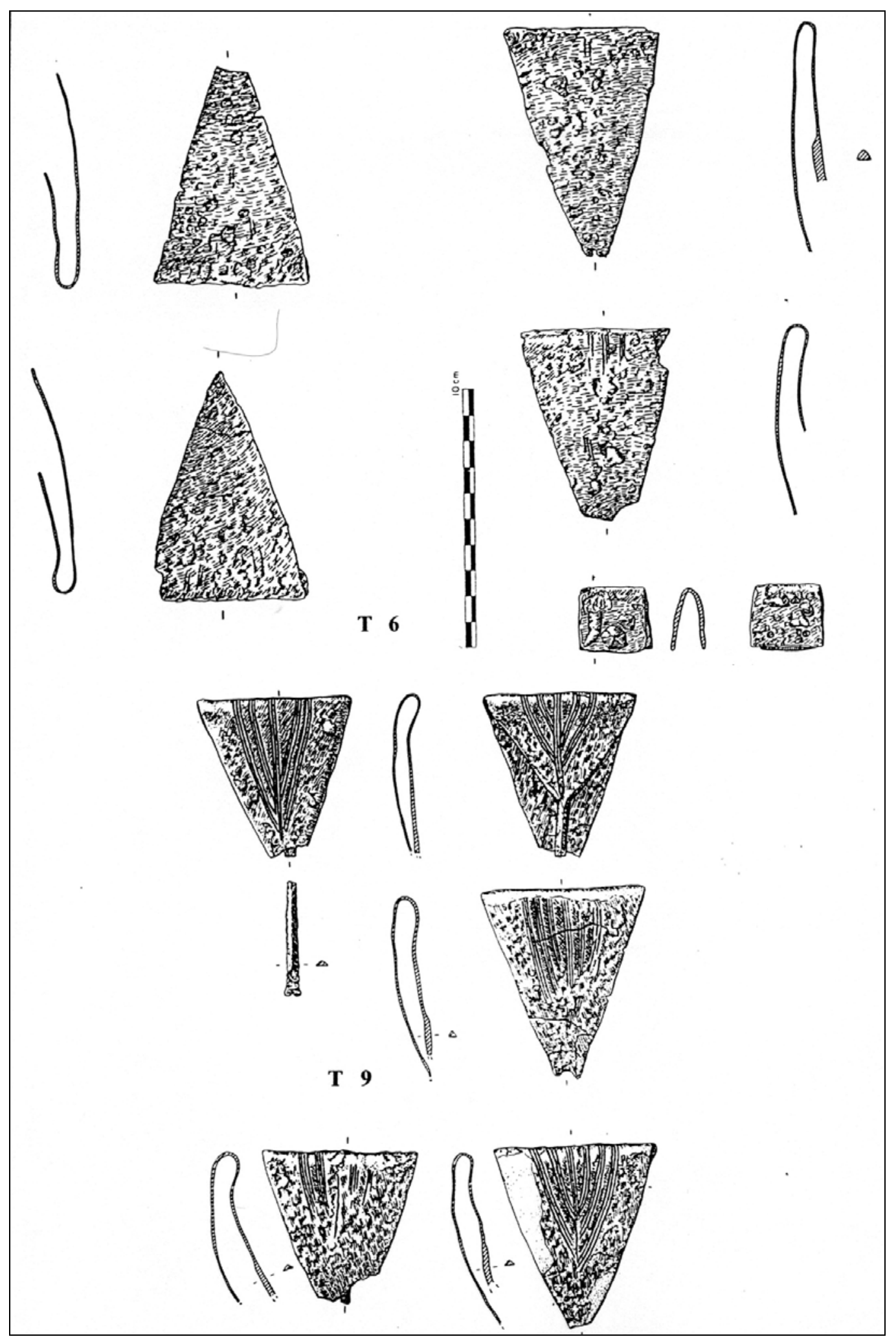

Fig. 17. Terminales de radio de las tumbas 6 y 9. 


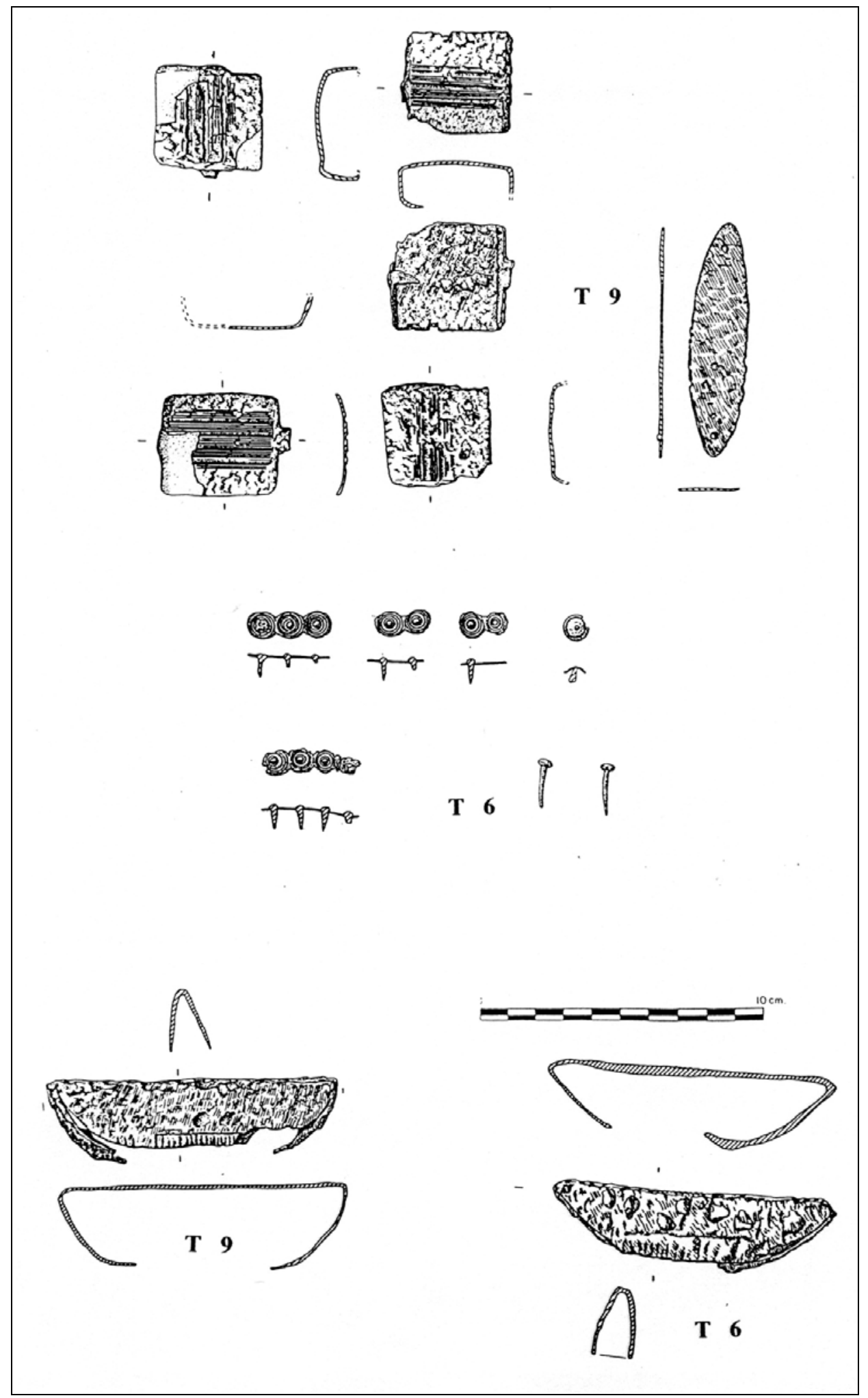

Fig. 18. Elementos del escudo. 


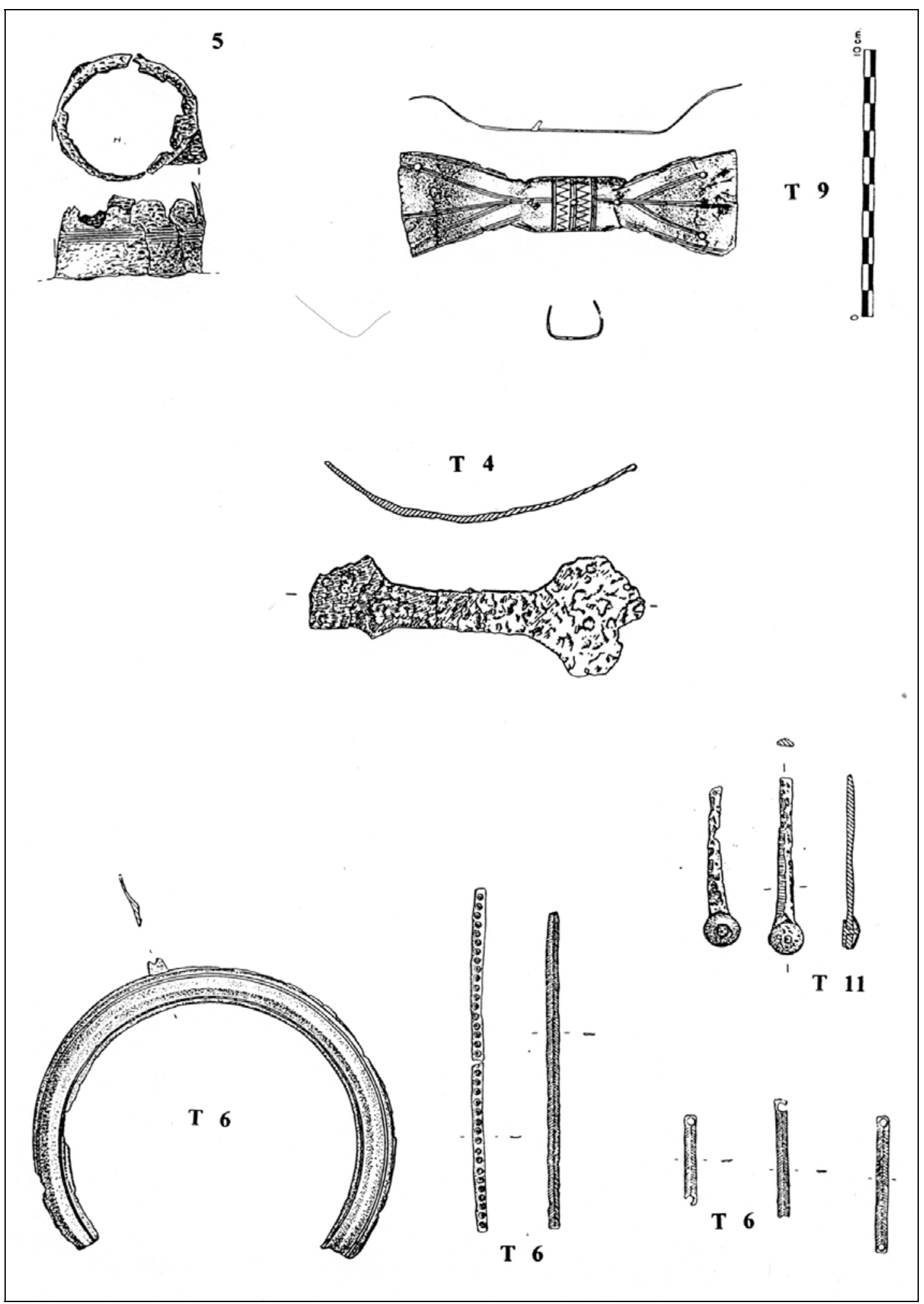

Fig. 19. Abrazaderas y otros elementos. 


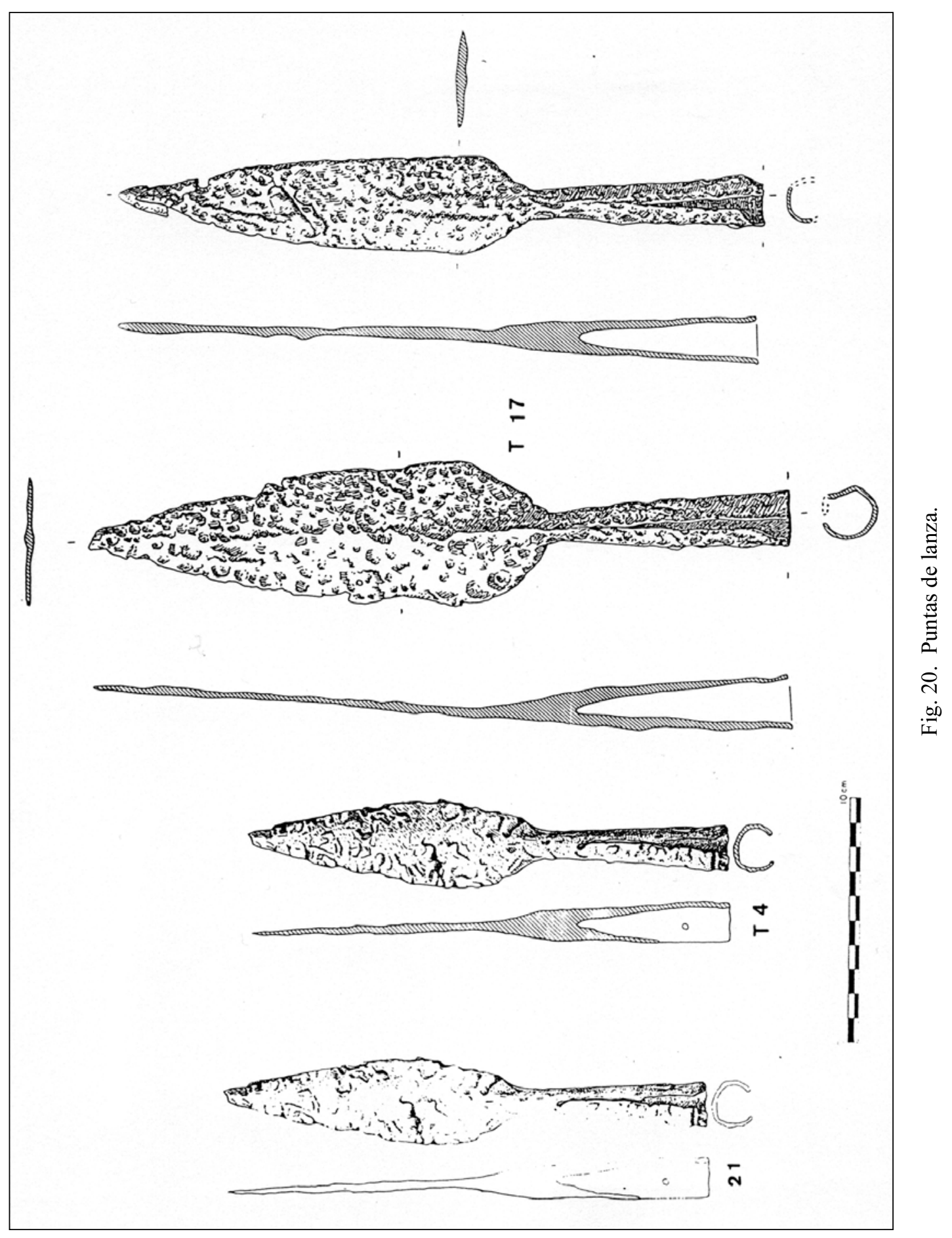


78

IGNACIO RUIZ VÉLEZ

Gladius XXV, 2005

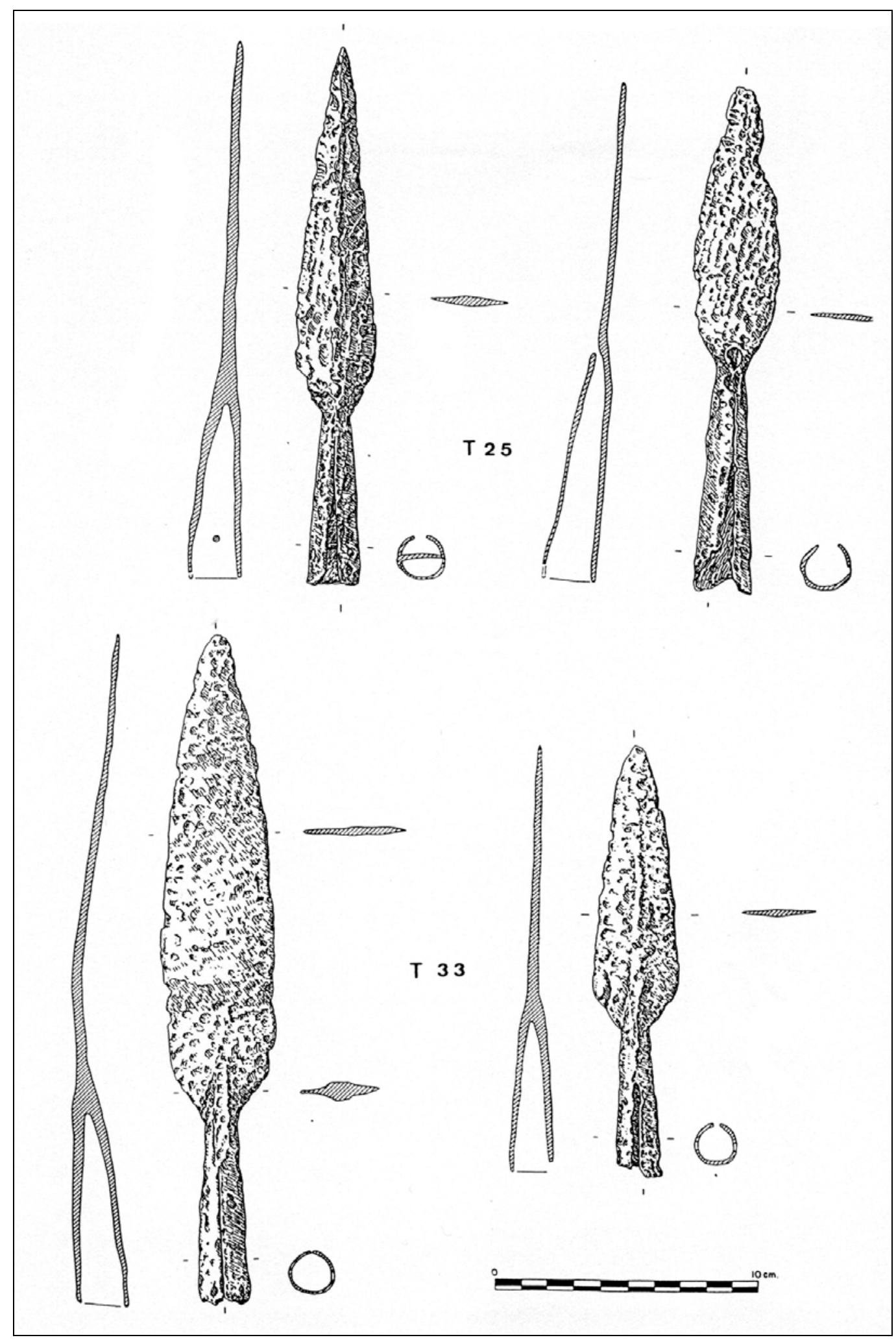

Fig. 21. Puntas de lanza. 


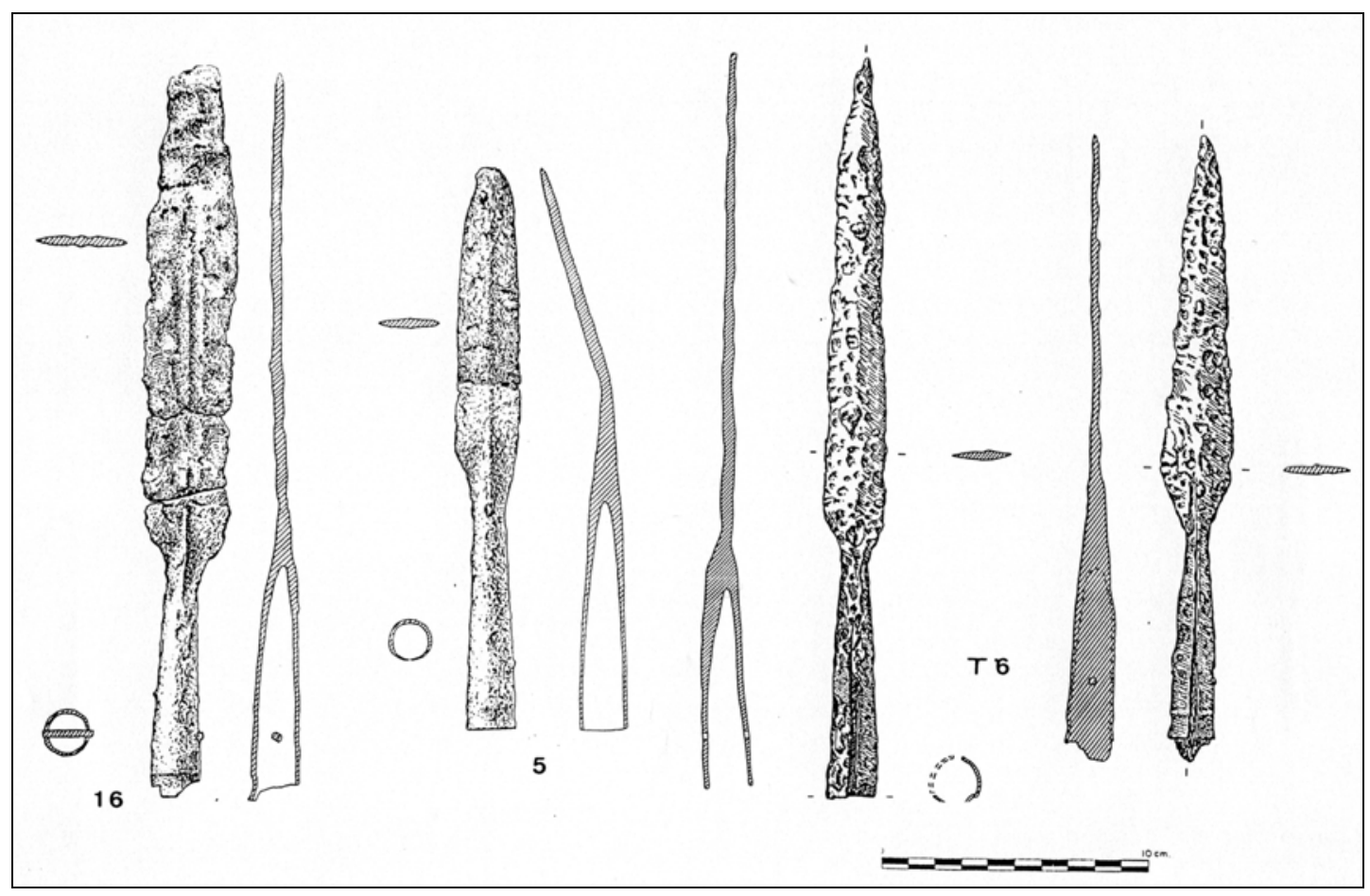

Fig. 22. puntas de lanza.

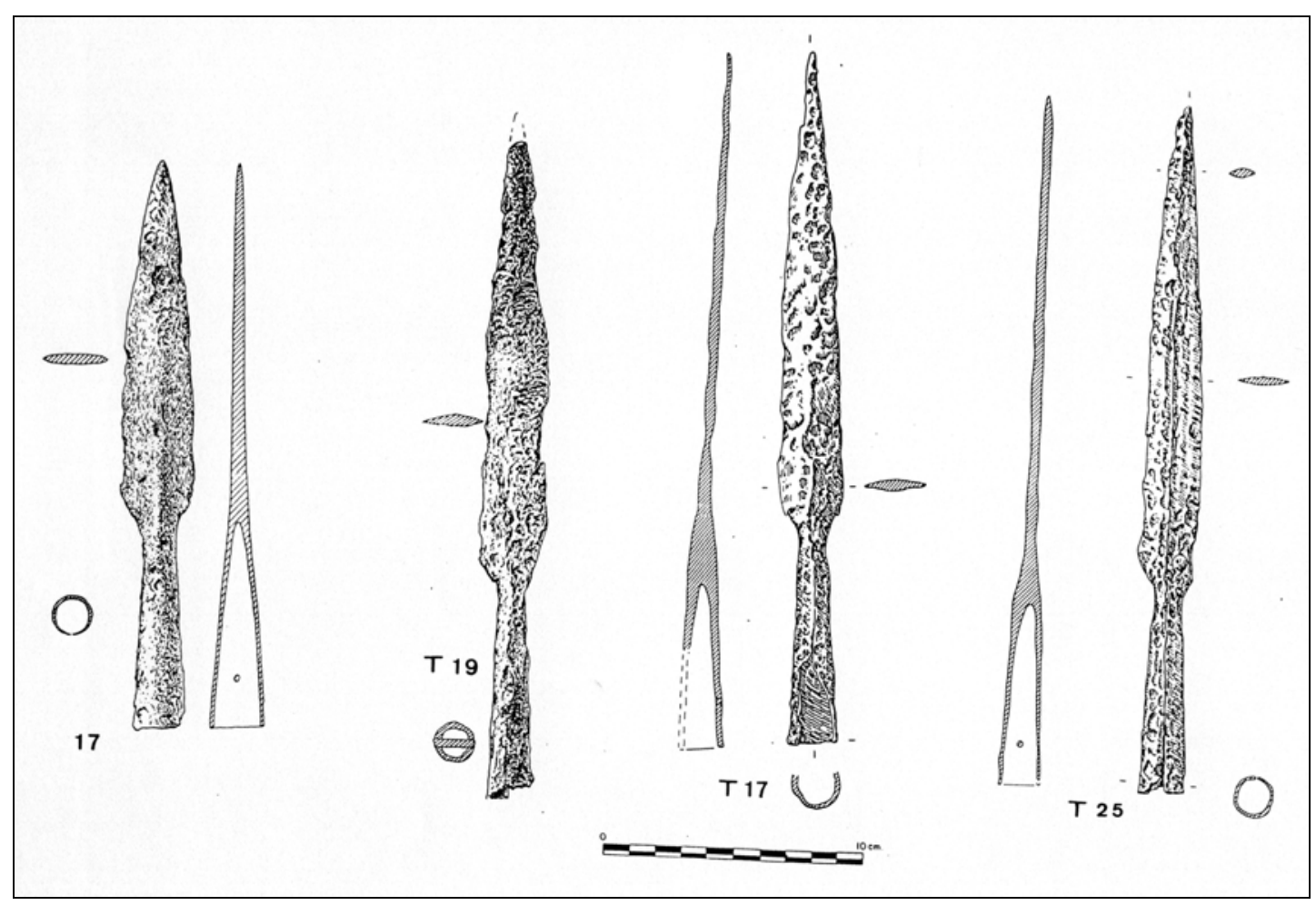

Fig. 23. Puntas de lanza. 


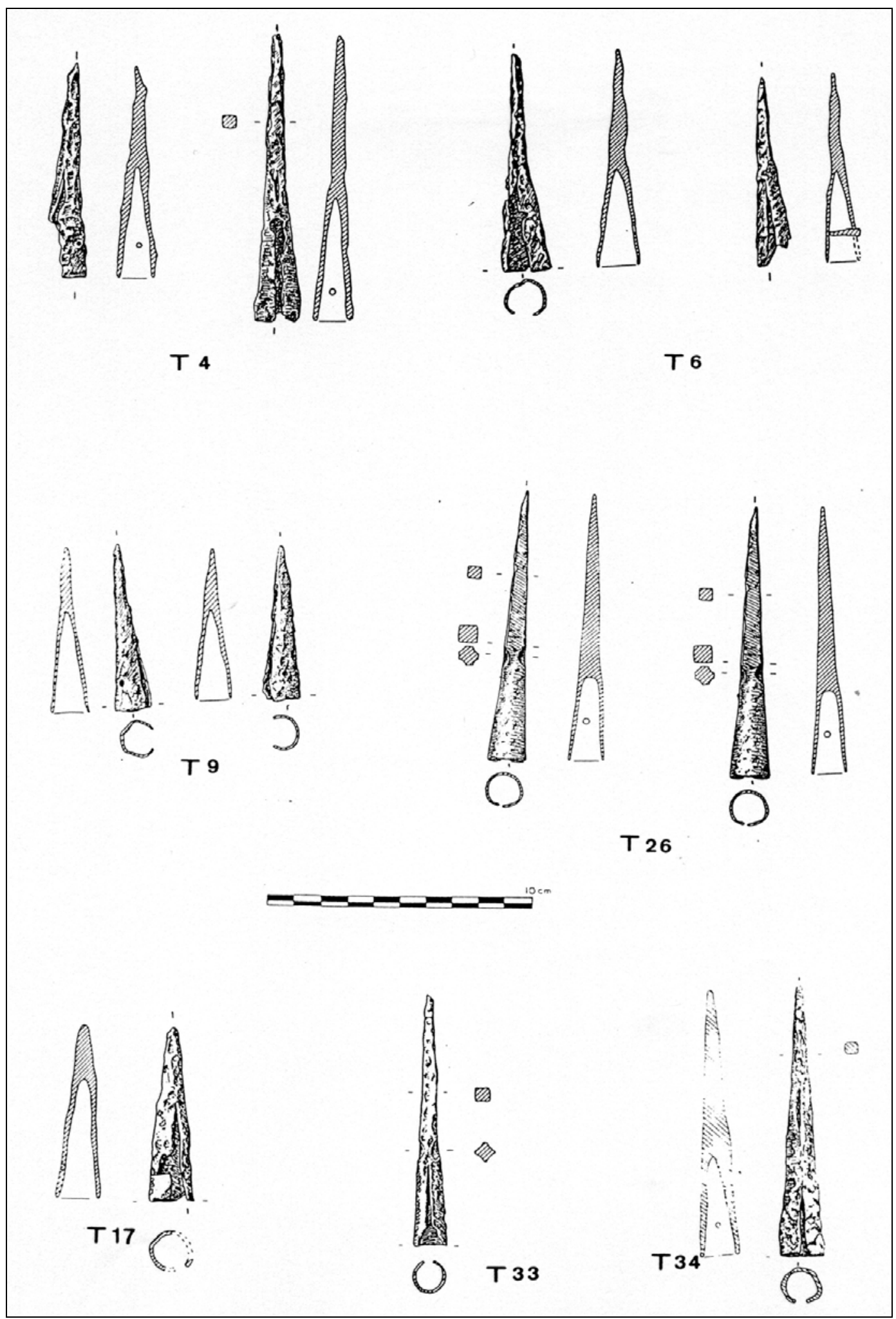

Fig. 24. Regatones. 


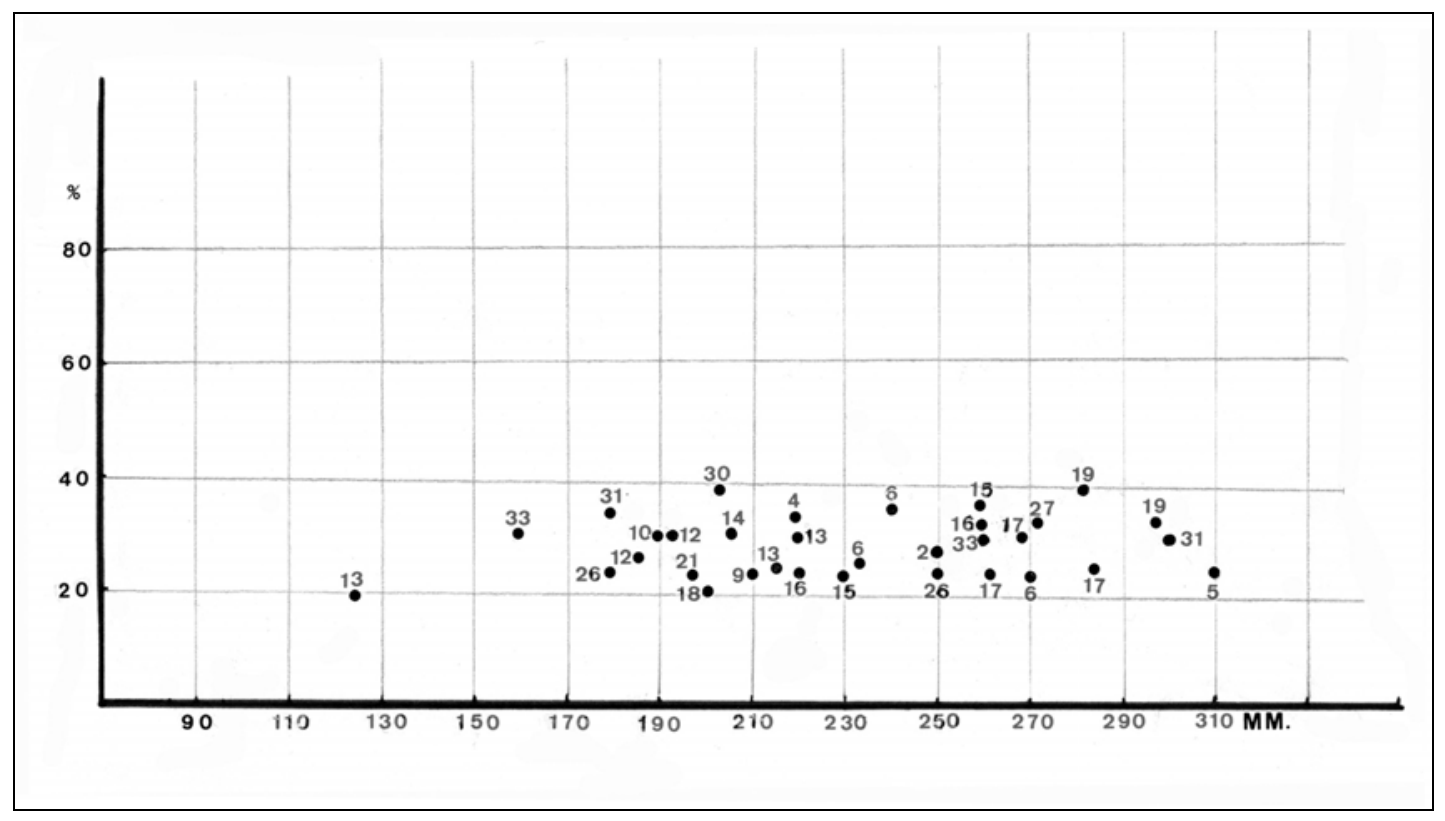

Fig. 25. Relación longitud-proporción tubo de lanzas.

\section{Elementos de la panoplia (puñal, escudo, cuchillo, punta de lanza- regatón)}

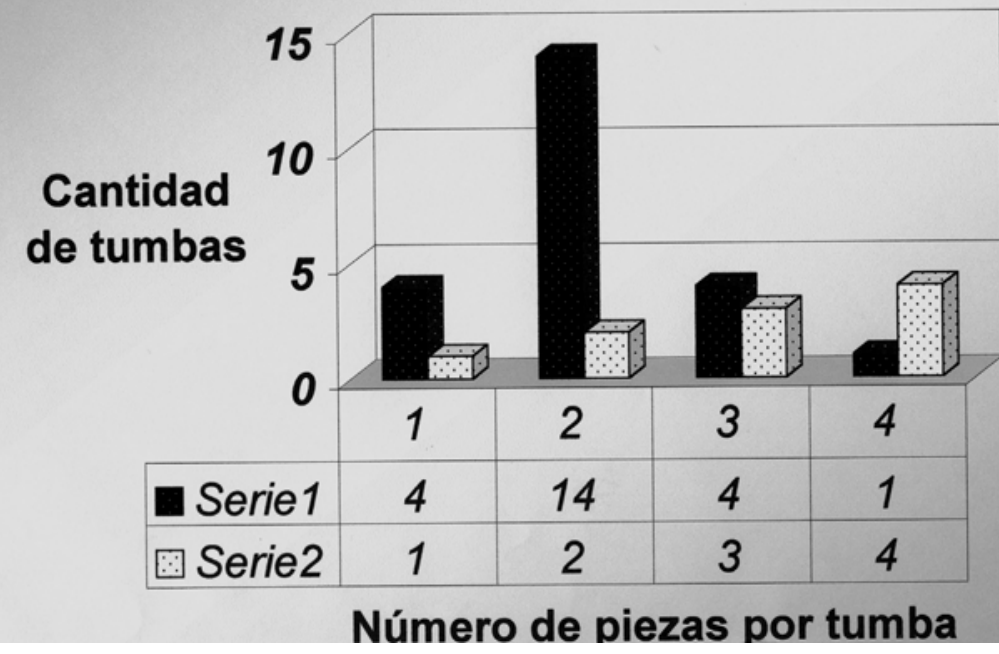

Fig. 26. Elementos de la panoplia por tumba. 


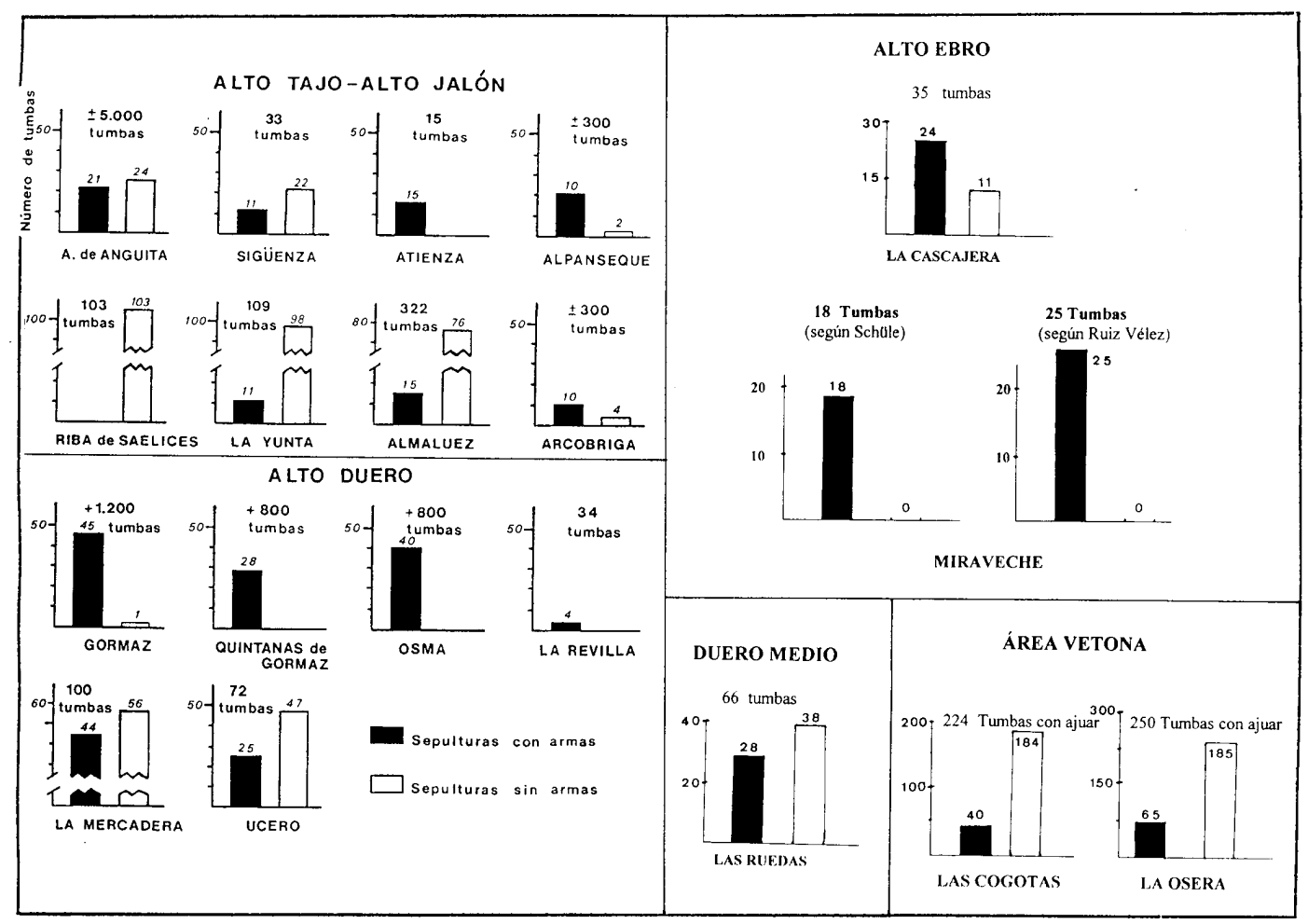

Fig. 27. Tumbas con o sin armas, según Lorrrio (1997), ampliado.

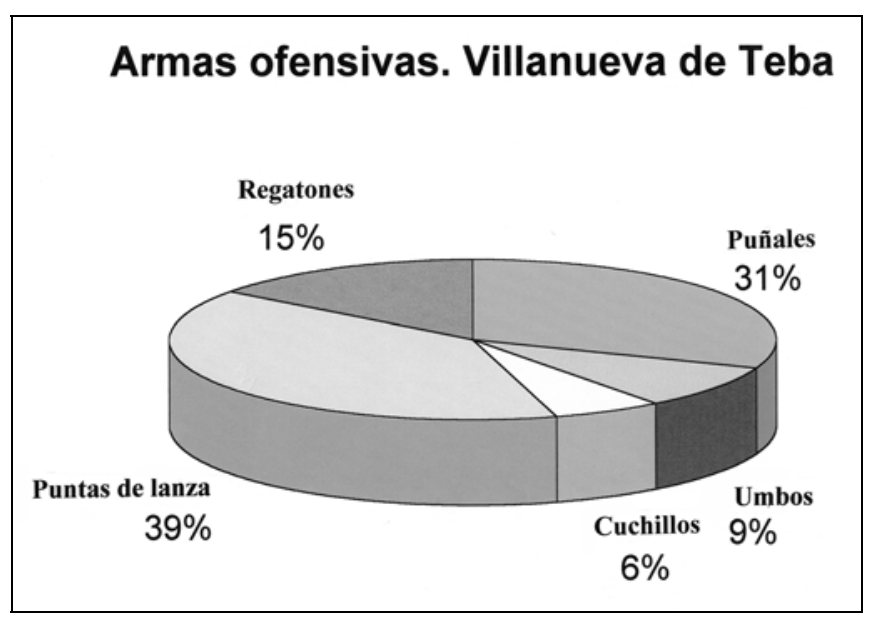

Fig. 28. Armas y su tanto por ciento. 